\title{
The distribution, density, and movements of feral pigeons Columba livia and their relationship with people
}

Alice C. Ryan

A thesis submitted to the Victoria University of Wellington in partial fulfilment of the requirements for the degree of Master of Science in Ecology and Biodiversity 


\section{Abstract}

Worldwide increases in the urban human population have led to a rise in humanwildlife conflict in cities. Mitigating human-wildlife conflict requires understanding of both wildlife and their relationship with humans. Feral pigeons (Columba livia), a ubiquitous commensal animal, are a source of human-wildlife conflict due to their waste which fouls and corrodes buildings and pavements, public health concerns and their tendency to forage in groups around people. Feral pigeons are abundant in Wellington City and information is needed to advise a new management strategy to reduce conflict. I aimed to measure the distribution and density of feral pigeons on a landscape scale in Wellington City and their movements in relation to artificial food. I also evaluated people's attitudes to feral pigeons and tolerance for control methods. I measured distribution using a resource use/availability study and density using distance sampling along eight line transects across the city centre in summer and winter. Variables measured for sites used and available to pigeons were assembled into models and compared using an Information Theoretic approach. Pigeon distribution was best explained by the model distance to pigeon feeder site, distance to public space, and landscape type $\left(w_{i}=0.696\right)$. Density was higher in winter $(6.8$ pigeons/ha $)$ than summer (4.5 pigeons/ha), especially in commercial areas (17.8 pigeons/ha winter c.f. summer 5.9 pigeons/ha). Pigeons selected areas closer to pigeon feeder sites and to public spaces, and to landscape types with a higher human density, which suggests public feeding is the main influence on pigeon distribution in Wellington City and limitation of public feeding should form the basis of a management strategy. I observed the movements of 48 banded birds caught at five park capture sites over 38 search sites from June to December in Wellington City to construct minimum convex polygons for the 20 birds that had nine or more observations. The average activity area was 1.87 ha, 
and activity areas ranged from 0.04 ha to 10.26 ha. Pigeons showed limited movement between sites, with 14 out of the $20(70 \%)$ seen at three or fewer sites. The small activity areas suggest food is locally abundant as pigeons do not have to travel far to meet daily energy requirements. A significant food reduction may be required to decrease the population and should focus on major feeding sites. To investigate people's attitudes to feral pigeons and their control I hand-delivered 800 two page questionnaires to 50 residents at 16 stratified random sites around Wellington City. Questions were asked on residents' attitudes towards pigeons, their environmental knowledge, experiences and actions, and their support for control methods. Attitude towards pigeons was ranked on a scale of $-1,0$, and 1 and tested using models composed of different variables. Respondents' attitudes towards pigeons were best explained by whether they fed birds and visited green space. Respondents who fed birds were less negative towards pigeons, while respondents who visited green spaces often were more likely to have a negative opinion. Bird feeders made up $21.5 \%$ of respondents while 5\% of respondents stated they fed feral pigeons. Regulatory control methods for limiting pigeon population size had support over lethal methods. Survey respondents who fed pigeons had little support for control methods, yet their behaviour change is crucial to the success of a management programme. This shows the importance of consulting the public and allowing them to participate in the management decision making process. As regulatory methods were not considered practical, and banning bird feeding was not considered sensible due to its popularity and the appreciation for wildlife it provides, recommendations were made to use an education and social marketing campaign to reduce pigeon feeding and promote responsible bird feeding. 


\section{Acknowledgements}

Firstly I would like to thank my fantastic supervisor Wayne Linklater. Thank you for you for always being willing to help, patiently guiding me in the right direction and for your comprehensive reading of drafts. Thanks to Symone Krimowa for being a great research partner. Your enthusiasm made our fieldwork extremely enjoyable. A big thank you to Monica Awasthy for sharing your wisdom and love of birds, and all those early mornings out catching pigeons. This would not have been possible without you and your help is greatly appreciated.

Thanks to all those who helped with the fieldwork, including Gaius, Louise and James, and to Peter Reese for kindly teaching me how to band birds. Jeff Benson was a great help with survey delivery. Thanks to my proof readers Chris, Travis, Jean and Louise, you did a great job. Thanks also to Juliet, Ted and the EMI team for being supportive and giving me the flexibility to continue working.

Finally, thanks to my family and friends for your continued support of my endeavours, and Dan for always giving me something to smile about. 


\section{Table of contents}

ABSTRACT II

ACKNOWLEDGEMENTS IV

TABLE OF CONTENTS V

LIST OF FIGURES VIII

CHAPTER ONE: GENERAL INTRODUCTION 1

Urban ecology 1

Commensal animals $\quad 2$

Human wildlife conflict and human dimensions 3

Feral pigeons 4

$\begin{array}{ll}\text { Study area and populations } & 7\end{array}$

Study objectives $\quad 12$

CHAPTER TWO: FEEDING DETERMINES FERAL PIGEON DISTRIBUTION AND DENSITY 13

Abstract 13

Introduction $\quad 14$

$\begin{array}{ll}\text { Method } & 17\end{array}$

$\begin{array}{ll}\text { Study area } & 17\end{array}$

Transect design 20

Landscape use and availability 20

Compiling predictors (fixed effects) 21

Compiling candidate models 22

Distance analysis 25

Landscape classification $\quad 26$

Results $\quad 26$

Discussion $\quad 30$

Management Implications $\quad 32$

CHAPTER THREE: LIMITED FERAL PIGEON MOVEMENTS SUGGEST ARTIFICIAL FOOD ABUNDANCE 34

Abstract $\quad 34$

$\begin{array}{ll}\text { Introduction } & 35\end{array}$ 
$\begin{array}{ll}\text { Method } & 37\end{array}$

$\begin{array}{ll}\text { Study area } & 37\end{array}$

$\begin{array}{ll}\text { Park capture sites } & 37\end{array}$

$\begin{array}{ll}\text { Capture and banding } & 40\end{array}$

Data collection and analysis $\quad 40$

$\begin{array}{ll}\text { Results } & 41\end{array}$

$\begin{array}{ll}\text { Discussion } & 46\end{array}$

CHAPTER FOUR: PROPENSITY TO FEED WILDLIFE AFFECTS ATTITUDES TO FERAL PIGEONS AND THEIR CONTROL 51

$\begin{array}{lr}\text { Abstract } & \mathbf{5 1} \\ \text { Introduction } & \mathbf{5 1} \\ \text { Method } & \mathbf{5 5} \\ \text { Study area } & 55 \\ \text { Household questionnaire } & 56 \\ \text { Statistical analyses } & 59 \\ \text { Results } & \mathbf{6 1} \\ \text { Questionnaire response } & 61 \\ \text { Attitudes towards pigeons and explaining factors } & 61 \\ \text { The bird feeding population and the pigeon feeding population } & 65 \\ \text { Responses to pigeon control } & 68 \\ \text { Discussion } & \mathbf{6 9} \\ \text { Management recommendations } & \mathbf{7 3} \\ \text { Summary } & 74 \\ \text { CHAPTER FIVE: GENERAL DISCUSSION } & \mathbf{7 6} \\ \text { Management implications } & \mathbf{7 9} \\ \text { REFERENCES } & \mathbf{8 3} \\ \text { APPENDIX ONE: DISTANCE ANALYSIS } & \mathbf{9 9} \\ \text { APPENDIX TWO: QUESTIONNAIRE } & \mathbf{1 0 4}\end{array}$




\section{List of tables}

Table 1.1 Demographic and geographic information on the seven suburbs of the study area in Wellington City (Wellington City Council 2011c). Income quartiles for the 2006 census (in $\$ N Z D$ ) are Low ( $\$ 0$ to $\$ 11,397$ ), Medium lowest $(\$ 11,398$ to $\$ 24,402$ ), Medium highest $(\$ 24,403$ to $\$ 42,449)$ and High $(\$ 42,449$ and over).

Table 2.1 The 17 candidate models and their fixed effects for feral pigeon distribution on a landscape scale in Wellington City.

Table 2.2 Candidate models for pigeon distribution on a landscape scale in Wellington City during summer and winter 2010 are in descending order based on Akaike's Information Criterion (AIC), $\mathrm{n}=379, \mathrm{~K}=$ number of parameters in the model.

Table 3.1 Band combination and banding site, and activity area of twenty banded feral pigeons with nine or more observations observed from June-December 2010 in Wellington City. Activity areas were estimated using 100\% Minimum Convex Polygons. The number of observations and number of sites over which the observations were distributed are also shown.

Table 4.1 Candidate models for Wellington residents' attitudes towards pigeons during November 2010 are in descending order based on Akaike's Information Criterion (AICc), $\mathrm{N}=237, \mathrm{~K}=$ number of parameters. 


\section{List of figures}

Figure 1.1 Map showing the seven suburbs in the study area in Wellington City, New Zealand.

Figure 2.1 Map of study area in Wellington City, New Zealand showing the eight transect routes.

Figure 2.2: Frequency distributions of used and available sites compared for a) distance to pigeon feeder site, b) distance to public space, and c) in four different landscape types in summer (left) and winter (right).

Figure 3.1. Map of the five park capture sites, 29 search sites and nine secondary search sites for banded feral pigeons in Wellington City from June-December 2010. 39

Figure 3.2 The number of observations and activity area of twenty feral pigeons observed in Wellington from June-December 2010 for: birds with bands and birds with both bands and a radio transmitter.

Figure 3.3 Activity areas of twenty feral pigeons banded and observed in Wellington City from June-December 2010.

Figure 4.1. Map of the 16 questionnaire distribution sites in Wellington City.

Figure 4.2 Respondents'attitudes towards feral pigeons in Wellington and whether or not they provide food or water for birds.

Figure 4.3 Respondents'attitudes towards feral pigeons in Wellington and how often they visited green spaces in the last year.

Figure 4.4 Respondents who provide food or water for birds listed the top three species they fed. Birds listed were tui (Prosthemadera novaeseelandiae), sparrow (Passer domesticus), duck (Anas platyrhynchos), feral pigeon (Columba livia), blackbird (Turdus merula), starling (Sturnus vulgaris), seagull, thrush (Turdus philomelos) and waxeye (Zosterops lateralis).

Figure 4.5 Comparison of age groups, highest level of education, annual income and sex of between bird feeders and non bird feeders.

Figure 4.6 Survey respondents' attitudes towards feral pigeons in Wellington and their support for various control methods. 


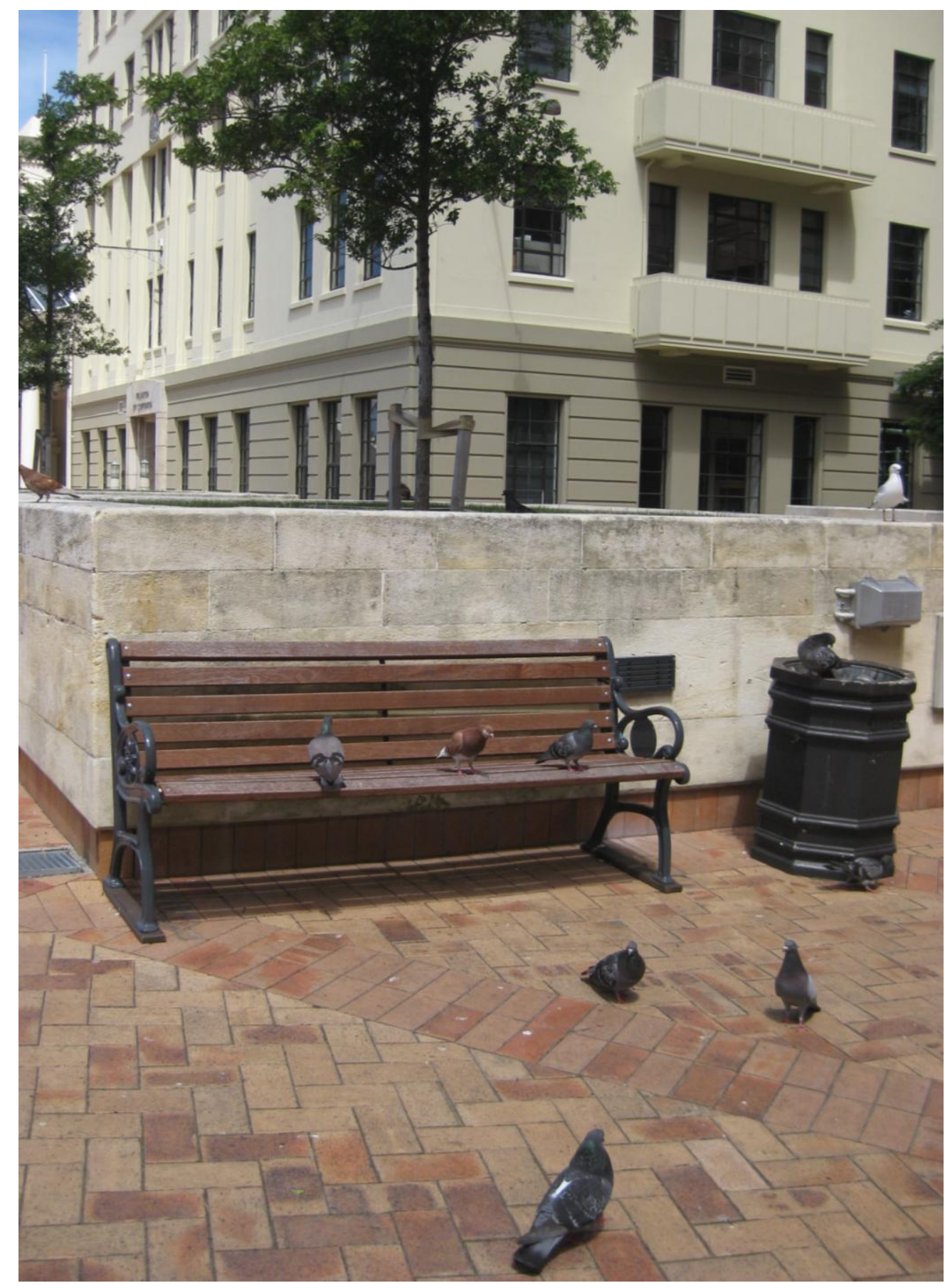

Feral pigeons Columba livia in Civic Square, Wellington City, New Zealand. 


\section{Chapter One: General Introduction}

The study of ecology is primarily concerned with relationships between animals and the environment (Krebs 2008). Traditionally ecologists have sought unmodified habitats in which to carry out their research (McDonnell 1997). But unmodified areas are diminishing and the impacts of humans are so extensive that including them in ecological research has become increasingly relevant (Vitousek et al. 1997). If we are to fully understand ecosystems in the world today and offer insights into the future, we must study human-dominated environments. Urban ecology studies have previously focussed on the effects of urbanisation on native species (Blair 1996, Rottenborn 1999) and urban species as pests (Tangley 1986). However much can be gained by applying traditional ecology principles to commensal species in urban environments.

\section{Urban ecology}

The world's population is becoming increasingly urbanised. By 2050 the urban population is expected to reach 6.3 billion, around $69 \%$ of the world's total population (United Nations 2010). In contrast, only $13 \%$ of the world's population lived in urban areas in the year 1900 (United Nations 2006). New Zealand is no exception to this trend as $86 \%$ of the population live in urban environments and this percentage is expected to increase in the future (Ministry of Social Development 2010). Urban environments are characterised by high levels of energy use (McIntyre 2000), built and impervious ground cover (Arnold \& Gibbons 1996) and high human population density (Pickett et al. 2011). While urbanised land covers only a small percentage of the world's surface, its effects on the environment are far reaching. The impacts of urbanisation include degraded ecosystems (Pouyat et al. 2002, Groffman et al. 2003, Walsh et al. 2005), 
biodiversity decline (McDonald et al. 2008), homogenisation of species (McKinney 2006) and modified climate (Souch \& Grimmond 2006).

The importance of applying ecological questions to human-dominated environments was raised some time ago (Tansley 1935), yet it was not until the past few decades that the field of urban ecology emerged as a discrete discipline (McDonnell 1997, Adams 2005). Despite the impacts of urbanisation on the environment, ecosystem function continues and urban environments have the potential to contribute to biodiversity (Miller \& Hobbs 2002, Pickett et al. 2011). The science of urban ecology is not based on ecology alone, rather it is an interdisciplinary field that merges ecology with social science (McIntyre et al. 2000). Urban ecology is a new field and lacks a strong theoretical background, although a number of different approaches and frameworks have been proposed (Young 2009). These range from experimental approaches combined with urban design to concept models that integrate human and ecological processes (Alberti et al. 2003, Felson \& Pickett 2005). Developing appropriate theoretical frameworks for the urban environment is considered one of the most important challenges that ecologists will face in the future (Alberti et al. 2003).

\section{Commensal animals}

While many species have been unable to adapt to urban areas, some have been able to exploit the abundant food resources found in the urban environment (Shochat et al. 2006). These species have undergone the process of synurbanization, whereby animal populations adjust to the conditions of the urban environment (Luniak 2004).

Widespread commensal species include rats (Rattus norvegicus and Rattus rattus), mice (Mus musculus), house sparrows (Passer domesticus) and feral pigeons (Columba 
livia). These animals live alongside humans and rely on them for food. Species which have successfully adapted to the urban environment tend to be ecological generalists with high reproductive capacities and prolonged breeding seasons (Luniak 2004, Moller 2009).

\section{Human wildlife conflict and human dimensions}

The rise of the human population, both in urbanised areas and elsewhere, has led to increases in both the frequency and severity of human-wildlife conflict (Madden 2004). Human-wildlife conflict occurs when 'the needs and behaviour of wildlife impact negatively on the goals of humans or when the goals of humans negatively impact the needs of wildlife' (World Parks Congress Recommendation 2003). Causes of humanwildlife conflict in the urban environment include vegetation damage to property (West \& Parkhurst 2002), aggressive behaviour (Jones \& Thomas 1999, Timm et al. 2004), disease transmission to humans (Magnino et al. 2009) and vehicle collisions (Stout et al. 1993), among many others.

Traditional approaches to the management of animals in conflict with people often involved killing the animals to reduce population numbers (Treves \& Naughton-Treves 2005, Dickman 2010). Although lethal methods are still used today, they often do not address the root of the problem. Human-wildlife conflict can be extremely complex, and a reduction in animal numbers may not reduce the conflict as human perceptions of the conflict can remain the same (Madden 2004). In addition, populations can recover quickly when individuals are removed. Lethal methods of control are also controversial with the public, and support for these methods is declining, particularly in developed countries (Treves \& Naughton-Treves 2005). 
A more recent approach to human-wildlife conflict management involves investigating the human dimensions of the conflict (Decker \& Chase 1997, Madden 2004, BaruchMordo et al. 2009). The consideration of human dimensions in wildlife management involves examining peoples' attitudes and actions towards wildlife and using the information to inform wildlife management strategies (Decker and Chase 1997, Treves et al. 2006). This approach is advantageous because public perceptions of the problem may differ from reality, so reducing wildlife damage may not actually lessen the conflict (Madden 2004). In addition, human-wildlife conflict can involve human-human conflict, and may be more a reflection of underlying social conflict rather than discontent with wildlife (Madden 2004). Therefore it is important to understand not only the ecology of the target population, but also public attitudes to the target species and methods for its control.

\section{Feral pigeons}

Feral pigeons are descendants of domesticated breeds of the wild rock dove. While the wild rock dove nests on coastal cliff ledges and rocky areas in the British Isles, the Mediterranean, and Northern Africa east to India, the feral pigeon has adapted to the urban environment and is found in cities worldwide (Long 1981, Johnston \& Janiga 1995). Feral pigeons have reached high densities in many cities (e.g. 9.4 pigeons/ha in Barcelona (Sol \& Senar 1992), 8.4 pigeons/ha in Basel (Haag-Wacknagel 1995), 20.8 pigeons/ha in inner city Milan (Sacchi et al. 2002) and 4-5 pigeons/ha in inner city Amsterdam (Buis \& van Wijnen 2001)). Although widely studied in Europe, little research has been carried out on feral pigeons in New Zealand (Dilks 1975a, Dilks 1975b, Moeed 1975). 
Feral pigeons are capable of breeding all year round, although the extent to which this occurs is dependent on food availability and climate, and most reproduction occurs in late spring and summer (Dunmore \& Davis 1963, Johnston \& Janiga 1995). Nest sites are selected by the males, and can be found either in isolation or in colonies and tend to be crudely constructed. Feral pigeons form breeding pairs that may last a lifetime and share duties incubating the eggs. They have an average clutch size of two eggs. The duration of the incubation is around 18 days, while fledging occurs around 28-32 days after hatching (Johnston \& Janiga 1995, Vatnick \& Foertsch 1998).

Feral pigeons are granivores and include a wide range of seeds in their diet. Seeds preferred by feral pigeons include peas, grain and maize. They require daily drinking water and this is largely obtained from sources such as fountains, puddles and ponds (Johnston \& Janiga 1995). Their foraging behaviour is extremely flexible, and while some carry out predictable foraging flights from the city to agricultural areas like their wild ancestors, others forage in cities and rely on artificial food sources from humans (Baldacinni et al. 2000, Murton et al. 1972b). Those without agricultural feeding grounds nearby tend to rely on feeding from the public and spilt or disposed food waste.

Feral pigeons are a common source of human wildlife conflict in urban areas. They are considered a pest due to their waste, which not only fouls surfaces but can also corrode footpaths, buildings and other structures (Johnston \& Janiga 1995, Gomez-Heras 2004). Pigeon waste can also block rainwater in the gutters and spouts of buildings. This can cause blockages which forces water into walls, resulting in expensive structural damage (Johnston \& Janiga 1995). In addition, their tendency to forage in flocks around humans 
for food has caused many people to consider them a nuisance, particularly around food establishments where they may act as a deterrent to potential customers. In places where pigeons rely on city-adjacent agriculture for food they can also reduce farmers' yields (Lawson 1979). Using potential control costs as a surrogate for losses, feral pigeon costs are estimated at \$US1.1 billion per year in the United States (Pimentel et al. 2000). Although feral pigeons carry a large number of diseases which are pathogenic to humans, the risk of transmission is low and only a small portion of these have been recorded as being transmitted to humans (Haag-Wackernagel \& Moch 2004, Magnino et al. 2009). People who are most at risk are those who live close to pigeon colonies, are immunocompromised, or have contact with pigeon waste as part of their occupation (Haag-Wackernagel 2005, Graczyk et al. 2007).

Management techniques are often sought to reduce population numbers and culling is the most common method (Murton et al. 1972b, Hoy \& Bivings 1987, Sol \& Senar 1992). However pigeon culls are usually unsuccessful, in part because they are not designed with an understanding of pigeon ecology (Sol \& Senar 1992, Johnston \& Janiga 1995). For example, pigeons are loyal to their food sources and baits put out often end up eaten by immigrant pigeons, especially if the baits are surplus to food requirements. In addition, if resident pigeons are killed they are often quickly replaced by immigrants and juveniles (Murton et al. 1972b, Sol \& Senar 1995). The use of contraceptives has had some success, however it is resource intensive and requires regular feeding of the target pigeons (Giunchi et al. 2007a, Avery et al. 2008, Dobeic et al. 2011). It is usually recommended as part of an integrated management programme rather than a single solution (Dobeic et al. 2011). Purpose-built pigeon lofts aim to manage pigeon population size through egg removal and controlled pigeon feeding 
(Haag-Wackernagel 1995, Dobeic et al. 2011). However egg removal may result in increased reproduction efforts, leading to a decrease in egg quality and the health of the population (Jacquin et al. 2010). Successful pigeon control programmes have involved educating the public to limit resource availability to pigeons, in particular food (HaagWackernagel 1995).

\section{Study area and populations}

The study area was located in Wellington City, New Zealand and included seven suburbs in and around the commercial district (Figure 1.1). Methods used previously to describe urban ecology study sites vary greatly, which limits comparison between studies. McIntyre et al. (2000) recommends the use of a number of different measures to describe urban study sites, and where possible these have been described below. 


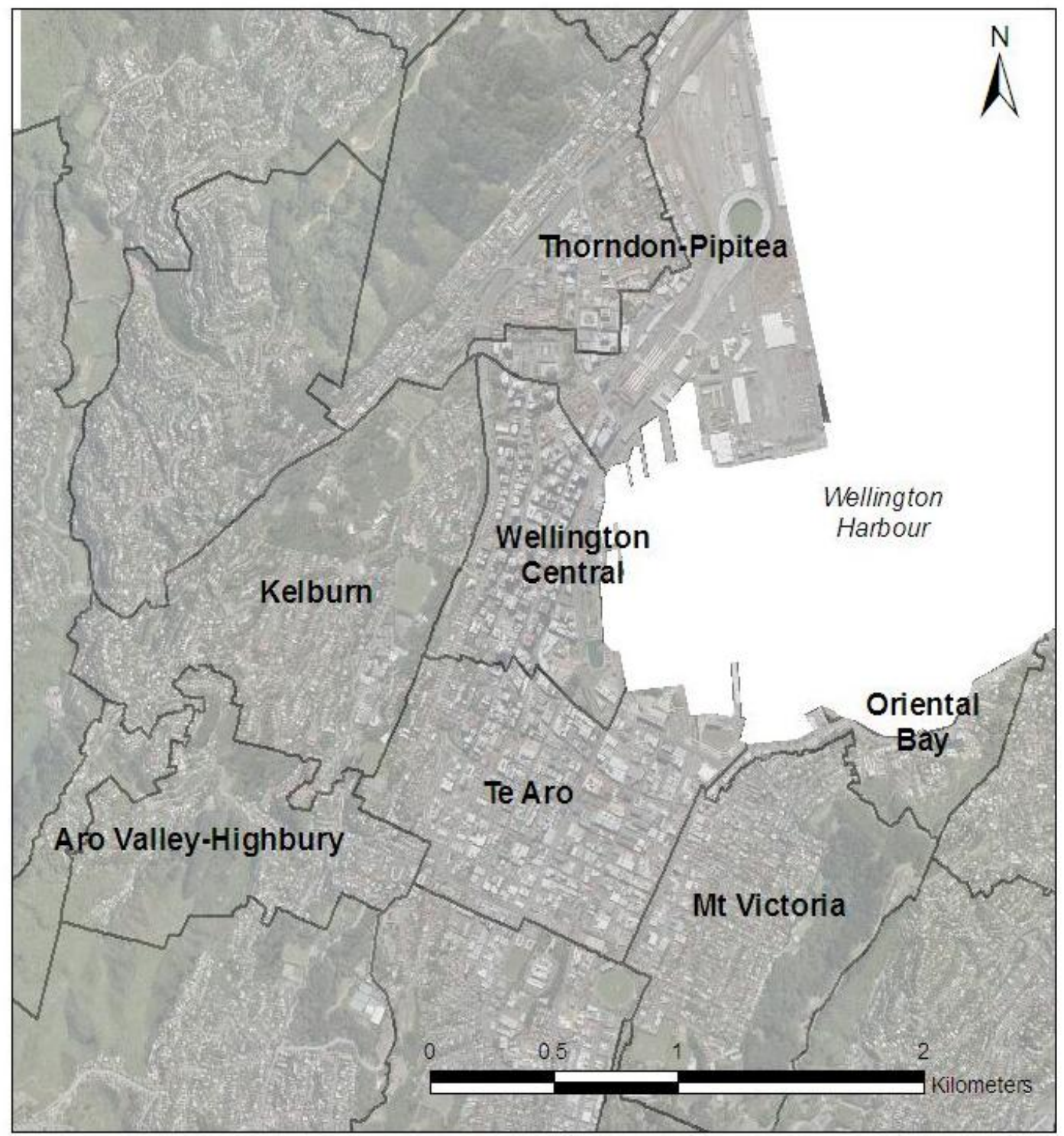

Figure 1.1 Map showing the seven suburbs in the study area in Wellington City, New Zealand. 
Wellington City is situated at the south-western coastal peninsular of the North Island,

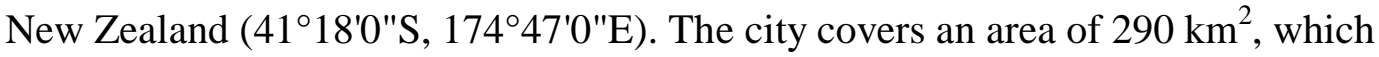
includes rural, bushland and coastal areas as well as urban areas concentrated in the flat lands surrounding the harbour (Wellington City Council 2011a). Dwellings in the city number 70,000 while urban roads have a total length of $626 \mathrm{~km}$ (New Zealand Transport Agency 2010, Wellington City Council 2011a). Wellington City is a relatively new urban area, as it was not substantially developed until the late 1800 s. Although European settlement occurred in 1840 and the region was long inhabited by the Taranaki Whanui and Ngāti Toa Māori, the human population remained small until the late 1800s (Wellington City Council 2011a).

The latest human population estimate for Wellington City is 197,700 (Wellington City Council 2011b). The population is $48 \%$ male and $52 \%$ female. The median income in Wellington City is $\$ 32,500$, in comparison with $\$ 24,400$ for the rest of New Zealand, and the unemployment rate is $4.8 \%$. The median age of the citizens is 33.1 years, while $55.5 \%$ of people have a post school qualification (Statistics New Zealand 2006). As the broad descriptions given of Wellington City may not accurately reflect particular characteristics of the seven suburbs in the study area, demographic and geographic information for each of the suburbs is outlined in Table 1.1. The seven suburbs were Thorndon-Pipitea, Wellington Central, Kelburn, Te Aro, Aro Valley-Highbury, Mt Victoria and Oriental Bay.

The city has a mild temperate climate with average monthly temperatures ranging from $8.8^{\circ} \mathrm{C}$ in July (mid-winter) to $17.1^{\circ} \mathrm{C}$ in February (late summer). Annual rainfall is $1249 \mathrm{~mm}$ and there are 2065 sunshine hours per year. Wind features strongly in the 
climate with an average windspeed of $22 \mathrm{~km} /$ hour, and 22 days of gale force wind per year (days with a mean speed above 63km/hour) (NIWA 2008).

Feral pigeons were brought to New Zealand by early European settlers in the 1850s and are now widespread throughout the country (Long 1981, Robertson et al. 2007). A study in Hawkes Bay showed that feral pigeons breed all year round but the extent of their breeding season in other parts of New Zealand is unknown (Dilks 1975a). Studies carried out in Christchurch and Hawkes Bay found that the diet of feral pigeons consisted of seeds such as pea (Pisum sp.), maize (Zea sp.), barley (Hordeurn sp.) clover (Trifolium sp.) and vetches (Vicia sp.) obtained from agricultural areas (Dilks 1975b, Moeed 1975). The majority of Wellington City's feral pigeon population lives in the inner city adjacent to the harbour, although flocks are also present in the outer suburbs. The pigeons roost and nest on buildings and under bridges and are seen in parks and streets foraging for food. As Wellington lacks nearby agricultural crop areas the pigeons' main source of food is likely to be food sources from people. 
Table 1.1 Demographic and geographic information on the seven suburbs of the study area in Wellington City (Wellington City Council 2011c). Income quartiles for the 2006 census (in \$NZD) are Low (\$0 to \$11,397), Medium lowest $(\$ 11,398$ to $\$ 24,402)$, Medium highest $(\$ 24,403$ to $\$ 42,449)$ and High $(\$ 42,449$ and over).

\begin{tabular}{|c|c|c|c|c|c|c|c|c|c|c|c|c|c|}
\hline \multirow[b]{2}{*}{ Suburb } & \multirow[b]{2}{*}{ Population } & \multirow{2}{*}{$\begin{array}{l}\text { Number of } \\
\text { dwellings }\end{array}$} & \multirow{2}{*}{$\begin{array}{l}\text { Area } \\
\left(\mathrm{km}^{2}\right)\end{array}$} & \multirow{2}{*}{$\begin{array}{c}\text { Population } \\
\text { density } \\
\left(\mathrm{km}^{2}\right)\end{array}$} & \multirow{2}{*}{$\begin{array}{l}\text { Primary } \\
\text { land cover }\end{array}$} & \multicolumn{4}{|c|}{ Housing type (\%) } & \multicolumn{4}{|c|}{ Income quartile (\%) } \\
\hline & & & & & & $\begin{array}{c}\text { Separate } \\
\text { house }\end{array}$ & $\begin{array}{c}\text { Medium } \\
\text { density }\end{array}$ & $\begin{array}{l}\text { High } \\
\text { density }\end{array}$ & Other & Low & $\begin{array}{l}\text { Medium } \\
\text { low }\end{array}$ & $\begin{array}{l}\text { Medium } \\
\text { high }\end{array}$ & High \\
\hline $\begin{array}{l}\text { Wellington } \\
\text { Central }\end{array}$ & 2052 & 1206 & 0.6 & 3634 & Commercial & 3.0 & 15.4 & 65.7 & 15.9 & 31.1 & 13.4 & 19.6 & 35.8 \\
\hline Te Aro & 6936 & 2754 & 1.2 & 5578 & Commercial & 5.6 & 33.7 & 46.8 & 13.8 & 32.8 & 15.7 & 19.8 & 31.7 \\
\hline $\begin{array}{l}\text { Aro Valley } \\
\text {-Highbury }\end{array}$ & 3435 & 1398 & 1.3 & 2703 & Residential & 50.5 & 34.4 & 10.1 & 4.5 & 29.6 & 21.6 & 19.8 & 29.0 \\
\hline Mt Victoria & 4860 & 2070 & 1.1 & 4261 & Residential & 35.0 & 49.2 & 9.4 & 6.3 & 15.2 & 15.9 & 24.4 & 44.4 \\
\hline
\end{tabular}




\section{Study objectives}

I investigated the distribution, density, and movements of feral pigeons in Wellington

City and their relationship with people. In Chapter Two I identify the factors that most influence pigeon distribution on a landscape scale using a resource use/availability study design. In addition I establish population density estimates across two seasons using line transect distance sampling. I use marking and radio telemetry to track the movements of feral pigeons in Chapter Three to determine the extent to which a food limitation programme should be applied. Lastly, in Chapter Four I use a postal mail survey questionnaire to determine factors that influence people's attitudes towards feral pigeons and evaluate their tolerance of different feral pigeon control methods. Since Chapters Two, Three and Four are written as separate manuscripts for publication some repetition of methods, especially study site descriptions, may occur. Chapter Five discusses and summarises the overall findings of the study. 


\section{Chapter Two: Feeding determines feral pigeon distribution and density}

\section{Abstract}

Studies on the distribution and density of animals can help explain the factors that drive animal population numbers, and subsequently provide information required to develop animal management strategies. Large numbers of feral pigeons Columba livia in Wellington City are considered a problem, and this study investigated their distribution and density on a landscape scale to inform a new management strategy. I recorded observations of feral pigeons in summer and winter along eight line transects totalling $15.4 \mathrm{~km}$ that extended from the harbours edge in a south-west direction across the city. Eight variables were measured for sites along transects used and available to pigeons to determine landscape level distribution. The variables were assembled into models, tested in R using a generalised linear model and then ranked according to Akaike's Information Criterion. I used distance sampling along the transects to assess pigeon density. Pigeon distribution on a landscape scale was best explained by the model of distance to pigeon feeder site, distance to public space, and landscape type $\left(w_{i}=0.696\right)$. Pigeons selected areas closer to pigeon feeder sites and to public spaces, and to landscape types with a higher human density, which suggests that artificial feeding is the main influence on pigeon distribution in Wellington City. Overall pigeon density was higher in winter (6.8 pigeons/ha) than in summer (4.5 pigeons/ha), and was especially higher in commercial areas in winter (17.8 pigeons/ha) compared to summer (5.9 pigeons/ha). Since pigeons appear to rely on people for food, the higher winter commercial density is thought to reflect the higher human density in commercial areas 
in winter, with fewer people in parks and wharf areas. Feral pigeon distribution and density is largely driven by artificial food sources, which suggests that a successful population management strategy will depend on a reduction in feeding from the public.

\section{Introduction}

Understanding the reasons for the density and distribution of a population is one of the principle goals of ecology (Krebs 2008). Historically, ecological research was carried out in natural areas away from human development (McDonnell \& Pickett 1993). However in the past few decades there has been a growing interest in the urban environment, and the number of urban studies is on the increase (Marzluff et al. 2001). To date, urban studies have tended to focus on native species and their responses to varying levels of urbanisation (Blair 1996, Rottenborn 1999, Clergeau et al. 2001). Since species in urban environments are often causes of human-wildlife conflict and are the main source of interactions urban residents have with nature, their relevance should not be overlooked (Haag-Wackerngael 1995, Belant 1997, Timm et al. 2004, Dunn et al. 2006).

One urban species that is the subject of much controversy is the feral pigeon Columba livia, found in urban environments worldwide (Johnston \& Janiga 1995). Feral pigeons have been able to exploit the abundance of food sources in urban environment and reach high densities (e.g. 9.4/ha in Barcelona (Sol \& Senar 1992), 8.4/ha in Basel (Haag-Wacknagel 1995) and 20.8/ha in inner city Milan (Sacchi et al. 2002)). They are regarded as pests, in particular due to their waste which fouls surfaces and causes damage to buildings and other man-made structures due to its corrosive nature (Johnston \& Janiga 1995, Gomez-Heras et al. 2004). They are also considered 
unhygienic due to the diseases they carry, some of which can be transmitted to humans (Haag-Wackernagel \& Moch 2004, Magnino 2009).

Like many large cities around the world, Wellington City has large flocks of pigeons residing in the inner city, resulting in complaints being made to the Wellington City Council (Wellington City Council 2007). Although culling is the most common method of pigeon control, culls are usually unsuccessful in the long-term because pigeon populations recover quickly after an initial population decrease (Sol \& Senar 1992, Johnston \& Janiga 1995). Previously, the WCC has proposed pigeon culls as a method of control but this has faced opposition from the public (Long 2007, Wellington City Council 2008, Whitehead 2008). It is acknowledged that public feeding of pigeons occurs in Wellington, yet it is not known what impact this has on the population. By gathering data on pigeon distribution and abundance, it could be determined which resources are crucial to pigeons and the extent of their dependence on people could be evaluated. This information could then be used to develop a new strategy to manage pigeon populations in Wellington.

Factors that play a role in explaining the distribution of any birds in urban areas include levels of urbanisation and building type (Emlen 1974, Blair 1996, Rottenborn 1999, Buis \& van Wijnen 2001, Clergeau et al. 2001, Sacchi et al. 2002, Melles et al. 2003, Villegas \& Garitano-Zavala 2010), human density (Jokimaki \& Suhonen 1998, Buis \& van Wijnen 2001) and vegetation (Melles et al. 2003, Sandstrom et al. 2006, Villegas \& Garitano-Zavala 2010). While a large number of studies on bird distribution in urban areas have focused only on the influence of local habitat factors (Emlen 1974, Blair 1996, Villegas \& Garitano-Zavala 2010), it is now recognised that characteristics of the 
landscape at a broader scale can also help explain animal distribution (Rottenborn 1999, Clergeau et al. 2001, Melles et al. 2003).

Previous studies on feral pigeon distribution have been carried out at both local and landscape scales. On a local scale, pigeon flock size has been linked to the abundance of grain spillage around docks (Murton et al. 1972a), while on a landscape scale pigeon numbers have also been linked to human population density (Jokimaki \& Suhonen 1998, Buis \& van Wijnen 2001), the number of houses per hectare and the annual mass of organic waste (Buis \& van Wijnen 2001), age of buildings (Sacchi et al. 2002) and the distance from the city centre (Johnston \& Janiga 1995).

Studying the density of feral pigeons can be difficult due to their gregariousness and clumped distribution and the complex, poor visibility nature of their habitat - the built environment. In addition it can be difficult for researchers to access pigeons' habitats, as their habitat range usually covers numerous buildings and properties each with different owners. Methods used previously to measure pigeon population density include fortnightly counts (Murton et al. 1972b), counts in public areas (Buis \& van Wijnen 2001), and full census counts using linear transects (Sacchi et al. 2002). These methods use counts that are thought to correlate with abundance. However when these counts are repeated, trends in numbers over time can sometimes reflect trends in detectability, rather than actual trends in abundance (Thompson 2002). Using techniques which incorporate and adjust for detectability can alleviate this problem. One such technique that has been successfully used to estimate pigeon density is distance sampling (Buckland et al. 2001, Giunchi et al. 2007b). 
The aim of this study was to quantify the extent of the feral pigeon population in Wellington City by determining the factors that explain their distribution on a landscape scale. Wellington City pigeons appear to spend a significant amount of their day foraging, and as feeding from the public is likely to form the main component of their diet it is expected that landscape variables related to artificial food sources will best explain pigeon distribution. In addition, distance sampling along transects was used to estimate pigeon density in Wellington. This study will establish a baseline for future studies, and provide information for the Wellington City Council to enable the development of a new evidence-based strategy to manage Wellington City's pigeon population.

\section{Method}

\section{Study area}

Wellington City is situated at the south-western coastal peninsular of the North Island, New Zealand ( $\left.41^{\circ} 18^{\prime} 0^{\prime \prime} \mathrm{S}, 174^{\circ} 47^{\prime} 0^{\prime \prime E}\right)$ and has a population estimated at 197,700 (Wellington City Council 2011b). The city covers an area of $290 \mathrm{~km}^{2}$, which includes rural, bushland and coastal areas as well as urban areas concentrated in the flat lands surrounding the harbour (Wellington City Council 2011a). The city has a mild temperate climate with average monthly temperatures ranging from $8.8^{\circ} \mathrm{C}$ in July (midwinter) to $17.1^{\circ} \mathrm{C}$ in February (late summer). Annual rainfall is $1249 \mathrm{~mm}$ and there are 2065 sunshine hours per year on average. Wind features strongly in the climate with an average windspeed of $22 \mathrm{~km} / \mathrm{hour}$, including 22 days of gale force wind per year (days with a mean speed above $63 \mathrm{~km} /$ hour) (NIWA 2008). The majority of the pigeon population lives in the commercial district in the inner city which is adjacent to the harbour (Figure 2.1), although flocks do reside in the outer suburbs. The study area 
encompassed the commercial district, and also included residential, wharf and park areas in and around the commercial district. 


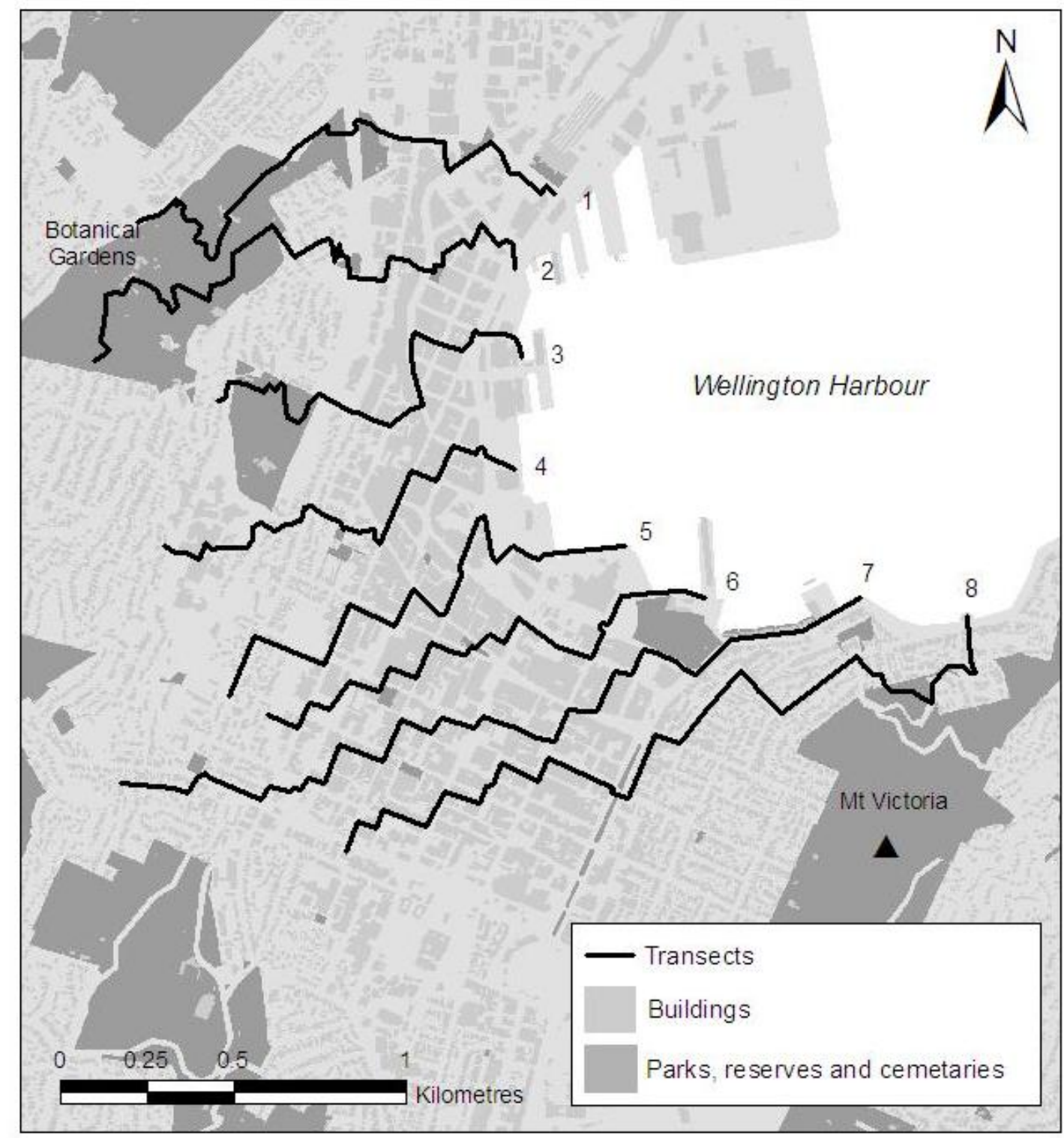

Figure 2.1 Map of study area in Wellington City, New Zealand showing the eight transect routes. 


\section{Transect design}

Data on pigeon distribution and density was described and estimated from line transects. A total of eight transects, totalling $15.4 \mathrm{~km}$, were mapped through the study area (Figure 2.1). Transect start points were allocated approximately every $300 \mathrm{~m}$ along the harbour's edge from an initial chosen start point. The transect line was determined by alternating left and right turns along streets in a south-west direction. A south-west direction was chosen because it would ensure a variety of road sizes, alleyways, paths and open spaces were sampled by the transect. If a turn would have brought a transect into contact with another transect line, then the transect continued in its current direction and the next possible turn in the same direction was taken. If a turning direction (left or right) would have led a transect away from the south west direction then the alternate direction was chosen. Transects were labelled 1-8 in a West-East direction (Figure 2.1). A team of two observers walked along the transects and recorded each a time a pigeon or group of pigeons was sighted. Odd numbered transects were sampled in the morning (8am-11am) and even numbered transects were sampled in the afternoon $(1 \mathrm{pm}-4 \mathrm{pm})$. The transects were sampled once in late summer (FebruaryMarch) and once in late winter (July-August), as these months were thought to display extremes in climate and in both natural and artificial resource availability.

\section{Landscape use and availability}

In order to understand pigeon distribution on a landscape scale in relation to different resources, environmental variables thought to affect the distribution of pigeons and other bird species were measured. These variables were measured for two types of sites: 1) sites at which pigeons were present (i.e. used) and 2) available sites. The used sites were obtained from observations of pigeons made along the transects. These sites were 
the location of the observer when a pigeon was sighted, rather than the exact pigeon locations. In order to reduce any effects this would have on the results, observations that had a distance greater than $80 \mathrm{~m}$ between the observer location and pigeon location were not included in the analysis. This issue was not thought to affect the results because $50 \%$ of observations were seen within $33 \mathrm{~m}$ of the observer and $90 \%$ of observations were seen within $67 \mathrm{~m}$ of the observer. In addition, variables were measured on a landscape scale that varies little across such small distances. Sites for the available data set were obtained by randomly generating distances between 1 and 200m, and plotting these points continuously along the total length of the transects. Although data was collected in both summer and winter, the data set was combined to test general models for pigeon resource use/availability.

\section{Compiling predictors (fixed effects)}

The variables chosen for measurement were based upon information from the literature as well as personal observations. A range of variables were included to cover the three main categories outlined above as being important: urbanisation and built structures, people and vegetation. The eight variables were: distance to city centre, distance to water's edge, landscape type, human density, distance to pigeon feeder site, distance to public space, vegetation, and grass.

Distance to city centre was the distance in metres to the city centre. The city centre was determined by placing a $1 \mathrm{~km}$ radius circle over a map of the city area where it encompassed as much of the commercial district as possible. The centre of this circle $\left(41^{\circ} 17^{\prime} 26.85^{\prime \prime} \mathrm{S}, 174^{\circ} 46^{\prime} 36.56^{\prime \prime} \mathrm{E}\right)$ was defined as the city centre. Distance to water's edge was the distance in metres to the edge of the harbour. Landscape type was a 
categorical variable describing Commercial, Green, Residential and Wharf areas. The definitions for these landscape types are described below. Human population density was the average number of humans per $\mathrm{km}^{2}$ for each of the seven suburbs in the study area. Distance to pigeon feeder sites was the distance in metres to the nearest known location where people 'pigeon feeders' regularly feed pigeons in bulk amounts (e.g. loaves of bread, bags of cooked rice). These locations were established from ad libitum observations during other activities (Chapter Three, Chapter Four). Distance to public space was the distance in metres to the nearest public space. Public spaces were defined as paved or grassy open spaces with public seating. Areas which met these criteria but were predominantly roadways or walking malls were not included. Vegetation was the percentage of total vegetation cover (including grass) within a 500m radius, visually estimated in GOOGLE EARTH 6.0 (Google Inc. 2011) using a quartered grid circle. Grass was the percentage cover within a 500m radius, visually estimated in GOOGLE EARTH using a quartered grid circle.

\section{Compiling candidate models}

The eight variables were then assembled into models structured around four themes: people, artificial food, environment structure and vegetation, in preparation for analysis using an Information Theoretic approach (Table 2.1). This method has advantages over frequentist hypothesis testing which is based upon a single null model. It allows for the comparison of multiple competing models which can then be ranked and weighted. In addition, when models have similar support model averaging can be used to make robust predictions (Johnson \& Omland 2004). Models were tested in R version 2.11.1 (R Development Core Team 2010) using a generalised linear model and then ranked according to Akaike's Information Criterion (Burnham \& Anderson 2002). The models 
used were a logistic regression equation where $1=$ used and $0=$ available. Models with $\Delta \mathrm{AIC} \leq 2$ were considered to have substantial support from the data and models with $\Delta \mathrm{AIC}>10$ to have no support (Burnham and Anderson 2002). 
Table 2.1 The 17 candidate models and their fixed effects for feral pigeon distribution on a landscape scale in Wellington City.

\begin{tabular}{|c|c|c|}
\hline Theme & Hypothesis origin & Fixed effects \\
\hline \multicolumn{3}{|l|}{ People } \\
\hline & $\begin{array}{l}\text { Jokimaki \& Suhonen } \\
\text { (1998) }\end{array}$ & Human density \\
\hline & Ryan & Human density, landscape type \\
\hline & Ryan & $\begin{array}{l}\text { Human density, landscape type, distance to } \\
\text { public space }\end{array}$ \\
\hline \multicolumn{3}{|c|}{ Artificial food } \\
\hline & $\begin{array}{l}\text { Haag-Wackernagel (1995), } \\
\text { Fuller et al. (2008) }\end{array}$ & Distance to pigeon feeder site \\
\hline & Ryan & Distance to public space \\
\hline & Ryan & Distance to public space, landscape type \\
\hline & Ryan & $\begin{array}{l}\text { Distance to pigeon feeder site, distance to } \\
\text { public space }\end{array}$ \\
\hline & Ryan & $\begin{array}{l}\text { Distance to pigeon feeder site, distance to } \\
\text { public space, landscape type }\end{array}$ \\
\hline & Ryan & $\begin{array}{l}\text { Distance to pigeon feeder site, distance to } \\
\text { public space, landscape type, human density }\end{array}$ \\
\hline \multicolumn{3}{|c|}{ Environment structure } \\
\hline & Ryan & Landscape type \\
\hline & Johnston \& Janiga (1995) & Distance to city centre \\
\hline & Ryan & Distance to wharf \\
\hline & Ryan & Distance to wharf, grass \\
\hline & Ryan & Distance to wharf, landscape type \\
\hline & Ryan & Distance to city centre, landscape type \\
\hline \multicolumn{3}{|c|}{ Vegetation } \\
\hline & Sandstrom et al. (2006) & Vegetation \\
\hline & Ryan & Vegetation, grass \\
\hline
\end{tabular}




\section{Distance analysis}

Pigeon density was estimated using distance sampling along transects. This method was chosen due to its ability to account for detectability, and because it has been shown to detect changes in abundance with more precision than quadrate counts. It has also been calculated to be more time efficient, resulting in reduced costs (Giunchi et al. 2007b). The main characteristic of distance sampling is the measurement of perpendicular distances from the transect line to the animal or group of animals. The perpendicular distance can be measured directly, however it can be more convenient to instead measure the distance of the observer to the animal at first sighting (Buckland et al. 2001). By also measuring the observer's angle of travel along the transect line and the angle of the transect to the animal $\left(0-360^{\circ} \mathrm{N}\right)$, this information can be used to calculate the perpendicular distance of the transect line to the animal. This method was used to calculate distances of pigeons to the transect line. The distance of the observer to the pigeon was measured using a rangefinder (Bushnell Yardage Pro $8 \times 36$ ). When the rangefinder was unable to give a measurement, usually when the pigeon was within $10 \mathrm{~m}$ of the observer, distances were estimated by using approximately $1 \mathrm{~m}$ paces. The angles were measured using a Casio digital compass (Casio Pathfinder PAG-40).

In order for results of distance sampling to be valid there are three assumptions that must be met: 1) all birds on the transect line are detected; 2) birds are detected before evasive movement is triggered; and 3) distances are measured accurately. The first and second assumptions were both met as pigeons were accustomed to the presence of people and did not take evasive action. As distances and angles were measured by a rangefinder and compass most of the time the third assumption was also most likely met. The data was analysed using DISTANCE 6.0 release 2 (Thomas et al. 2010, 
Appendix 1). As pigeon group size varies, it was important to account for the effect that group size may have had on detectability. This was done by using a regression of observed cluster size against distance to test for a relationship. Where no relationship is found average group size is used with the density estimate of groups to estimate population size.

\section{Landscape classification}

The transect routes and pigeon observations were mapped using GOOGLE EARTH and divided up into four landscape types: Green, Residential, Wharf and Commercial. Green areas comprised both exotic and native plantings as well as modified park areas. Residential areas were predominantly single or double story individual dwellings. Commercial areas were single to multi-story shops and businesses and wharf areas were predominantly wharf frontage. However, it was found that there were not enough observations in the Green, Residential, and Wharf areas for analysis in DISTANCE, so landscape type analysis was carried out for the Commercial areas only. Total transect lengths for each landscape type were Green 5.0km, Residential 1.4km, Commercial $7.5 \mathrm{~km}$ and Wharf $1.5 \mathrm{~km}$.

\section{Results}

Feral pigeon distribution on a landscape scale was best explained by the model of distance to pigeon feeder site, distance to public space, and landscape type ( $\triangle \mathrm{AIC}<2, w_{i}$ $=0.696)($ Table 2.2). The model of distance to pigeon feeder site, distance to public space, landscape type, and human density also had substantial support $\left(\triangle \mathrm{AIC}<2, w_{i}=\right.$ 0.279), while the next best performing model distance to public space and distance to 
pigeon feeder site had some support $\left(\Delta \mathrm{AIC}<7, w_{i}=0.025\right)$. No other models were supported by the data.

The pigeons selected for areas closer to pigeon feeder sites, generally within $300 \mathrm{~m}$ (Figure 2.2a). Pigeons also selected for areas closer to public spaces (Figure 2.2b). This association was slightly stronger in summer, as a larger proportion of observations were within $50 \mathrm{~m}$ of a public space compared to the proportions of winter observations. When comparing the landscape types, pigeons showed strong selection for commercial areas in winter, and avoidance of green and residential landscape types in both seasons (Figure 2.2c.)

Summer pigeon density was estimated to be 4.5 pigeons/ha, while winter pigeon density was 6.8 pigeons/ha. Of the observations in the commercial areas only, density was estimated at 5.9 pigeons/ha in summer and at 17.8 pigeons/ha in winter (see Appendix 1 for distance analysis). 
Table 2.2 Candidate models for pigeon distribution on a landscape scale in Wellington City during summer and winter 2010 are in descending order based on Akaike's Information Criterion (AIC), n=379, K=number of parameters in the model.

\begin{tabular}{|c|c|c|c|c|c|c|}
\hline Hypothesis origin & Theme & Models, fixed effects & $\boldsymbol{K}$ & AIC & $\Delta \mathrm{AIC}$ & Akaike $w_{i}$ \\
\hline Ryan & Artificial food & $\begin{array}{l}\text { Distance to pigeon feeder site, distance to public space, } \\
\text { landscape type }\end{array}$ & 6 & 408.7 & 0 & 0.696 \\
\hline Ryan & Artificial food & $\begin{array}{l}\text { Distance to pigeon feeder site, distance to public space, } \\
\text { landscape type, human density }\end{array}$ & 7 & 410.5 & 1.83 & 0.279 \\
\hline Ryan & Artificial food & Distance to pigeon feeder site, distance to public space & 3 & 415.4 & 6.69 & 0.025 \\
\hline Ryan & People & Human density, landscape type, distance to public space & 6 & 428.0 & 19.32 & 0.000 \\
\hline Ryan & Artificial food & Distance to public space, landscape type & 5 & 431.2 & 22.50 & 0.000 \\
\hline $\begin{array}{l}\text { Haag-Wackernagel (1995), } \\
\text { Fuller et al. (2008) }\end{array}$ & Artificial food & Distance to pigeon feeder site & 2 & 454.3 & 45.57 & 0.000 \\
\hline Johnston \& Janiga (1995) & Environment & Distance to city centre & 1 & 454.9 & 46.15 & 0.000 \\
\hline Ryan & Environment & Distance to centre, landscape type & 5 & 455.1 & 46.41 & 0.000 \\
\hline Ryan & Artificial food & Distance to public space & 2 & 458.0 & 49.30 & 0.000 \\
\hline Sandstrom et al. (2006) & Vegetation & Vegetation & 2 & 467.9 & 59.23 & 0.000 \\
\hline Ryan & Vegetation & Vegetation, grass & 3 & 469.9 & 61.23 & 0.000 \\
\hline Ryan & People & Human density, landscape type & 5 & 479.3 & 70.64 & 0.000 \\
\hline Ryan & Environment & Distance to wharf, landscape type & 5 & 484.4 & 75.73 & 0.000 \\
\hline Ryan & Environment & Landscape type & 4 & 484.9 & 76.18 & 0.000 \\
\hline Ryan & Environment & Distance to wharf, grass & 3 & 489.1 & 80.38 & 0.000 \\
\hline Jokimaki \& Suhonen (1998) & People & Human density & 2 & 495.6 & 86.92 & 0.000 \\
\hline Johnston \& Janiga (1995) & Environment & Distance to wharf & 2 & 506.9 & 98.23 & 0.000 \\
\hline
\end{tabular}


a)
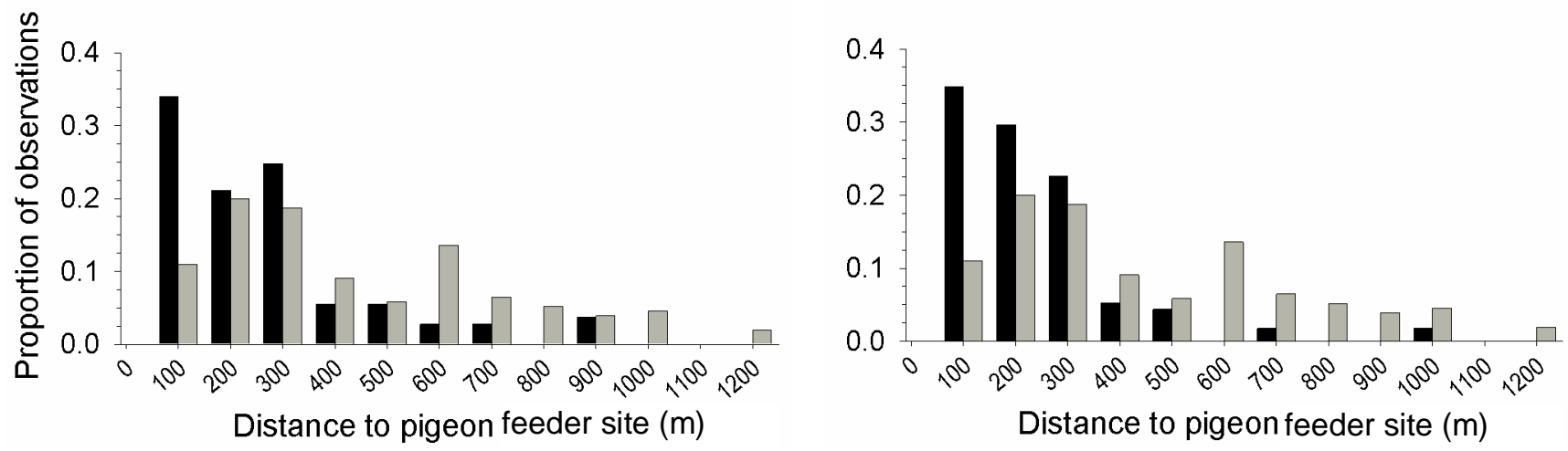

b)

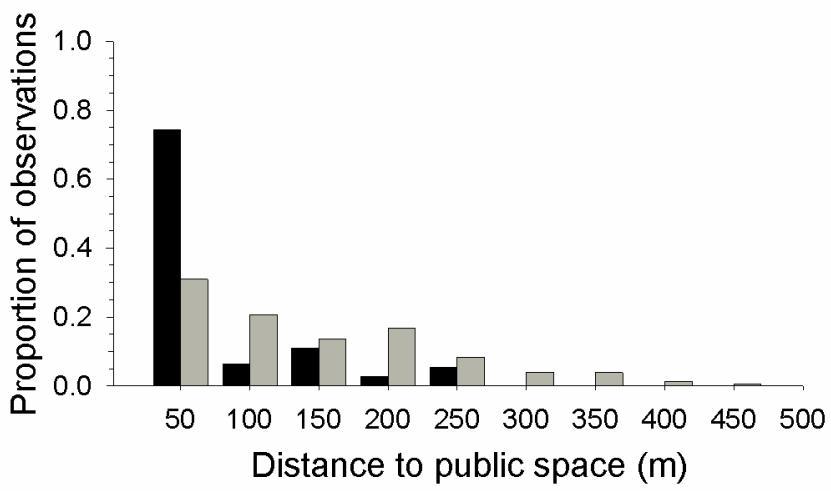

c)
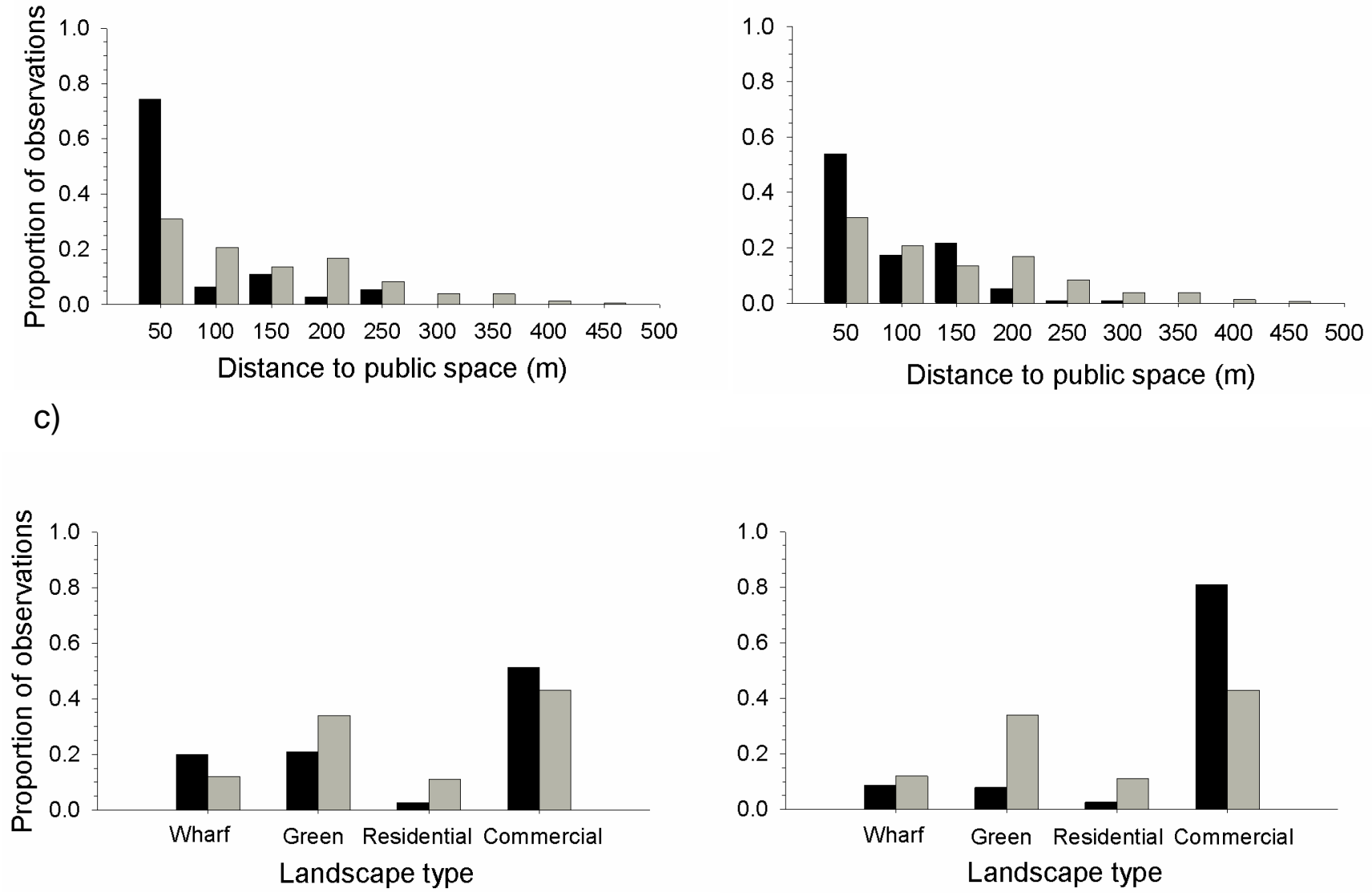

Figure 2.2: Frequency distributions of used $\square$ and available $\square$ sites compared for a) distance to pigeon feeder site, b) distance to public space, and c) in four different landscape types in summer (left) and winter (right). 


\section{Discussion}

The leading models to explain pigeon distribution on a landscape scale included distance to pigeon feeder site, distance to public space and landscape type. This shows that pigeon feeding plays an important role in determining the distribution of Wellington City's pigeon population, as it does in many other cities (HaagWackernagel 1995) and the importance of regular food resources from humans has been highlighted previously (Murton et al. 1972a, Fuller et al. 2008). A study that investigated pigeon distribution on a local scale in Wellington City also found that artificial food determined pigeon distribution. Pigeons were found to be in close proximity to places where people eat, such as cafes and outdoor seating (Krimowa 2011). The presence of distance to public spaces in the best performing model is also likely to relate to artificial food availability. As well as being the location of many pigeon feeder sites, public spaces also provide food in the form of casual feeders. Casual feeders are people who feed pigeons small amounts of their own meal on an irregular basis. The importance of landscape in the model may relate to increased artificial feeding in landscape types with greater human population density. There is likely to be increased causal feeding in public spaces in the commercial area compared to other landscape types due to greater numbers of people.

Pigeon distribution in Wellington City was not explained by distance to city centre, as suggested by Johnston \& Janiga (1995). This measure is not a mechanistic explanation, and instead represents a number of different variables such as human density and building density. The explanatory power of this variable is likely to depend on the features of the city's landscape, which is most likely why it did not explain pigeon distribution in Wellington City. It may explain pigeon distribution in cities that have an 
urban gradient expanding evenly out from the city centre, but not in places that do not have this type of urban gradient. The layout of Wellington City is determined by the harbour and the hills and does not conform to this circular urban gradient. Distance to water's edge was included in the analysis as it was considered to be a better fit to the urban gradient of Wellington city. However it was not important as it was the worst performing model, and is probably not an accurate characterisation of the city's urbanisation gradient.

Vegetation cover did not explain pigeon distribution but this was not surprising. Although vegetation cover has been shown to explain the distribution of other bird species pigeons use different resources compared to those species (Melles et al. 2003, Sandstrom et al. 2006). For example, pigeons often obtain their food from people rather than natural areas and buildings rather than trees are used for roosting (HaagWackernagel 1995, Ferman et al. 2010). Human density performed poorly, which may be due to the low-resolution measure of human density used: the average number of humans per $\mathrm{km}^{2}$ for each of the seven suburbs in the study area. In addition, the human density measure refers to the number of people residing permanently in the area. Given that around 30,000 people commute into Wellington City to work, with the majority of these working in the city centre, a measure of the number of people present during the daytime would be more relevant (Wellington City Council 2011d).

The overall pigeon density was higher in winter (6.8 pigeons/ha) than in summer $(4.5$ pigeons/ha). This is in contrast to results from European studies, where pigeon numbers peak in summer and autumn and then decrease in winter due to poor survival rates and limited breeding (Johnston \& Janiga 1995, Giunchi et al. 2007a, Giunchi et al. 2007b). 
Higher winter densities in Wellington City may be due to the mild temperate oceanic zone, which encompasses New Zealand. The range in temperatures in the oceanic zone is much smaller than in continental Europe, and temperatures rarely drop below freezing in Wellington. So the comparatively higher winter temperatures and lack of snow during winter in Wellington may explain why the pigeon population did not show a winter decline as seen in European countries. Pigeons may also be less detectable in summer than winter, as they are more likely to be on the nest during the spring and summer months. A study in Italy found that during this time 50 to $70 \%$ of nests were occupied (Giunchi et al. 2007a). In winter pigeons may also be out courting or searching for mates in preparation for the start of the main breeding period in spring, and so more detectable.

There was a large difference in density between commercial areas in summer (5.9 pigeons/ha) and in winter (17.8 pigeons/ha). This suggests that pigeons use their environment differently depending on the season. Pigeons are known to adjust their feeding behaviour to human resources and if pigeons are relying on people for food this difference could reflect the distribution of people between seasons (Rose et al. 2006b). Due to colder weather, parks and the wharf area may be frequented less in winter by people eating their food, leading to a higher concentration of people in the commercial areas. It may also mean that pigeons shift from relying on food sources directly from people to a more opportunistic feeding strategy which utilises rubbish and skip bins that are more abundant in the commercial areas.

\section{Management Implications}

These results show the significance of artificial food sources to the distribution and density of Wellington's pigeon population. As long as there are food resources 
available, culling will be unlikely to have a long-term impact on pigeon population numbers. High juvenile feral pigeon mortality is often caused by juveniles being outcompeted for food by adults (Sol et al. 1998). Removing pigeons by culling will release this pressure and allow juvenile pigeons to take advantage of the best available food sources, increasing their breeding success (Sol et al. 2000). Therefore a food limitation programme that decreases the amount of food available to pigeons is likely to have the most impact on pigeon numbers. Winter may be an important time to focus on reducing food availability, as pigeons are more concentrated in commercial areas, and there may be less feeding by casual feeders in parks and wharves. In addition, pigeons are more vulnerable at this time of year due to the poorer climate. Reducing food in spring and summer may be just as important however, given that these are usually the peak breeding months for pigeons. The most crucial aspect of the food limitation strategy will be to decrease the amount of feeding by the public, in particular pigeon feeders who feed large amounts of food. As a change in human behaviour will be required it may be useful to investigate people's relationships with pigeons. 


\section{Chapter Three: Limited feral pigeon movements suggest artificial food abundance}

\section{Abstract}

Wildlife managers can use studies on animal movements to provide information on the importance and availability of food resources and subsequently inform management strategies. Large numbers of feral pigeons Columba livia are a source of human-wildlife conflict in Wellington City, and their overpopulation is due to an abundance of artificial food resources. Feral pigeon movements in the central city were assessed to determine the scale at which a food limitation management strategy should be applied, as greater movements will require a larger scale food limitation plan. I observed the locations of 48 banded birds caught at five park capture sites over 38 search sites from June to December in Wellington City. I used ARCMAP version 9.3 and HAWTHS ANALYSIS TOOLS version 3.27 to construct $100 \%$ minimum convex polygons for the 20 birds that had nine or more observations. The average activity area was 1.87 ha and $14(70 \%)$ of the activity areas were smaller than 1 ha. The smallest activity area was 0.04ha and the largest was 10.26ha. Overall the pigeons showed limited movement between sites, with 14 out of the 20 (70\%) seen at three or fewer locations. Only two of the total 48 birds were seen at a different park capture site other than the one they were caught at. The small scale of the activity areas suggest that food is locally abundant as pigeons do not have to travel far to meet daily energy requirements. The much larger activity areas of some birds suggests that while the majority of pigeons remain within a small area, some individuals may move further afield to other sites. As food appears to 
be abundant a food limitation programme should focus on the sites that provide the largest amounts of artificial food, as an overall population decrease is not likely unless there is a significant reduction in food availability.

\section{Introduction}

Ecologists have long sought to understand the processes that drive animal movements and their spatial organisation. These spatial patterns are usually studied through application of the home range concept, which is defined as 'the area, usually around a home site, over which the animal normally travels in search of food' (Burt 1943). Home range size is influenced by many factors including food availability (Tufto et al. 1996), density (Erlinge 1990) and sex (Said \& Servanty 2005); but food availability is considered to be the primary influence on home range size (McLoughlin \& Ferguson 2000). Since range size usually decreases as food becomes more available, range size studies can provide information on food availability which can then be used to advise management decisions (Hixon 1980, Tait \& Krebs 1981, Tufto et al. 1996).

Abundant in cities worldwide, feral pigeons Columba livia are considered a pest due to their waste which fouls and corrodes surfaces, as well as their tendency to forage around people for food (Johnston \& Janiga 1995, Gomez-Heras et al. 2004). They carry diseases pathogenic to humans, and although the rate of disease transmission is low for the general population this is still a concern for many people (Haag-Wackernagel \& Moch 2004, Haag-Wackernagel 2005, Magnino et al. 2009). In many cities culling has been used as a management technique, yet culls are only a short-term solution and are often unsuccessful (Murton et al. 1972b, Sol \& Senar 1992, Johnston \& Janiga 1995). 
Lethal methods of wildlife control are also often controversial with the public (Treves et. al 2006).

An alternative method to culling is the limitation of resources such as food. This can decrease numbers in bird populations by reducing the rate of breeding and survival, especially recruitment (Newton 1980). Many pigeon populations around the world are dependent on artificial food sources such as feeding from the public and discarded food, and limiting these food sources can be an appropriate management strategy (Murton et al. 1972b, Johnston \& Janiga 1995, Rose et al. 2006b). Feral pigeons in Wellington City are a source of human-wildlife conflict and artificial food probably plays a large role in sustaining the population (Wellington City Council 2007, Chapter Two). The food comes from both pigeon feeders, who feed the pigeons large amounts of food on a regular basis, as well as casual feeders in parks (Chapter Two). Planned pigeon culls were cancelled due to public protest and a new management strategy is required (Wellington City Council 2008). Data collected on feral pigeon movements could provide an understanding of how site-dependent pigeons are and therefore help determine the spatial scale at which food limitation needs to be applied.

This study will investigate the range sizes and movements of pigeons in central Wellington in relation to sites where artificial food is supplied by the general public. It is expected that if there is an abundance of artificial food at park sites in the central city 1) pigeons will generally have smaller range sizes, and 2) pigeons will demonstrate site loyalty and not move between feeding sites. This information will be used to suggest an appropriate scale for a food limitation management strategy. 


\section{Method}

\section{Study area}

The study was carried out in Wellington City, which is situated at the south-western coastal peninsular of the North Island, New Zealand $\left(41^{\circ} 18^{\prime} 0^{\prime \prime} \mathrm{S}, 174^{\circ} 47^{\prime} 0^{\prime \prime} \mathrm{E}\right)$, and has a population estimated at 197,700 (Wellington City Council 2011b). The city covers an area of $290 \mathrm{~km}^{2}$, which includes rural, bushland and coastal areas as well as urban areas concentrated in the flat lands surrounding the harbour (Wellington City Council 2011a). The city has a mild temperate climate with average monthly temperatures ranging from $8.8^{\circ} \mathrm{C}$ in July (mid-winter) to $17.1^{\circ} \mathrm{C}$ in February (late summer). Annual rainfall is $1249 \mathrm{~mm}$ and there are 2065 sunshine hours per year. Wind features strongly in the climate with an average windspeed of $22 \mathrm{~km} /$ hour, and 22 days of gale force wind per year (days with a mean speed above 63km/hour) (NIWA 2008).

The pigeon population lives in the commercial district in the inner city, which is adjacent to the harbour, although flocks are also seen in the outer suburbs. The study area encompassed four city suburbs: Thorndon-Pipitea, Wellington Central, Te Aro and Aro Valley-Highbury. Aro Valley-Highbury is primarily residential housing, while Thorndon-Pipitea, Wellington Central and Te Aro are comprised mainly of commercial buildings and wharf areas. Parks and both native and exotic plantings were found throughout the four suburbs.

\section{Park capture sites}

Pigeons were caught and banded in five parks in inner Wellington: Lambton Quay, Aro Park, Manners-Victoria Square (MV Square), Te Aro Park and Glover Park (Figure 3.1). These parks all have pigeons present and have artificial food available due to 
public feeding. All parks contain public seating. Lambton Quay and Manners-Victoria Square are primarily paved parks, with some shrub and tree plantings, while Te Aro and Glover Park are a combination of paving and lawn grass, with a few tree plantings. Aro Park is mainly lawn with trees and shrubs. The pigeons were caught either using a mist net or a drop net. Each bird was leg banded for reliable identification, weighed, and the tarsus length, bill length, bill width, wing length, and tail length were measured. Banding consisted of two coloured plastic bands on one leg and one plastic coloured band and one numbered metal band on the other leg. The capture and banding procedures approved by VUWs Animal Ethics Committee permit number 2009R20 "Feral pigeon behaviour and ecology". 


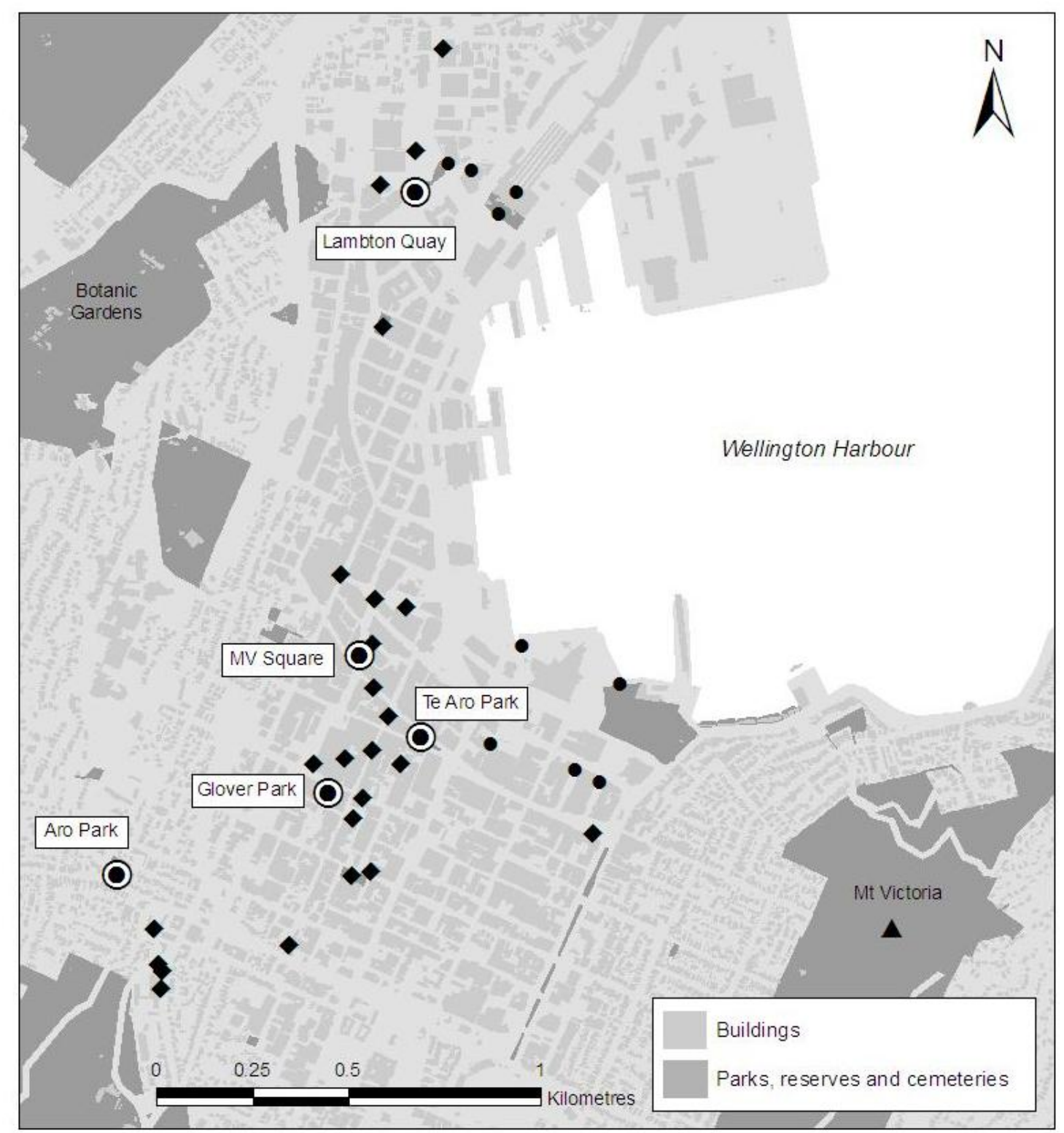

Figure 3.1. Map of the five park capture sites $\mathcal{O}, 29$ search sites $\downarrow$ and nine secondary search sites $\bullet$ for banded feral pigeons in Wellington City from June-December 2010. 


\section{Capture and banding}

In addition to the bird banding, tail mounted radio transmitters were attached to birds at four of the five sites: Glover Park (4), Te Aro Park (1) Manners-Victoria Square (1) and Aro Park (2). Transmitters were tied to the base of the tail feathers with dental floss and super glue was used to secure the knots (Awasthy 2011). The first two transmitter attachments at Glover Park were unsuccessful as both birds lost their transmitters within eight days of attachment, most likely to due to the glue not being completely dry upon release. The next six birds were kept for up to 20 minutes before release to ensure the glue was dry and transmitters were secured. Of these birds, one lost its transmitter between 16 and 23 days after attachment, while another lost its transmitter between 3 and 31 days after attachment. The exact date of the loss of the transmitters is uncertain because the birds were not able to be located when searched for during this time. One bird was not seen again after 28 days post transmitter attachment. Observations continued to be gathered on the remaining three birds, however at times it was difficult to obtain a radio signal amongst the tall buildings in the city environment. The radio signal may have been contained due to pigeons roosting inside structures such as carpark buildings. Due to these limitations radio tracking was discontinued after 2 months.

\section{Data collection and analysis}

The data collection for the banded birds consisted of regular searches of 29 sites frequented by pigeons, including the park capture sites, from early-June until lateDecember (Figure 3.1). Only areas frequented by pigeons were included as search sites, so search effort was dependent on pigeon distribution and not necessarily uniform around the park capture sites. These sites were searched on average 1-2 times per 
fortnight. In addition a further nine supplementary sites were searched on average 1-2 times per month. Any pigeons observed while walking between these sites were also checked for bands and ad libitum observations made while carrying out other activities were also included. Sites were searched on both weekdays and weekends during daylight hours. Every time a banded bird was observed its site and activity were recorded. The sites of the banded birds were then entered into ARCMAP version 9.3 (ESRI 2008) and 100\% Minimum Convex Polygons (MCPs) were determined using HAWTHS ANALYSIS TOOLS version 3.27 (Beyer 2004). Unfortunately due to the limited number of observations, these range size estimates were not considered to be reliable estimates of home ranges. Henceforth these areas will be referred to as activity areas, rather than home ranges. The number of different sites a bird was seen at was also calculated.

\section{Results}

Forty-eight birds were banded in total, with three birds banded at Lambton Quay, eight at Aro Park, nine at Manners-Victoria Square, 10 at Te Aro Park and 18 at Glover Park. Five of the 48 birds were not seen again after banding while ten birds were seen on four or fewer occasions. Of these ten birds, six were observed only in the first month since banding and not seen again. Thirteen birds had between 5 and 8 observations, and the remaining twenty were seen on nine or more occasions (Table 3.1). 
Table 3.1 Band combination and banding site, and activity area of twenty banded feral pigeons with nine or more observations observed from June-December 2010 in Wellington City. Activity areas were estimated using 100\% Minimum Convex Polygons. The number of observations and number of sites over which the observations were distributed are also shown.

\begin{tabular}{llccc}
\hline $\begin{array}{l}\text { Band } \\
\text { Combination }\end{array}$ & Banding Site & $\begin{array}{c}\text { Number of } \\
\text { observations }\end{array}$ & $\begin{array}{c}\text { Number of } \\
\text { sites }\end{array}$ & $\begin{array}{c}\text { Activity } \\
\text { area (ha) }\end{array}$ \\
\hline M/Y W/O & Te Aro Park & 16 & 5 & 0.94 \\
M/Y R/G & Te Aro Park & 11 & 4 & 0.50 \\
M/Y W/G & Te Aro Park & 13 & 4 & 4.20 \\
M/Bk Y/G & MV Square & 16 & 4 & 0.39 \\
M/Bk R/Y & MV Square & 15 & 4 & 10.26 \\
M/Bk Bk/O & MV Square & 13 & 5 & 9.35 \\
M/Bk O/Y & MV Square & 13 & 2 & 0.04 \\
M/Bk G/O & MV Square & 13 & 3 & 0.25 \\
M/R G/Y & Lambton Quay & 22 & 3 & 0.79 \\
M/R Y/Bk & Lambton Quay & 10 & 3 & 1.14 \\
M/G G/Bk & Glover Park & 14 & 6 & 2.42 \\
M/G Bk/R & Glover Park & 12 & 1 & 0.07 \\
M/G W/R & Glover Park & 9 & 3 & 0.94 \\
M/G Y/Bk & Glover Park & 9 & 3 & 0.32 \\
M/G Y/O & Glover Park & 11 & 3 & 0.67 \\
M/O G/Y & Aro Park & 24 & 3 & 3.97 \\
M/O R/Bk & Aro Park & 12 & 2 & 0.10 \\
M/O Y/Bk & Aro Park & 12 & 2 & 0.11 \\
M/O R/Y & Aro Park & 9 & 3 & 0.97 \\
M/O R/G & Aro Park & 10 & 1 & 0.05 \\
\hline
\end{tabular}


Individual birds were seen at between one and six different sites, and of the 20 birds with nine or more observations, $14(70 \%)$ were observed at only one, two or three different sites. There was limited movement between the five park capture sites, as only two of the forty eight birds were seen at a park capture site other than the one they were caught and banded in. A Te Aro Park bird was seen once at Glover Park and once at MV Square, while a Glover Park bird was seen at Te Aro Park on two occasions.

Activity areas for the twenty birds with nine or greater observations are presented in Table 3.1. The size of the activity areas varied greatly between individuals, as the smallest activity area was 0.04 ha while the largest was 10.26 ha (Figure 3.2). The average activity area for the twenty birds was 1.87 ha; however most activity areas were smaller. Fourteen $(70 \%)$ of the activity areas were smaller than 1 ha and nine of them smaller than 0.5 ha. The activity areas are displayed in Figure 3.3. Of the twenty birds, eighteen were adults, one was juvenile and the age class of one was not determined. 


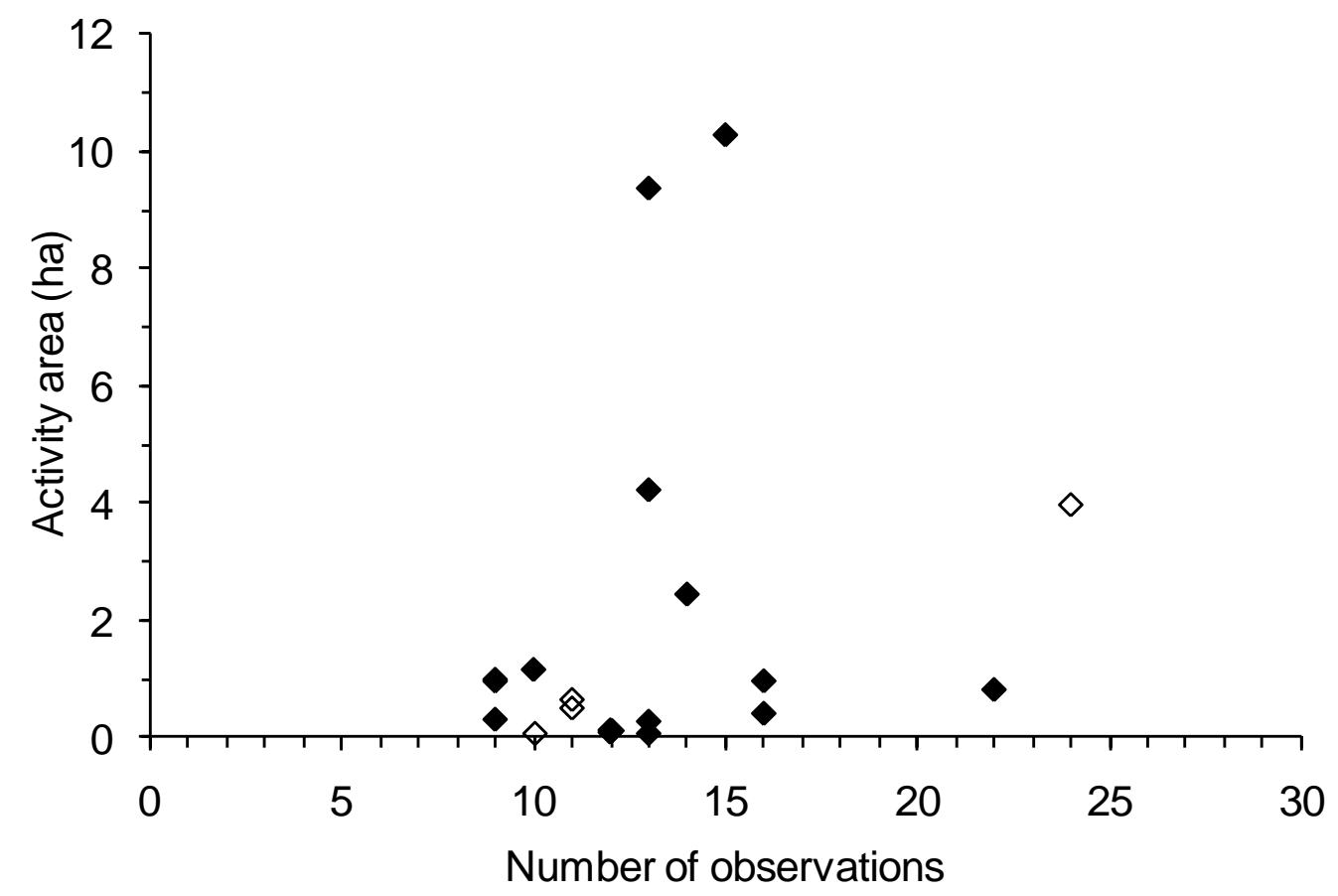

Figure 3.2 The number of observations and activity area of twenty feral pigeons observed in Wellington from June-December 2010 for: $\diamond$ birds with bands and $\diamond$ birds with both bands and a radio transmitter. 


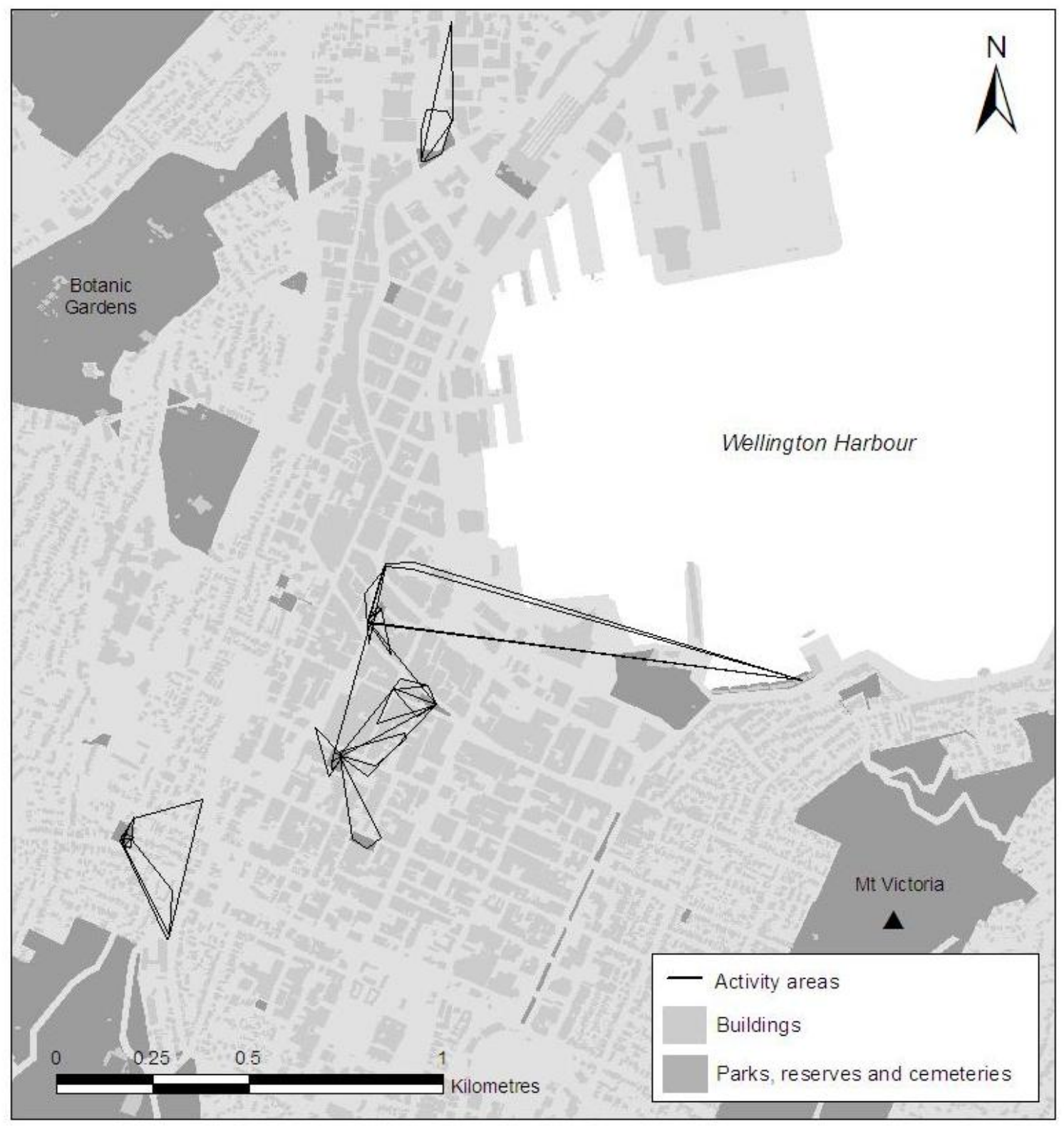

Figure 3.3 Activity areas of twenty feral pigeons banded and observed in Wellington City from June-December 2010. 


\section{Discussion}

Feral pigeons in Wellington City had limited movements, as $70 \%$ of the activity areas calculated for the twenty birds with nine or more observations were smaller than 1 ha, and the average activity area was 1.87 ha. These twenty birds were seen at only a small number of different locations, with 14 (70\%) seen at three or fewer locations. The pigeons also showed site loyalty, as only two of the total 48 banded birds were seen at a different park capture site other than the one where they were caught. This was despite the fact that three of the sites (Te Aro Park, MV-Square and Glover Park) were all within 320m of each other. A similar result was found in Barcelona, Spain, where pigeons had an average range size of 1.64 ha and showed little movement between feeding sites (Sol \& Senar 1995). As pigeons generally travel smaller distances when food resources are locally abundant, this suggests artificial food resources in Wellington are likely to be plentiful (Soldatini et al. 2006).

Pigeon foraging strategies play a large role in determining the extent of feral pigeon movements (Soldatini et al. 2006). Johnston \& Janiga (1995) identified two main foraging strategies in feral pigeons 1) foraging in squares, streets and parks near the home loft and 2) foraging in agricultural areas (e.g. Little 1994). The flights to agricultural areas are most similar to those of their wild rock dove ancestors, which fly on daily foraging flights from colonies to their feeding grounds (Baldaccini et al. 2000). Rose et al. (2006b) identified a third strategy, foraging on docks and railway lines in harbours on spilled grain during the shipping process. This strategy is considered intermediate between the first two, in terms of both travel distance and food reliability, where agricultural resources are considered more reliable and city resources less so. The activity areas in this study are small and situated within the central city, which 
suggests that pigeons in Wellington forage according to the first strategy, in the urban environment around human food sources (Chapter Two). The absence of substantial agricultural crop areas and grain shipping industry in Wellington add weight to this conclusion.

Although most of the pigeons' activity areas were small, there was a substantial difference between the smallest activity area (0.04ha) and the largest activity area (10.26ha). In a study which used GPS to track pigeon movements in Basel, Switzerland, pigeons exhibited similar behaviour. Maximum distances travelled varied widely (between 0.03 and $5.29 \mathrm{~km}$ ) yet over $32 \%$ of pigeons tracked were never found more than $0.3 \mathrm{~km}$ away from their loft (Rose et al. 2006b). Previous studies have showed female pigeons travel longer distances than males, due to their preference for the more reliable food sources from agricultural areas outside the city (Johnston \& Janiga 1995, Rose et al. 2006b). However, this is unlikely to occur in Wellington because it does not have any agricultural food sources just outside the city. Instead, the variation in range sizes may be explained by movements of some individuals between different flocks. Some studies have previously suggested that pigeon flocks are unstable, with pigeons regularly moving between different flocks and feeding sites (Lefebvre 1985, Rose et al. 2006b), while others have suggested that pigeon flocks are stable in their composition of individuals (Murton et al. 1972a, Sol \& Senar 1995). The different results on flock stability have been partly attributed to differences in the type and availability of food resources between the different cities in the studies. Situations may also occur where flocks have characteristics of both stability and instability. Sol \& Senar (1995) suggested that while pigeon flocks are stable for the most part, a smaller number of individuals regularly move between flocks and feeding sites. This could explain why 
some individuals had much larger activity areas than many of the birds in this study. Birds that move between flocks have larger activity areas, while the birds that stay at the same feeding site close to their nest have smaller activity areas.

Although there were not enough observations for minimum convex polygons (MCPs) to be reliable estimates of home range, many of the pigeon's movements were restricted to particular sites. Figure 3.2 showed that many of the activity areas did not increase even as the number of observations increased. This suggests activity areas may remain on the small side even if adequate observations were obtained. There are a number of reasons as to why some birds were observed only a small number of times compared to others, when feral pigeons in Wellington are generally thought to be site loyal. Firstly, birds with nests will be less visible than others without, as nesting sites are usually hidden away in buildings. Secondly, mortality due to motor vehicles or to people is a possibility. There was an unconfirmed report of bird stoning that resulted in deaths of banded pigeons. For the five birds not seen again since banding, death due to capture induced stress is also possible. Finally, roaming pigeons that are not site-loyal may visit unmonitored sites in the suburbs. Future studies may wish to include sites in the suburbs in regular searches for banded birds to provide information on movements from the inner city to the outer suburbs. Banding birds in the outer suburb aggregation sites would also provide information on movements from the outer suburbs to the city centre.

The use of radio tracking in the study was unsuccessful due to the obstruction of signals by buildings and other structures, particularly when birds are on their nests. Bird banding can provide information on pigeon movements but the pigeon's legs must be visible to obtain an observation. In addition, observations will be limited to areas 
chosen by the observer to be searched. One technique that avoids these limitations is GPS. GPS is able to monitor pigeon location continuously, resulting in more accurate results and has been used successfully to track pigeons (Rose et al. 2006a).

Most of the pigeons' activity areas were smaller than 1ha, and pigeons showed high site loyalty. Although there were some limitations to the data, the small activity area sizes suggest that artificial food in central Wellington is plentiful, as the birds did not have to travel far to meet their daily energy requirements. The much larger activity areas of a few individuals suggests that while the majority of pigeons remain within a small area, some individuals may move further afield to other sites. This suggests that pigeon culls in Wellington may not be a successful management tool, as roaming individuals from areas not targeted could take the place of the individuals removed by the cull. Since most of pigeons appear to have localised ranges around key artificial food sites, reducing population numbers via a reduction in artificial food might be an appropriate management strategy.

This study aimed to provide information on the extent to which a reduction in feeding should be carried out. The results suggested that the majority of pigeons do not move far from their feeding site, and consequently that artificial food is plentiful. This indicates that a significant reduction in food availability needs to occur for a population decrease to be successful. Therefore the extent of the food limitation programme should cover the major food sites in the city. As long as the sites with the largest amounts of artificial food availability continue providing food, a significant population decrease is not likely. These sites should be targeted and can be identified fairly easily as they are likely to be those that have the largest number of pigeons. Although the roaming 
individuals that already move between sites may continue feeding in other areas not targeted, a significant decrease in food availability overall should decrease the population. In addition these pigeons are likely to be the exception rather than the rule as pigeons tend to stay with the same food source for long as possible (Giraldeau 1984, Johnston \& Janiga 1995). Pigeon management is likely to require a significant management of human behaviour. 


\section{Chapter Four: Propensity to feed wildlife affects attitudes to feral pigeons and their control}

\section{Abstract}

An understanding of people's relationships with wildlife is necessary for the mitigation of urban human-wildlife conflict. As feral pigeons in Wellington City are reliant on public feeding, examining human-pigeon relationships is essential to limit feeding and consequently reduce population numbers and conflict. To investigate attitudes to feral pigeons I hand delivered 800 questionnaires to 50 residents at 16 stratified random sites around central Wellington City. Models composed of variables influencing attitude towards pigeons (ranked $-1,0$, and 1) were tested using a robust linear model ( $\mathrm{n}=237)$. Respondents' attitudes towards pigeons were best explained by the model bird feeding and green spaces $\left(\Delta \mathrm{AICc}<2, w_{i}=0.430\right)$. Bird feeders were less negative towards pigeons, while respondents who visited green spaces were more negative. Regulatory control methods were preferred to shooting or poisoning. Respondents who fed pigeons had little support for control methods, yet their behaviour change is crucial to the success of a management programme. This highlights the importance of public consultation and participation in the management decision making process.

\section{Introduction}

Human-wildlife conflict occurs when wildlife damage property or threaten people's health and safety. Research on human-wildlife conflict in cities is increasingly 
important because the majority of people now live in cities that are expanding in number and size with commensurate increases in human-wildlife conflict in urban landscapes (Messmer 2009, Population Reference Bureau 2010). Common causes of human-wildlife conflict in urban areas include animal aggression (Jones \& Thomas 1999, Timm et al. 2004), vectored disease (Magnino et al. 2009), vehicle collisions (Stout et al. 1993) and damage to vegetation (West \& Parkhurst 2002). Conflicts occur with both native and introduced species and most often when they are numerous (Garrott et al. 1993, Messmer 2009).

Reducing human-wildlife conflict has traditionally depended on lethal control to reduce animal numbers or target particular animals (Treves \& Noughton-Treves 2005). Culling, however, is often only a temporary solution because populations recover quickly due to high reproductive rates or immigration (Murton et al. 1972b, Baker \& Harris 2006). Local population recovery at extermination sites will be particularly rapid if animals are fed. Culling will probably also be strongly opposed by some stakeholders, particularly amongst those with a propensity to feed wildlife. Indeed, wildlife feeders may increase feeding rates when and where animal control is threatened. Moreover, even amongst stakeholders who support culling, lower animal numbers may not resolve the conflict because their experience, beliefs or attitudes to the animal remain unchanged (Madden 2004). Human-wildlife conflict may remain unresolved because the underlying issue is essentially human-human conflict (Madden 2004). Thus, resolving human-wildlife conflict in urban landscapes will require approaches which integrate the ecological and human dimensions of the problem (Decker \& Chase 1997, Treves et al. 2006). Research to identify the diversity of stakeholder attitudes to the problem animal and its control to target management are 
essential for successful conflict resolution. It is also important to quantify stakeholder attitudes to establish the magnitude of the problem, as sometimes a vocal minority can give the impression a problem is greater than the actual reality.

As the manner in which people perceive and respond to wildlife conflict is influenced by their attitudes towards wildlife, understanding the factors that determine these attitudes is extremely important. Relationships between people and wildlife are complex and shaped by a large number of factors, including experiences with nature, especially during childhood (Chawla 1999, Palmer et al. 1999), close friends and family (Chawla 1999, Palmer et al. 1999) level and type of education (Palmer et al. 1999, Tikka et al. 2000), environmental knowledge and awareness (Dettmann-Easler \& Pease 1999), and proximity to wildlife (Karlsson \& Sjostrom 2007). Adding another layer of complexity are the effects of demographics such as age (Kellert \& Berry 1987), and gender (Kellert \& Berry 1987, Hill 1998) which is considered to be extremely influential. Of these factors, experiences with nature such as bird feeding and outdoor experiences are particularly related to positive attitudes towards wildlife and the environment (Rollinson et al. 2003, Chawla 1999). Therefore increased environmental engagement could result in greater positive attitudes to wildlife and subsequently more favourable outcomes for wildlife in the management of wildlife issues.

Urbanisation however, reduces positive interactions with wildlife, especially with endemic or native species. A disconnect between people and the natural world (Miller 2005) may reduce support for wildlife and habitat conservation (Finger 1994, Kals et al. 1999). Nevertheless, many people in urban environments maintain a relationship with nature by feeding wildlife or visiting parks. Wildlife feeding is often in the form of bird 
feeding, with reported bird feeding rates by households of 36-48\% in Australia (Rollinson et al. 2003, Ishigame \& Baxter 2007), and 20\% in the United States (Deis 1986). Bird feeding therefore, even of common urban species, might be critical to people's positive and generalised relationship with the natural world and attitudes to wildlife (Dunn et al. 2006). However, bird feeding can also have negative effects on the target population. These include long-term changes in bird population dynamics (Robb et al. 2008), concerns regarding dependency on anthropogenic food (Jones \& James Reynolds 2008) the facilitation of disease spread (Bradley \& Altizer 2006), inappropriate diets (Rollinson et al. 2003), and population increases in already abundant species (Parsons et al. 2006). Bird feeding can also exacerbate human-wildlife conflict due to the increased animal population densities it creates and the habituation of wildlife to people (Rollinson et al. 2003). Therefore the impacts of bird feeding on urban human-wildlife conflict need to be carefully considered.

Rock pigeons (Columba livia) are introduced and commensal in urban areas throughout the world (Long 1981). Often occurring at high densities, feral pigeons are considered a pest particularly because their waste fouls and corrodes surfaces, resulting in increased maintenance costs (Johnston \& Janiga 1995). Pigeons foraging around people also causes aggravation and raises concerns about pigeon-human disease transmission (Haag-Wackernagel \& Moch 2004). Yet feral pigeons also attract devoted groups of feeders who often rely on them for social interactions (Weber et al. 1994, Jerolmack 2006). These contrasting attitudes make it difficult to find management solutions which are acceptable to all stakeholders. 
Wellington City, New Zealand, has a pigeon population which is a source of humanwildlife conflict. The main causes of people's complaints to city government arise from places where pigeons aggregate in large numbers such as inner city parks and businesses selling food (Wellington City Council 2007). Pigeons in Wellington City are largely dependent on anthropogenic food and so reducing feeding by people may be the most direct way of reducing population numbers and human-pigeon conflict (Chapter Two). This study aimed to understand human-pigeon relationships in Wellington City and how these might affect a management strategy. Firstly we determined the perceived magnitude of pigeon-human conflict in Wellington City by asking whether people's attitudes towards feral pigeon abundance in Wellington City were positive, negative or neutral. Secondly, we investigated whether environmental engagement (through bird feeding or visits to outdoor areas) influenced people's attitudes towards pigeons. Finally, we determined people's attitudes to various methods of pigeon control, as it is important to gain public acceptance in wildlife management issues.

\section{Method}

\section{Study area}

Wellington City is situated at the south-western coastal peninsular of the North Island, New Zealand $\left(41^{\circ} 18^{\prime} 0^{\prime \prime} \mathrm{S}, 174^{\circ} 47^{\prime} 0^{\prime \prime} \mathrm{E}\right)$. The city covers an area of $290 \mathrm{~km}^{2}$, which includes rural, bushland and coastal areas as well as urban areas concentrated in the flat lands surrounding the harbour (Wellington City Council 2011a). The seven suburbs in the study area were Thorndon-Pipitea, Wellington Central, Kelburn, Te Aro, Aro Valley-Highbury, Mt Victoria and Oriental Bay. These covered the inner city and adjacent suburbs. The majority of the pigeon population lives in the commercial district in the inner city which is adjacent to the harbour, although flocks do reside in the outer 
suburbs. The city has a mild temperate climate with average monthly temperatures ranging from $8.8^{\circ} \mathrm{C}$ in July (mid-winter) to $17.1^{\circ} \mathrm{C}$ in February (late summer). Annual rainfall is $1249 \mathrm{~mm}$ and there are 2065 sunshine hours per year. Wind features strongly in the climate with an average windspeed of $22 \mathrm{~km} / \mathrm{hour}$, and 22 days of gale force wind per year (days with a mean speed above 63km/hour) (NIWA 2008).

Wellington City has a population of 197,700 people (Wellington City Council 2011a) characterised as comparatively young, educated and high-income. The population is $48 \%$ male and $52 \%$ female. Residents median age is 33.1 years, $55.5 \%$ have a postschool qualification, and median incomes are higher than the New Zealand average (i.e., $\$ 32,500$ cf. $\$ 24,400$, respectively) (Statistics New Zealand 2006).

\section{Household questionnaire}

A preparatory letter, two-page questionnaire and reminder letter were distributed by hand to 800 households at 16 randomly allocated sites (50 questionnaires per site) between 8 and 26 November, 2010, in the central suburbs of Wellington City where the majority of pigeons live (Figure 4.1). Questionnaire distribution sites were allocated along the same transect lines used to measure the density and distribution of pigeons (Chapter Two). The sites were chosen by generating random points for each transect line. Points that did not fall amongst residential housing were shifted to the nearest residential area. If there was no residential housing within $200 \mathrm{~m}$ of the point, new points were generated. Each transect line was allocated two sites, apart from the longest transect which had three sites, and the shortest transect which had one site, amounting to 16 sites in total. 


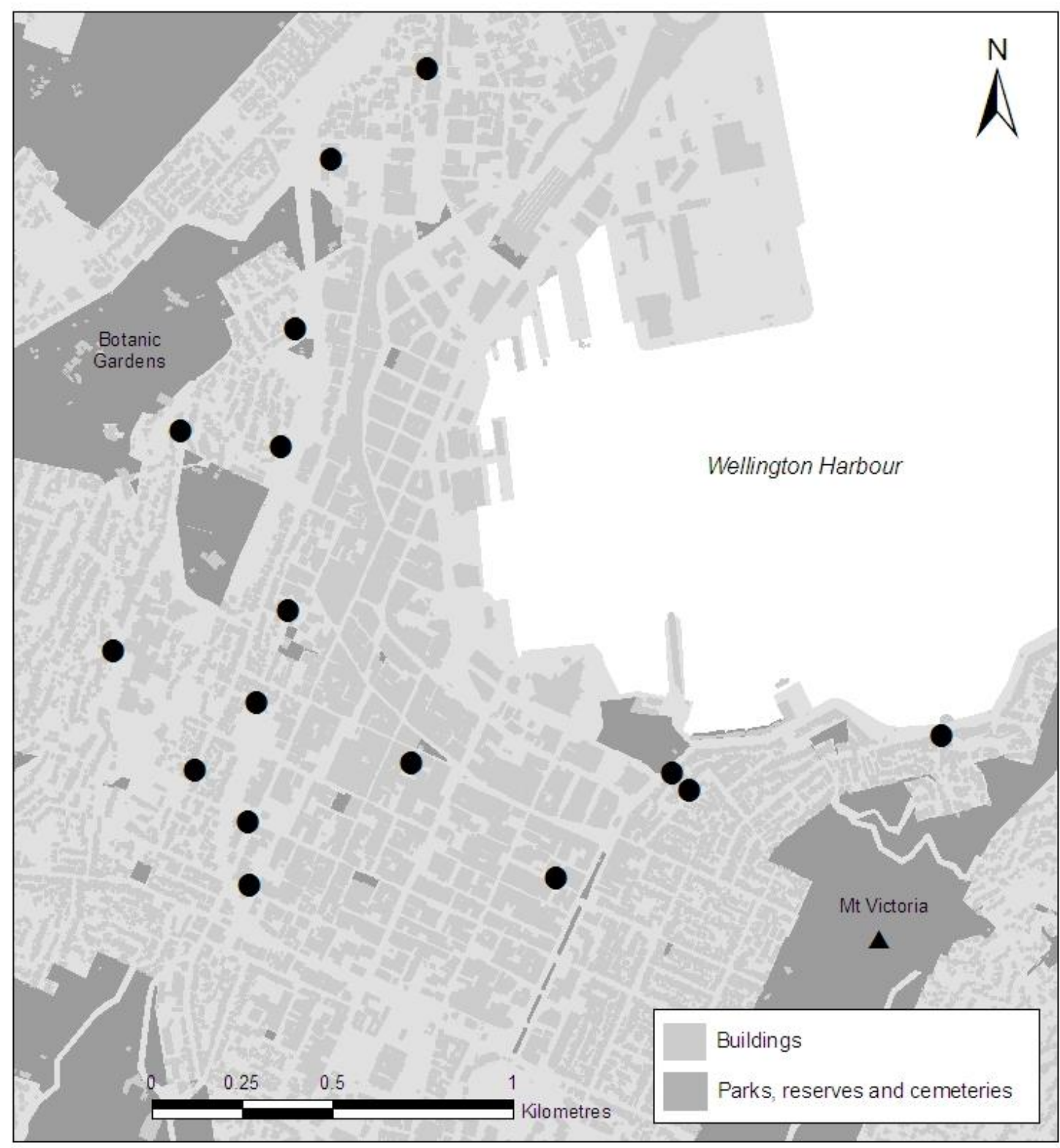

Figure 4.1. Map of the 16 questionnaire distribution sites in Wellington City. 
The preparatory letter was delivered during the first week advising the household that they would soon be receiving a questionnaire. The questionnaire and explanatory letter were delivered in the second week, and a letter reminding people to complete the survey was delivered in the third week. The questionnaire was designed to quantify and explain residents' attitudes to feral pigeon abundance (see Appendix 2 for questionnaire). Attitude to pigeon abundance was quantified by asking residents whether they thought there were 'too many', 'about the right amount', or 'not enough' pigeons in Wellington. An option of 'no opinion' was also provided. Responses were scored as -1 (too many), 0 (about the right amount or no opinion) and +1 (not enough). Responses of 'about the right amount' were grouped together with those indicating 'no opinion' as both were considered to represent a neutral attitude towards pigeon abundance. To understand attitudes to pigeon control, respondents were provided with a list of population control techniques and asked which ones they would support for the management of pigeon numbers in Wellington City.

In order to assess the influence of bird feeding on attitudes towards pigeon abundance respondents were asked whether or not they fed birds, and if so which species. Green space visits, a measure of outdoor experiences, was assessed by asking respondents how often they visited green spaces, on a five point scale ranging from 'not at all' to '2-3 times a week'. Five other factors also thought to influence attitudes to wildlife were measured: childhood experiences with nature, childhood outdoors, environmental actions, biodiversity knowledge, and environmental awareness. Respondents rated their time spent engaging with nature as a child, and outdoors in various environments as a child, on a 5 point likert scale. Environmental actions were measured by asking respondents whether they had in the last month, composted, recycled, or used own bags 
at supermarket, and in the last year had donated to an environmental charity, volunteered for an environmental organisation, attended a public meeting in support of the environment, or signed a petition in support of the environment. Biodiversity knowledge was tested by asking respondent to correctly identify colour photographs of eight different birds. The photographs included four native and four introduced exotic species, and a mixture of well known and lesser known species. Each correct answer was awarded one point. Environmental awareness was tested by asking respondents to list the three greatest threats to native plants and animals in New Zealand. Threats were determined from a consensus of the scientific literature to be invasive species, habitat loss and fragmentation, and over-exploitation (Dopson et al. 1999, Clout 2001, Saunders \& Norton 2001, Walker et al. 2006, Kingsford et al. 2009, Kelly \& Sullivan 2010). The responses were then grouped according to these classifications, and one point was given for each threat correctly identified. Finally demographic questions collected information on the respondents' sex, age, highest level of education and income.

\section{Statistical analyses}

We compared the demography of survey respondents to the demography of the population in the seven suburbs that were part of the study area using a chi-square test. The population data was obtained from the 2006 census results (Wellington City Council 2011b). Age categories in the census did not exactly match those in the questionnaire, however the test was still carried out as the difference between categories was a maximum of two years. 
Hypotheses for residents' attitude to pigeon abundance were evaluated using an Information-theoretic approach (IT). An IT approach has advantages over traditional hypothesis null-hypothesis testing because it allows for multiple competing hypotheses to be compared evidentially. When hypotheses have similar support model averaging can be used to make robust predictions (Johnson \& Omland 2004). The IT analysis had two stages. First, we evaluated models for respondents' attitudes towards feral pigeon abundance without demographic fixed-effects. The seven fixed effects were bird feeding, green spaces, child experience, child outdoors, knowledge, action and awareness. These were assembled into models representing alternative hypotheses. The models were described using the robust linear model (rlm) procedure in $\mathrm{R}$ version 2.11.1 (R Development Core Team 2010) and ranked according to Akaike's Information Criterion. Models with $\triangle \mathrm{AIC} \leq 2$ were considered to have substantial support from the data and models with $\triangle \mathrm{AIC}>10$ to have no support (Burnham \& Anderson 2002). Second, we determined which demographic model best explained respondents' attitudes towards feral pigeon abundance in Wellington City. Models were assembled based upon the factors of sex, age, education and income. We then added the best demographic model to the confidence set of models from the first analysis to identify which were substantially improved by the additional of the leading demographic model. Models were ranked and weighted to identify the confidence set of leading models (i.e., $\left.\sum \omega>0.95\right)$. 


\section{Results}

\section{Questionnaire response}

Two hundred and eighty (35\%) of the questionnaires were returned. Of these, 43

returned questionnaires were excluded from this analysis because some questions were not answered. Twenty-one questionnaires were excluded due to missing income data, while another twelve had data missing on childhood activities (3), childhood outdoor experiences (3), sex (2), pigeon opinion (2), green spaces (1) or age (1). Another ten were excluded due to missing information on multiple questions.

More females $(n=136,57.4 \%)$ than males responded $(n=101,42.6 \%)$ but there was a relatively even representation amongst age classes, excepting the oldest: 18-25 years (19.0\%), 26-35 years (23.2\%), 36-50 years $(21.9 \%), 51-70$ years $(27.8 \%)$, and over 70 years $(8.0 \%)$. Respondents were highly educated (no formal education $2.5 \%$, high school $13.1 \%$, trade $13.9 \%$, Bachelor's degree $46 \%$, and postgraduate qualification $24.5 \%$ ) and high-income (less than $\$ 10,0009.7 \%, \$ 10,000-\$ 30,00014.8 \%$, $\$ 30,001-$ $\$ 50,00015.6 \%, \$ 50,001-\$ 70,00021.5 \%, \$ 70,001-\$ 100,00017.7 \%$, and over $\$ 100,000$ 20.7\%. Respondents were more educated $X^{2}(4, N=237)=159.61, p<0.001$, older $X^{2}$ $(4, N=237)=36.58, p<0.001$ and higher-income $X^{2}(5, N=237)=314.2, p<0.001$ than the overall population from the seven suburbs of the study area but the sex ratio was not significantly different $X^{2}(1, N=237)=3.76, p>0.005$.

\section{Attitudes towards pigeons and explaining factors}

Respondents' attitudes to pigeons were characterised as negative because they thought there were too many $(n=107,45 \%)$, neutral because they thought there were about the right amount $(n=62,26 \%)$ or had no opinion about the number $(n=61,26 \%)$, or positive 
4because they thought there were not enough $(n=7,3 \%)$. Respondents attitude (negative, neutral or positive) towards pigeons was best explained by the three models including bird feeding which were the only models to receive substantial support and constitute the confidence set of models (i.e., $\Delta \mathrm{AICc}<2, \sum w>0.95$, Table 1). People who provided food or water for birds were more likely to have a positive or neutral attitude to the abundance of feral pigeons (Figure 4.2). The regularity with which respondents visited green spaces also contributed to the leading model (Table 4.1). Respondents who visited green space more often were more likely to hold a negative attitude about pigeon abundance (Figure 4.3). Although the model of bird feeding and environmental action was included in the confidence set of models, it did not outperform the model including only bird feeding. Thus, environmental actions appear not to contribute to explaining different attitudes to pigeon abundance. The leading demographic model of sex was the only model to receive substantial support (i.e., $\Delta \mathrm{AICc}<2, w_{i}=0.838$ ), and sex procured greater model weights than other predictors (i.e., $\sum w_{\text {sex }}=0.959$, $\left.\sum w_{\text {education }}=0.060, \sum w_{\text {age }}=0.056, \sum w_{\text {income }}=0.049\right)$. However, the addition of sex to the confidence set of models did not substantially improve their explanatory power (i.e. AICc bird feeding + sex $=383.7$, AICc bird feeding + green space + sex $=383.9 \mathrm{cf}$. AICc in Table 4.1). 
Table 4.1 Candidate models for Wellington residents' attitudes towards pigeons during November 2010 are in descending order based on Akaike's Information Criterion (AICc), $\mathrm{N}=237, \mathrm{~K}=$ number of parameters.

\begin{tabular}{lcccc}
\hline Model & $\mathrm{k}$ & AICc & DAICc & Akaike $w_{i}$ \\
\hline bird feeding + green spaces & 4 & 382.4 & 0.00 & 0.424 \\
bird feeding & 3 & 382.5 & 0.09 & 0.405 \\
action + bird feeding & 4 & 384.3 & 1.87 & 0.166 \\
child activities + child outdoors & 4 & 394.4 & 12.03 & 0.001 \\
child activities & 3 & 394.4 & 11.97 & 0.001 \\
green spaces & 3 & 394.5 & 12.09 & 0.001 \\
green spaces + child outdoors & 4 & 395.8 & 13.38 & 0.001 \\
knowledge & 3 & 395.9 & 13.52 & 0.000 \\
knowledge + awareness & 4 & 396.3 & 13.92 & 0.000 \\
\hline
\end{tabular}




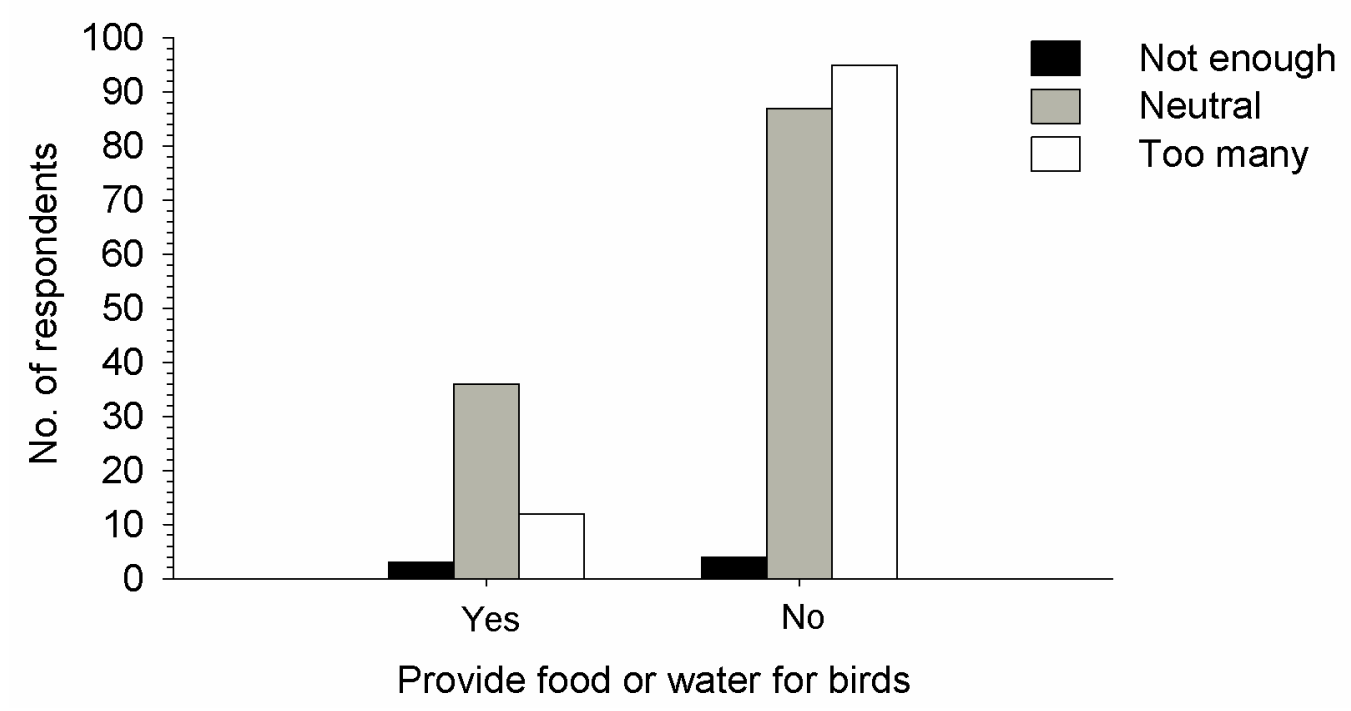

Figure 4.2 Respondents'attitudes towards feral pigeons in Wellington and whether or not they provide food or water for birds.

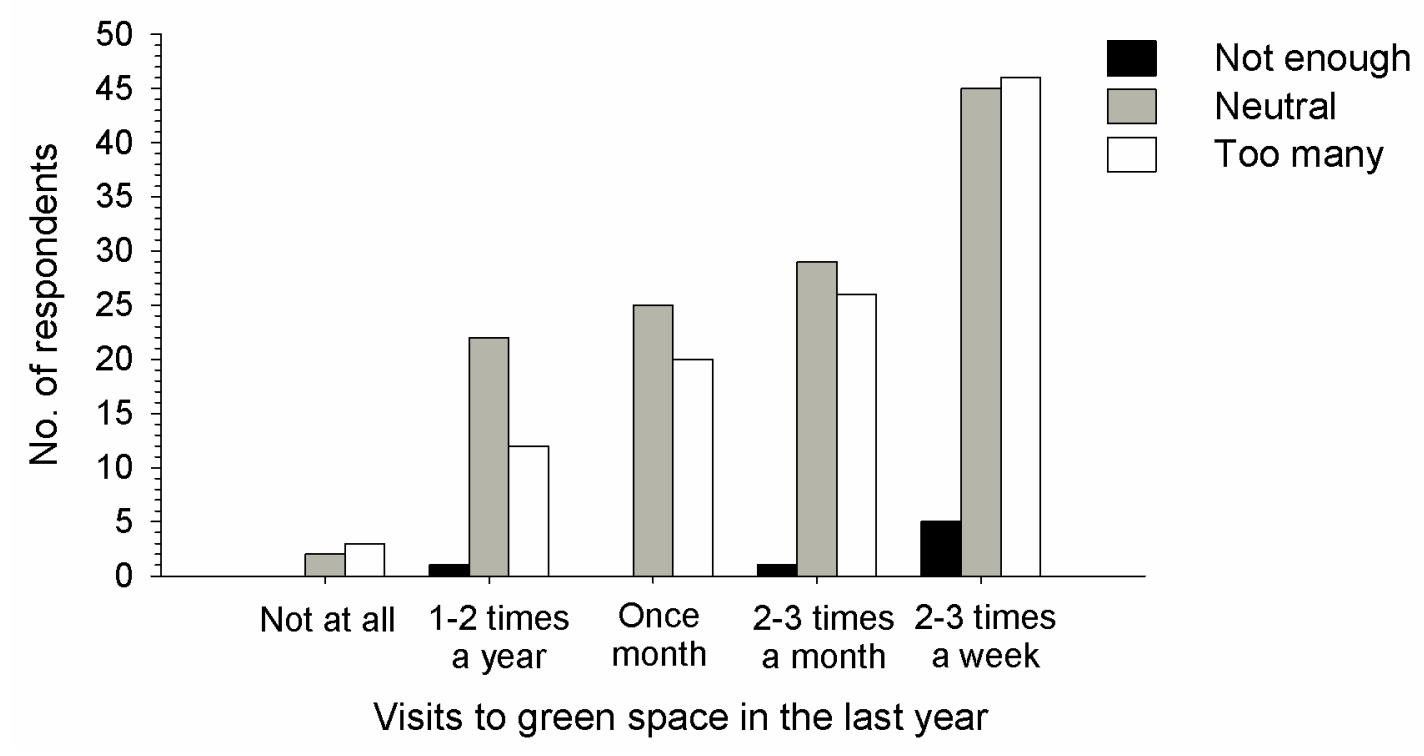

Figure 4.3 Respondents'attitudes towards feral pigeons in Wellington and how often they visited green spaces in the last year. 
The bird feeding population and the pigeon feeding population

People ( $\mathrm{n}=51$ ) who provided food or water for birds (bird feeders) listed tui Prosthemadera novaeseelandiae, sparrows Passer domesticus, ducks Anas platyrhynchos, feral pigeons Columba livia and blackbirds Turdus merula as the species they most fed (Figure 4.4). A respondent's education, age or income were not associated with their propensity to feed birds (Figure 4.5a, 4.5b, 4.5c). People with no education appeared not to feed birds, however this group included only six respondents. Respondent sex, however, did appear to explain their propensity to feed birds. Females were more likely to feed birds than males (Figure 4.5d). Out of the 51 respondents $(21.5 \%)$ who provided food or water to birds, eleven identified pigeons as one of the bird species they fed. Those who fed pigeons were also predominantly female (eight out of eleven) and represented in the 18-25, 36-50, and 51-70 age groups, had incomes from $\$ 10,000$ to over $\$ 100,000$, and identified themselves as NZ European (8) or Asian (3). All respondents except one had tertiary degrees. 


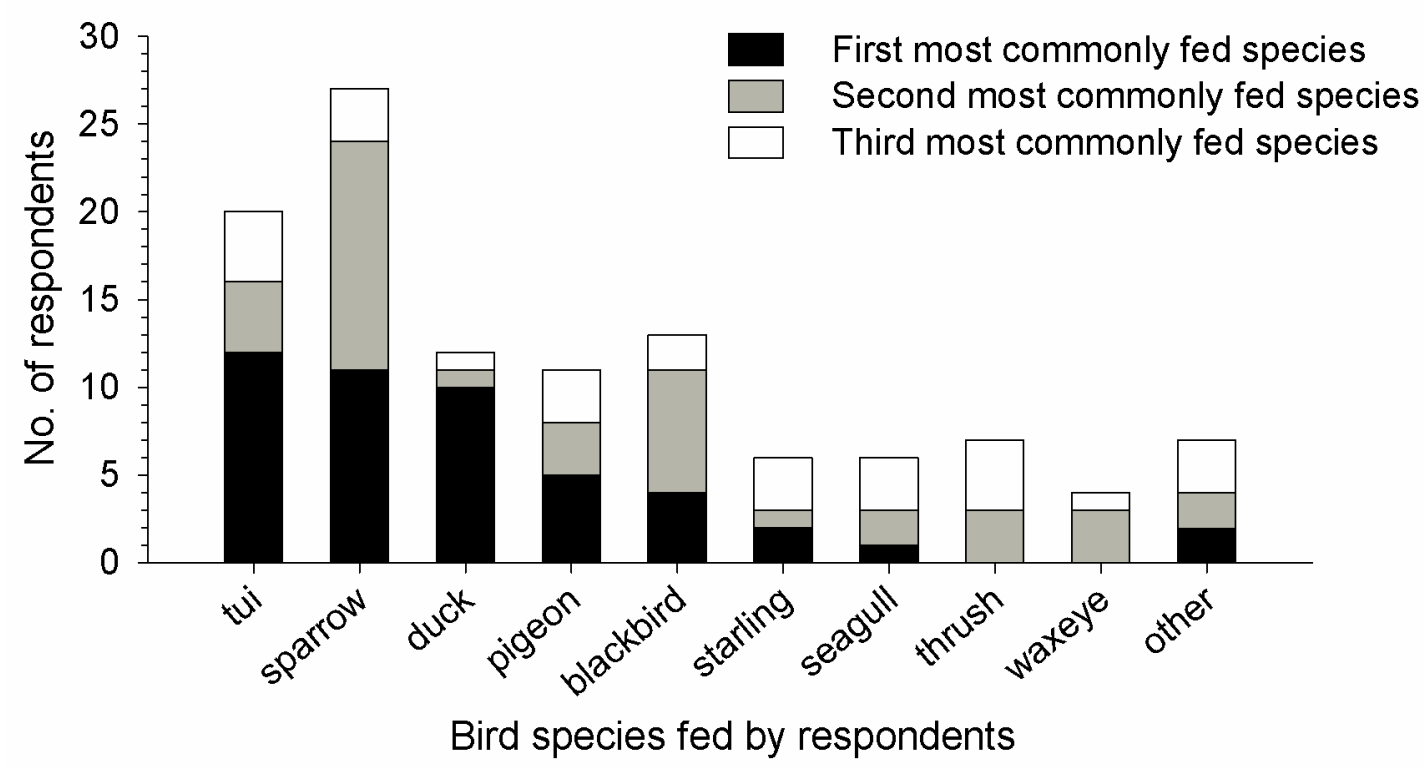

Figure 4.4 Respondents who provide food or water for birds listed the top three species they fed. Birds listed were tui (Prosthemadera novaeseelandiae), sparrow (Passer domesticus), duck (Anas platyrhynchos), feral pigeon (Columba livia), blackbird (Turdus merula), starling (Sturnus vulgaris), seagull, thrush (Turdus philomelos) and waxeye (Zosterops lateralis). 


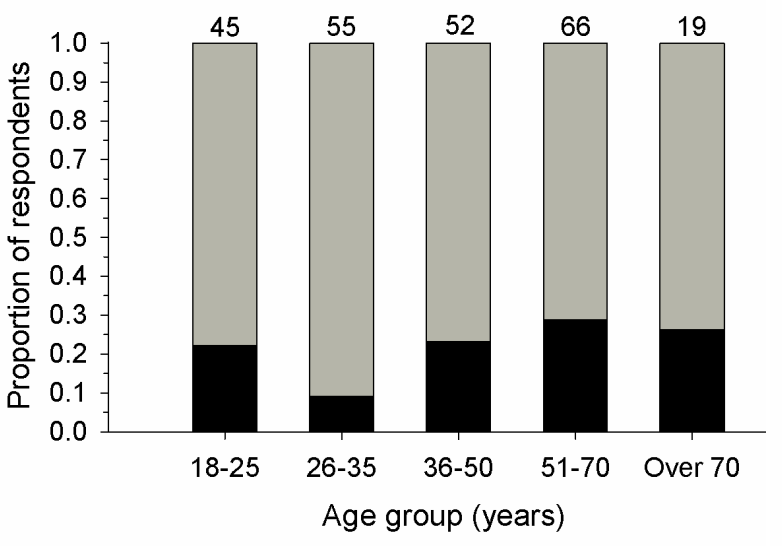

a)

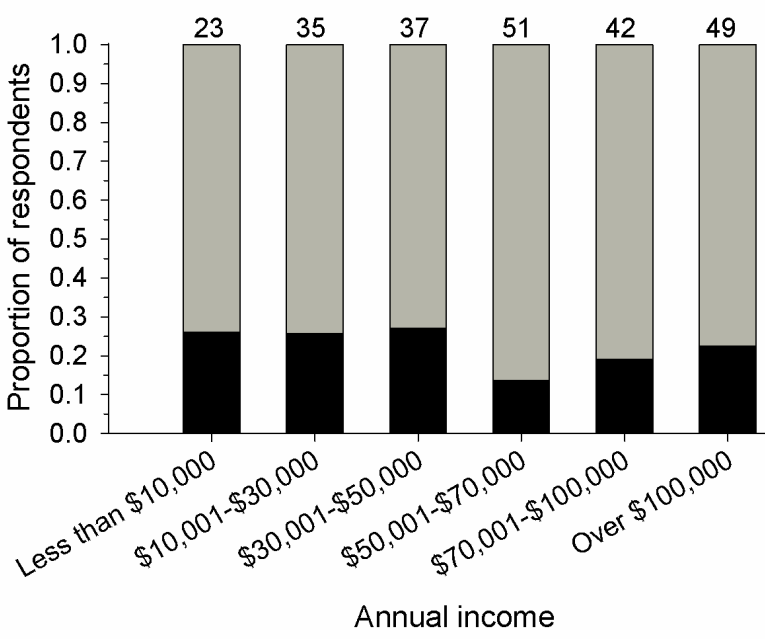

c)

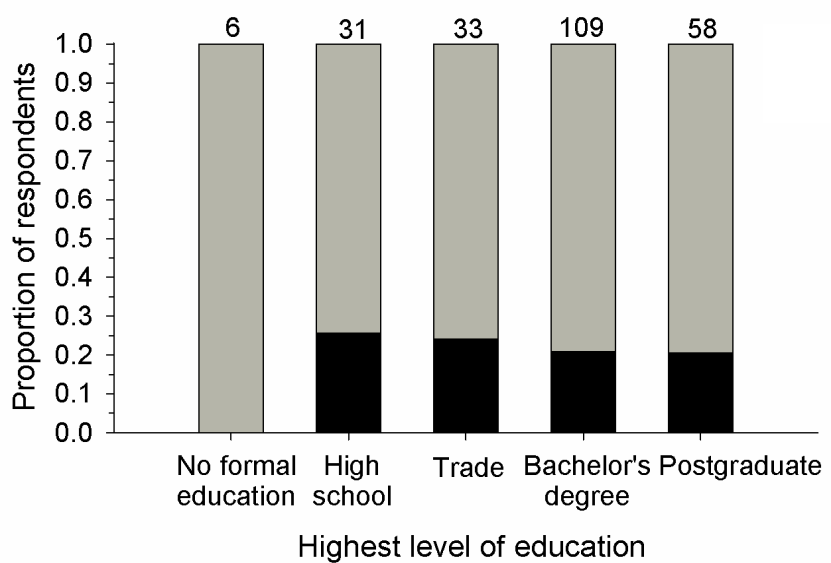

b)

Highest level of education

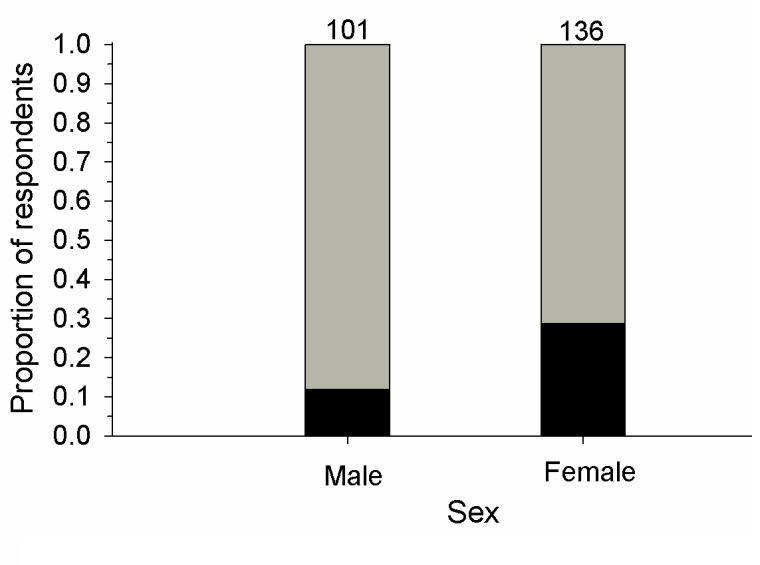

d)

Figure 4.5 Comparison of age groups, highest level of education, annual income and sex of between $\square$ bird feeders and $\square$ non bird feeders. 


\section{Responses to pigeon control}

The methods of population control with most support were those that involved regulation rather than lethal methods. The preferred method was regulation to erect nesting and roosting barriers, followed by regulation to prevent feeding on refuse or by the public. The least favoured option was shooting, followed by poisoning and destruction of nests. The opinions of control differed depending on the attitudes people had towards pigeons. Respondents who believed there were too many pigeons were more likely to support lethal methods of control, while those who had a neutral opinion were more likely to support regulatory controls on nesting and feeding (Figure 4.6). Respondents who believed there were not enough pigeons in Wellington supported none of the control methods.

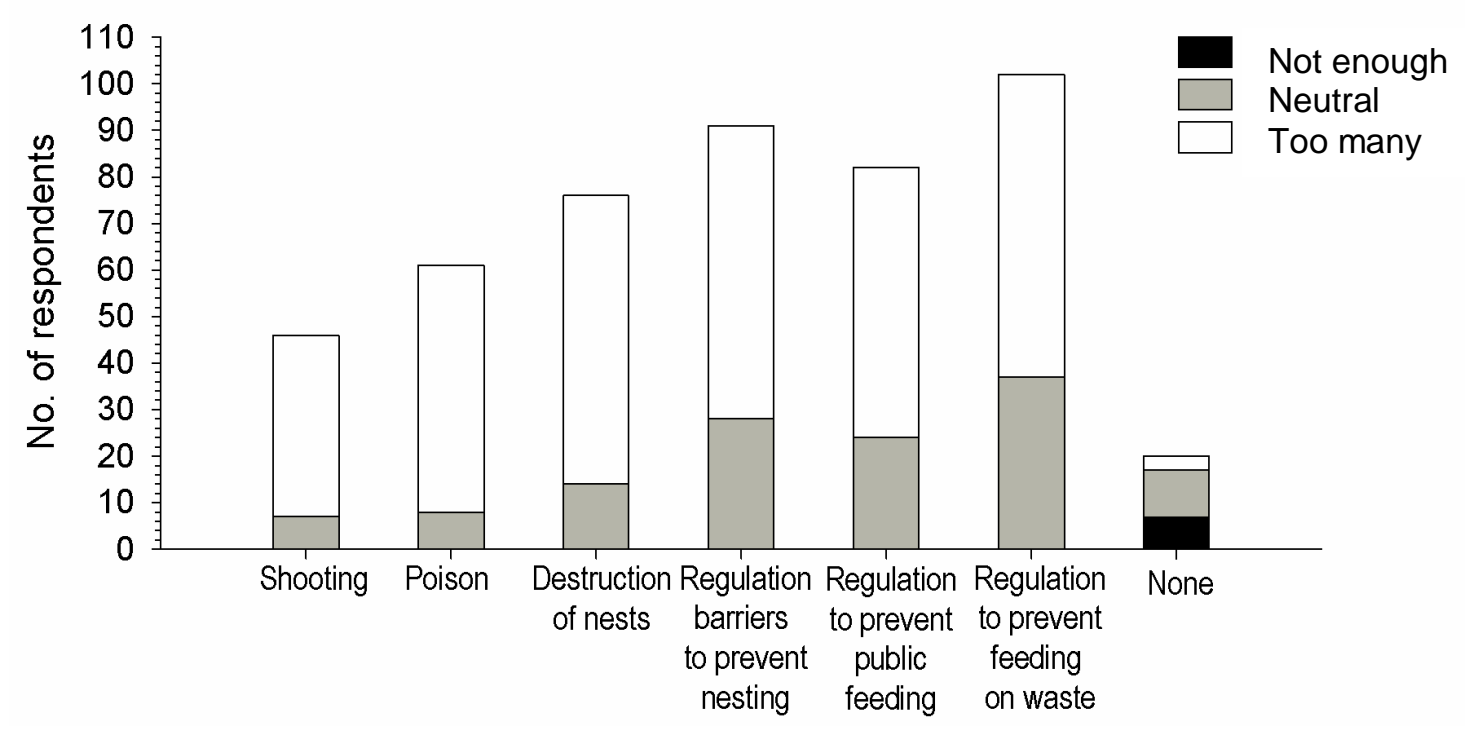

Figure 4.6 Survey respondents' attitudes towards feral pigeons in Wellington and their support for various control methods. 
The eleven bird feeders who fed pigeons showed little support for control methods. Shooting, waste regulation, feeding regulation and public feeding regulation each had the support of one person, while barrier regulation had the support of two people. Nest destruction was supported by three people. Pigeon control using poison was supported by none of the pigeon feeders.

\section{Discussion}

Attitudes towards feral pigeon abundance in Wellington were similarly split between neutral and negative, with a handful of positive responses. This demonstrates the importance of perception in human-wildlife conflict, as there were two contrasting opinions of the same situation. Respondents considered to have a neutral attitude to pigeon abundance are not necessarily indifferent to control methods, as the neutral response included those who considered there to be 'about the right amount' number of pigeons in Wellington. The primary reason people gave for having a negative attitude towards pigeons was pigeon waste. As almost $50 \%$ of survey respondents had a negative attitude to pigeon abundance this suggests that the human-pigeon conflict in Wellington is of great enough magnitude to warrant attention.

Respondent's attitudes towards feral pigeons in Wellington were best explained by the model of bird feeding and green spaces. People who provided food or water for birds (of any species) were less likely to have a negative attitude towards feral pigeons in Wellington. This is not surprising as the practice of bird feeding, like other forms of wildlife interactions, is considered to lead to a greater appreciation of wildlife 
(Rollinson et al. 2003). Alternatively, it may be that people who already like birds have a tendency to feed them. Nevertheless, bird feeding in Wellington poses a problem as feeding of pigeons is thought to be responsible for the abundance of pigeons and subsequent human-wildlife conflict. Although benefits such as greater interest and empathy for wildlife may be gained from feeding pigeons (Rollinson et al. 2003) these could be outweighed by the exacerbation of human-pigeon conflict.

In contrast to bird feeders, respondents who visited green spaces more often were more likely to believe that there are too many pigeons in Wellington. This may be explained by the fact that two of the most commonly green spaces visited by people were Midland Park and Te Aro Park, which have large numbers of pigeons. Parks which have high numbers of pigeons may be places where people are most likely to have negative interactions with pigeons. Negative interactions could include sitting close to pigeon waste while they eat their food, or have pigeons foraging around them while they eat. As people that visit parks often already believe pigeon abundances are too high, these people are likely to be most responsive to instructions to refrain from feeding pigeons.

The control methods with the most support were those that involved regulation rather than lethal techniques, while the least favoured method was shooting, followed by poisoning. This result is in line with the public response to a proposal to cull pigeons in Wellington City in 2008, which was cancelled due to public protest (Wellington City Council 2008). Attitudes towards culling appear not to have changed since this time as it still faces opposition. Lethal methods of wildlife control are often controversial with the public, and support for these methods is declining, particularly in developed countries (Treves \& Noughton-Treves 2005). Generally, support for lethal methods of 
wildlife management increases relative to peoples' concern about the wildlife problem (Loker et al. 1999). This is evident here as those who believed there were too many pigeons showed more support for lethal methods, while those who believed there were not enough pigeons did not support any kind of control. However, in some cases there is little support for lethal control, even from those most affected by the conflict (Jones \& Thomas 1998). This shows that rather than making assumptions, investigating the human dimensions of a particular conflict is extremely important, as no two situations are exactly the same. The respondents had diverse opinions on control methods, which is a challenge many wildlife managers face when dealing with human-wildlife conflict (Decker \& Chase 1997, Loker et al. 1999)

The bird feeders who fed pigeons showed very little support for the control methods proposed. This has created for a dilemma for wildlife managers, whereby people feeding birds has resulted in increased abundances and therefore human-pigeon conflict, yet these people are the ones who are most against the use of pigeon control methods. This is because an interaction with wildlife can lead to greater appreciation of the animals, resulting in increased empathy and a lowered tolerance for control. This predicament shows the importance of consulting the public and allowing them to participate in the management decision making process. In particular, it is important to include those who are most against control, as this study shows they are the ones whose behaviour needs to change for the situation to improve.

Although methods of regulation had more support than lethal methods, regulation would be likely to invoke negative responses from the public, particularly if costs were imposed on businesses. Barriers and other devices can work to prevent birds nesting 
and roosting, however they are costly and not recommended by some due to the harm they can cause to pigeons if not installed correctly (Haag-Wackernagel 2002). Barriers are already utilised in some places in Wellington, and while they can be appropriate for control at specific sites, they tend to redistribute the population rather than decrease population numbers. Since the pigeons' main source of food comes from pigeon feeders rather than food waste, regulation to control waste would not be likely result in a population decrease (Chapter Two). Regulation to prevent people feeding pigeons would be difficult to police, and given that many people enjoy feeding birds, regulation to prevent bird feeding would be unpopular with the public. Rather than regulation it would be preferable to educate people and encourage voluntary actions to reduce pigeon feeding.

Surveys such as these can often be biased due to non-respondents, as people with an interest in the study subject are more likely to answer the survey (White et al. 2005). In this study people with an interest in birds and wildlife, and those with an opinion on pigeons, were more likely to answer the survey. So it is possible the general population may have a higher proportion of people with a neutral opinion on pigeons. However this probably doesn't affect the results for the reasons why people have certain attitudes towards pigeons. Comparisons of the survey respondents' demographics with those of the study population showed that respondents tended to have higher levels of education and income, and were older. 


\section{Management recommendations}

Chapter Two suggested that limiting public feeding is the most effective way of reducing feral pigeon population numbers in Wellington City. This would require a change in human behaviour, which could be carried out through the use of an education and social marketing campaign. It could be targeted to two different areas: reducing pigeon feeding from feeders and the promotion of responsible bird feeding.

1) Reduce pigeon feeding in city parks. In Wellington City pigeons rely on food from both 'pigeon feeders', people who regularly feed bulk amounts of bread, rice and grain to pigeons, and 'casual feeders', people who feed small amounts of their own meal on an irregular basis (Chapter Two). A population decrease is dependent on a reduction of this feeding, and for this to be successful the target audience needs to be considered. In this study pigeon feeders tended to be female, of all ages, and with university education. Although it is not known whether the survey respondents who fed pigeons were pigeon feeders or casual feeders, a study that investigated human-pigeon interactions suggested that pigeon feeders do tend to be female (Weber et al. 1994). Although pigeon feeders are far less in number than casual feeders, they are probably the more important group to target due to the large amount of food they regularly provide pigeons.

2) Promote responsible bird feeding. Bird feeding is a popular pastime (over $20 \%$ of survey respondents in this study). It also allows people in urban areas to interact positively with wildlife, leading to a greater appreciation of nature which can lead to higher conservation action (Rollinson et al. 2003). Therefore 
it is recommended that responsible bird feeding be promoted, and native rather that introduced birds should be the target species. Rather than targeting pigeon feeders, who often have a special affiliation with pigeons, this aspect of the campaign will be useful in reducing food made available to pigeons by general bird feeders. The provision of seeds in bird feeders designed to discourage pigeons should be promoted, and seeds preferred by pigeons should be avoided. Pigeons have strong seed preferences and the use of certain seeds disliked by pigeons may also discourage pigeons.

\section{Summary}

People's attitudes towards feral pigeons in Wellington City were best explained by whether or not they fed birds and how often they visited green spaces. People who fed birds generally were less likely to have a negative opinion of pigeons while people who visited green spaces often were more likely to have a negative opinion. Attitudes towards pigeon population numbers were similarly split between too many and neutral, with only a few respondents believing there were not enough pigeons in Wellington. Although regulatory methods of pigeon control had more support than lethal control methods, issues surrounding regulatory methods means that they are still not appropriate management techniques for feral pigeons in Wellington. The pigeon feeders showed very little support for the control methods proposed. This has created a dilemma for wildlife managers, whereby people feeding birds has resulted in increased abundances and therefore human-pigeon conflict, yet these people are the ones who are most against the use of pigeon control methods. Recommendations to reduce humanpigeon conflict in Wellington are 1) reduce pigeon feeding in city parks; and 2) promote responsible bird feeding, through the implementation of an education and social 
marketing campaign. These results show how it is important to understand public attitudes to wildlife in human-wildlife conflicts, particularly when reducing the conflict requires a change in human behaviour. 


\section{Chapter Five: General discussion}

The contribution of this thesis has been to determine the factors that influence feral pigeon distribution and density on a landscape scale. Pigeon movements were assessed to understand artificial food availability. In addition, a social survey delivered to Wellington residents was used to understand attitudes to feral pigeons and their control. Together, this information was used to make recommendations for feral pigeon management in Wellington City.

Feral pigeon distribution in Wellington was influenced by artificial feeding from the public. Pigeons selected for areas closer to pigeon feeder sites, places where people regularly feed pigeons in bulk amounts. They also selected for public spaces, which as well as often being pigeon feeder sites, provide food in the form of casual feeders who feed pigeons smaller amounts on an irregular basis. Landscape type also played a role in determining pigeon distribution. Pigeons showed strong selection for commercial areas in winter, and avoidance of green and residential landscape types in both seasons. This is likely to relate to increased artificial feeding in landscape types with higher human density.

Pigeon density was higher in winter (6.8 pigeons/ha) than in summer (4.5 pigeons/ha). This is in contrast to results from European studies, where pigeon numbers peak in summer and autumn and then decrease in winter due to poor survival rates and limited breeding (Johnston \& Janiga 1995, Giunchi et al. 2007a, Giunchi et al. 2007b). This may be explained by the lower temperatures of winters in European cities compared to Wellington. In addition more pigeons on nests during spring and summer may mean 
pigeons are less visible during this time (Giunchi et al. 2007a). Pigeons were also more concentrated in commercial areas (17.8 pigeons/ha) in winter compared to summer (5.9 pigeons/ha). Since pigeons rely on people for food, this may reflect changes in the micro-distribution of people between seasons. Due to colder weather, parks and the wharf area may be frequented less in winter, leading to a higher concentration of people eating in the commercial areas. It may also signal a change in the pigeons' foraging strategy between seasons, from relying on food sources directly from people to a more opportunistic feeding strategy which utilises rubbish and skip bins that are more abundant in the commercial areas. Furthermore, it may also reflect the need for shelter in poorer weather.

The feral pigeons had limited movements as over two thirds of the activity areas were smaller than 1 ha. The pigeons also showed site loyalty, as only two of the total 48 birds were seen at a different park capture site other than the one where they were caught. In addition the birds were seen at only a small number of different sites, with most seen at three or fewer sites. Given that pigeons generally travel smaller distances when food resources are locally abundant, the small activity area sizes suggest that artificial food in central Wellington is plentiful, as the birds did not have to travel far to meet their daily energy requirements (Soldatini et al. 2006). Although most activity areas were small, there was a large difference between the smallest and largest activity areas. This may be due to the dynamics within the pigeon population as suggested by Sol and Senar (1995). While the core group of pigeons at a site is stable, a smaller number of individuals appear to move between flocks and feeding sites. 
The main factors influencing people's attitudes towards pigeons was whether or not they provided food or water for birds generally, or visited green spaces. People who fed birds were less likely to have a negative opinion of feral pigeons in Wellington. This is not surprising as the practice of bird feeding, like other forms of wildlife interactions, is considered to lead to a greater appreciation of wildlife (Rollinson et al. 2003). People who visited green spaces more often were more likely to have a negative opinion of pigeons. This is probably due to the fact that the types of green spaces people tended to visit were inner city parks. Here people are more likely to have a negative interaction with pigeons, for example sitting next to pigeon waste while they eat their meal.

The control methods with the most support were those that involved regulation rather than lethal techniques, while the least favoured method was shooting, followed by poisoning. The survey respondents who fed pigeons showed little support for control methods, and none of them supported pigeon control using poison. This has created a dilemma for wildlife managers, whereby people feeding birds has resulted in increased abundances and therefore human-pigeon conflict, yet these people are the ones who are most against the use of pigeon control methods. This is because an interaction with wildlife can lead to greater appreciation of the animals, resulting in increased empathy and a lowered tolerance for control. This predicament shows the importance of consulting the public and allowing them to participate in the management decision making process. In particular, it is important to include those who are most against control, as this study shows they are the ones whose behaviour needs to change for the situation to improve. 


\section{Management implications}

Although methods of regulation had more support than lethal methods, regulation would be likely to invoke negative responses from the public, particularly if costs were imposed on businesses. Barriers are expensive and do not reduce pigeon numbers at a population level, they may instead just redistribute the population. Regulation to prevent feeding on waste would not be effective since the pigeons main source of food comes from pigeon feeders, not waste. Regulation to prevent public feeding would be difficult to police, and would also be unpopular considering that $20 \%$ of the Wellington population are bird feeders.

Since the feral pigeon population is sustained by artificial food from the public, in order to reduce population numbers there needs to be a decrease in the amount of public feeding. The majority of pigeons do not move far from their feeding site, and consequently artificial food is probably plentiful. This indicates that a significant reduction in food availability needs to occur for a population decrease to be successful. Therefore the extent of the food limitation should cover the major food sites in the city. As long as the sites with the largest amounts of artificial food availability continue providing food, a significant population decrease is not likely. Winter may be an important time to focus on reducing food availability, as pigeons are more concentrated in the commercial areas, and there may be less feeding by casual feeders in parks and wharves. In addition, pigeons are more vulnerable at this time of year due to the poorer climate. Reducing food in spring and summer may be just as important however, given that these are usually the peak breeding months for feral pigeons. There appears to be core groups of pigeons that remain within short distances of their feeding sites as well as a smaller number who move further afield to other sites. Since these roaming 
individuals could take the place of any removed pigeons, culling is likely to be an ineffective management strategy.

The Wellington City Council is aware that feeding of pigeons by the public is a problem and has posted signs in parks asking people not to feed them. However because people continue to feed the pigeons it appears a more direct approach is required, in the form of a public education and social marketing campaign. Such a programme in Basel, Switzerland, combined with purpose-built lofts where feeding was permitted successfully reduced pigeon numbers by 50\% (Haag-Wackernagel 1995). This program involved the distribution of pamphlets and posters, which spread the message that it was harmful to feed the pigeons because over population had led to poor living conditions and high levels of disease. The campaign was also publicised by television, radio, newspapers and magazines. While successful overall, pigeon feeding was continued by foreigners who did not receive the message to stop feeding. In addition, some pigeon feeders were so ostracised by the general public that they felt unable to feed pigeons in areas where it was still permitted. Whether Wellington City's pigeons are diseased due to overpopulation is not known, but this is an angle that could be investigated.

The campaign could focus on two closely related aspects: 1) reduce pigeon feeding in city parks and 2) promote responsible bird feeding. The education programme needs to consider how best to target the two different artificial food providers: pigeon feeders and casual feeders. While casual feeders are likely to respond to a general education campaign the approach taken towards pigeon feeders, who often feel strongly about pigeons, will need to be carefully considered. Most are already aware of the problems 
other people have with pigeons, yet continue to feed anyway, sometimes using secretive behaviour. Some consider it their duty to feed and hold a responsibility for the pigeons, others feed for reasons of loneliness, because they like animals, or just as something to do (Weber et. al 1994). Understanding pigeon feeders' attitudes towards a food limitation will be important as a change in behaviour of pigeon feeders is crucial to the campaign's success.

The recommendation to promote responsible bird feeding, rather than an outright ban is given due to the popularity of bird feeding and the benefits it provides in the form of wildlife appreciation. Banning bird feeding would be met with opposition as over $20 \%$ of Wellington residents stated they fed birds, and it was the least popular of the regulatory methods. Bird feeding also allows people to interact with nature, leading to a greater appreciation of nature which can lead to higher conservation action (Rollinson et al. 2003). Promoting the feeding of native birds rather than pigeons would mean people could still enjoy and benefit from bird feeding, without contributing to the overabundance the pigeons in Wellington City. Casual feeders would most likely find the transition to feeding different bird species fairly straightforward. Native birds can be targeted by avoiding seeds that pigeons prefer should be avoided while the feeding of those they disliked should be encouraged. The provision of sugar water is a useful way of targeting native birds which rely on nectar (Department of Conservation 2011).

This study showed how knowledge on both species ecology and human dimensions in a human-wildlife conflict combined to provide a greater understanding of the situation. People had a large influence on feral pigeon ecology in Wellington City and consequently would also play a large role in the success of any management strategy. 
As urban species often rely on people for food, many urban human-wildlife conflicts are likely to be intertwined in this way. Resolution of these human-wildlife conflicts is likely to require a change in human behaviour. This highlights the need for researchers in ecology to integrate their studies with social science to manage wildlife, especially in urban environments. 


\section{References}

Adams LW. 2005. Urban wildlife ecology and conservation: A brief history of the discipline. Urban Ecosystems 8: 139-156.

Alberti M, Marzluff J, Shulenberger E, Bradley G, Ryan C, Zumbrunnen C. 2003. Integrating humans into ecology: Opportunities and challenges for studying urban ecosystems. Bioscience 53: 1169-1179.

Arnold CL, Gibbons CJ. 1996. Impervious surface coverage: the emergence of a key environmental indicator. Journal of the American Planning Association 62: 243-258.

Avery ML, Keacher KL, Tillman EA. 2008. Nicarbazin bait reduces reproduction by pigeons (Columba livia). Wildlife Research 35: 80-85.

Awasthy M. 2011. Kereru in urbanised landscape. Unpublished doctoral dissertation. Victoria University, Wellington, New Zealand.

Baker PJ, Harris S. 2006. Does culling reduce fox (Vulpes vulpes) density in commercial forests in Wales, UK? European Journal of Wildlife Research 52: 99-108.

Baldaccini N, Giunchi D, Mongini E, Ragionieri L. 2000. Foraging flights of wild rock doves (Columba l. livia): a spatio-temporal analysis. Italian Journal of Zoology 67: 371-377.

Baruch-Mordo S, Breck SW, Wilson KR, Broderick J. 2009. A tool box half full: how social science can help solve human-wildlife conflict. Human Dimensions of Wildlife 14: 219-223.

Belant JL. 1997. Gulls in urban environments: Landscape-level management to reduce conflict. Landscape and Urban Planning 38: 245-58. 
Beyer HL. 2004. Hawth's Analysis Tools for ArcGIS. Available at http://www.spatialecology.com/htools.

Blair RB. 1996. Land use and avian species diversity along an urban gradient. Ecological Applications 6: 506-519.

Bradley CA, Altizer S. 2006. Urbanization and the ecology of wildlife diseases. Trends in Ecology and Evolution 22: 95-122.

Buckland ST, Anderson DR, Burnham KP, Laake JL, Borchers DL, Thomas L. 2001. Introduction to distance sampling: estimating abundance of biological populations. Oxford University Press, Oxford, UK.

Buis JA, van Wijnen JH. 2001. Survey of feral rock doves (Columba livia) in Amsterdam, a bird-human association. Urban Ecosystems 5: 235-241.

Burnham K, Anderson D. 2002. Model selection and multi-model inference: a practical information-theoretic approach. Second edition. Springer-Verlag, New York.

Burt WH. 1943. Territoriality and home range concepts as applied to mammals. Journal of Mammalogy 24:346-352.

Chawla L 1999. Life paths into effective environmental action. Journal of Environmental Education 31: 15-26.

Clergeau P, Jokimaki J, Savard JPL. 2001. Are urban bird communities influenced by the bird diversity of adjacent landscapes? Journal of Applied Ecology 38: 1122-1134.

Clout M 2001. Where protection is not enough: active conservation in New Zealand. Erratum. Trends in Ecology \& Evolution 16: 415-416. 
Craig J, Anderson S, Clout M, Creese B, Mitchell N, Ogden J, Roberts M, Ussher G. 2000. Conservation issues in New Zealand. Annual Review of Ecology and Systematics 31: 61-78.

Decker DJ, Chase LC. 1997. Human dimensions of living with wildlife: a management challenge for the 21st century. Wildlife Society Bulletin 25: 788-795.

Deis R. 1986. Is bird feeding a no-no? Defenders 54:17-18.

Department of Conservation. 2011. Attract birds to your garden. Retrieved from http://www.doc.govt.nz/getting-involved/home-and-garden/attract-birds-to-yourgarden/

DeStefano S, DeGraaf RM. 2003. Exploring the ecology of suburban wildlife. Frontiers in Ecology and the Environment 1: 95-101.

Dettmann-Easler D, Pease JL 1999. Evaluating the effectiveness of residential environmental education programs in fostering positive attitudes toward wildlife. Journal of Environmental Education 31: 33-39.

Dickman AJ. 2010. Complexities of conflict: the importance of considering social factors for effectively resolving human-wildlife conflict. Animal Conservation 13: $458-466$.

Dilks PJ. 1975a. The breeding of the feral pigeon (Columba livia) in Hawke's Bay. Notornis 22: 295-301.

Dilks PJ. 1975b. Diet of feral pigeons (Columba livia) in Hawke's Bay, New Zealand. New Zealand Journal of Agricultural Research 18: 87-90.

Dobeic M, Pintaric S, Vlahovic K, Dovc A. 2011. Feral pigeon (Columba livia) population management in Ljubljana. Veterinarski Arhiv 81: 285-298. 
Dopson S, de Lange PJ, Ogle CC, Rance BD, Courtney SP, Molloy J. 1999. The conservation requirements of New Zealand's nationally threatened vascular plants. Threatened Species Occasional Publication No.13, Department of Conservation, Wellington, New Zealand.

Dunmore R, Davis DE. 1963. Reproductive condition of feral pigeons in winter. The Auk 80: 374.

Dunn RR, Gavin MC, Sanchez MC, Solomon JN. 2006. The pigeon paradox: dependence of global conservation on urban nature. Conservation Biology 20: 18141816.

Emlen JT. 1974. An urban bird community in Tucson, Arizona: derivation, structure, regulation. Condor 76: 184-197.

Erlinge S, Hoogenboom I, Agrell J, Nelson J, Sandell M. 1990. Density-related homerange size and overlap in adult field voles (Microtus agrestis) in Southern Sweden. Journal of Mammology 71: 597-603.

ESRI. 2008. ArcMap version 9.3. Environmental Systems Research Institute, Redlands, California.

Felson AJ, Pickett STA. 2005. Designed experiments: New approaches to studying urban ecosystems. Frontiers in Ecology and the Environment 3: 549-556.

Ferman LM, Peter HU, Montalti D. 2010. A study of feral pigeon Columba livia var. in urban and suburban areas in the city of Jena, Germany. Arxius de Miscellania Zoologica 8: 1-8.

Finger M. 1994. From knowledge to action - exploring the relationships between environmental experiences, learning, and behaviour. Journal of Social Issues 50: 141160. 
Fuller RA, Warren PH, Armsworth PR, Barbosa O, Gaston KJ. 2008. Garden bird feeding predicts the structure of urban avian assemblages. Diversity and Distributions 14: 131-137.

Garrott RA, White PJ, Vanderbilt White CA. 1993. Overabundance: an issue for conservation biologists? Conservation Biology 7: 946-949

Giraldeau LA. 1984. Group foraging: the skill pool effect and frequency-dependent learning. American Naturalist 124: 72-79.

Giunchi D, Baldaccini NE, Sbragia G, Soldatini C. 2007a. On the use of pharmacological sterilisation to control feral pigeon populations. Wildlife Research 34: $306-318$.

Giunchi D, Gaggini V, Baldaccini NE. 2007b. Distance sampling as an effective method for monitoring feral pigeon (Columba livia f. domestica) urban populations. Urban Ecosystems 10: 397-412.

Gomez-Heras M, Benavente D, Alvarez de Buergo M, Fort R. 2004. Soluble salt minerals from pigeon droppings as potential contributors to the decay of stone based Cultural Heritage. European Journal of Mineralogy 16: 505-509.

Google Inc. 2011. Google Earth version 6.0.3.2197. Available at http://www.google.com/earth/index.html

Graczyk TK, Sunderland D, Rule AM, da Silva AJ, Moura INS, Tamang L, Girouard AS, Schwab KJ, and Breysse PN. 2007. Urban feral pigeons (Columba livia) as a source for air- and waterborne contamination with Enterocytozoon bieneusi spores. Applied and Environmental Microbiology 73: 4357-4358.

Groffman PM, Bain DJ, Band LE, Belt KT, Brush GS, Grove JM, Pouyat R, Yesilonis IC, Zipperer WC. 2003. Down by the riverside: urban riparian ecology. Frontiers in Ecology and the Environment 6: 315-321. 
Haag-Wackernagel D. 1995. Regulation of the street pigeon in Basel. Wildlife Society Bulletin 23: 256-260.

Haag-Wackernagel D. 2002. Feral pigeons: management experiences in Europe. In 'Proceedings of the 2nd Convegno Nazionale sulla Fauna Urbana: Specie Ornitiche Problematiche: Biologia e Gestione nelle Citt`a e nel Territorio'. Tuscany, Florence.

Haag-Wackernagel D. 2005. Parasites from feral pigeons as a health hazard for humans. Annals of Applied Biology 147: 203-210.

Haag-Wackernagel D, Moch H. 2004. Health hazards posed by feral pigeons. Journal of Infection 48: 307-313.

Hill CM 1998. Conflicting attitudes towards elephants around the Budongo Forest Reserve, Uganda. Environmental Conservation 25: 244-250.

Hixon MA. 1980. Food production and competitor density as the determinants of feeding territory size. American Naturalist 115: 510-530.

Hetmanski T, Barkowska M. 2007. Density and age of breeding pairs influence feral pigeon, Columba livia reproduction. Folia Zoologica 56: 71-83.

Hoy MD, Bivings AE. 1987. An evaluation of controlled hunting for management of feral pigeons. Third Eastern Wildlife Damage Control Conferencve, Gulf Shores, Alabama.

Ishigame G, Baxter GS. 2007. Practice and attitudes of suburban and rural dwellers to feeding wild birds in Southeast Queensland, Australia. Ornithological Science 6: 11-19.

Jacquin L, Cazelles B, Prevot-Julliard A, Leboucher G, Gasparini J. 2010.

Reproduction management affects breeding ecology and reproduction costs in feral urban pigeons (Columba livia). Canadian Journal of Zoology 88: 781-787. 
Jerolmack C 2006. Rethinking the interaction order: Sociability among pigeons and people. Paper presented at the annual meeting of the American Sociological Association, Montreal Convention Center, Montreal, Quebec, Canada.

Johnson JB, Omland KS. 2004. Model selection in ecology and evolution. Trends in Ecolgy and Evolution 19: 101-108.

Johnston RF, Janiga M. 1995. Feral Pigeons. Oxford University Press, New York.

Jokimaki J, Suhonen J. 1998. Distribution and habitat selection of wintering birds in urban environments. Landscape and Urban Planning 34: 253-263.

Jones DN, Reynolds SJ. 2008. Feeding birds in our towns and cities: a global research opportunity. Journal of Avian Biology 39: 265-271.

Jones DN, Thomas LK. 1998. Managing to live with Brisbane's wildlife: magpies and the management of positive and negative interactions. Proceedings of the Royal Society of Queensland 107: 45-49.

Jones DN, Thomas LK. 1999. Attacks on humans by Australian magpies: management of an extreme suburban human-wildlife conflict. Wildlife Society Bulletin 27: 473-478.

Kals E, Schumacher D, Montada L. 1999. Emotional affinity toward nature as a motivational basis to protect nature. Environment and Behavior 31: 178-202.

Karlsson J, Sjostrom M 2007. Human attitudes to wolves, a matter of distance. Biological Conservation 137: 610-616.

Kellert SR, Berry JK 1987. Attitudes, knowledge, and behaviors toward wildlife as affected by gender. Wildlife Society Bulletin 15: 363-371.

Kelly D, Sullivan JJ. 2010. Life histories, dispersal, invasions, and global change: progress and prospects in New Zealand ecology, 1989-2029. New Zealand Journal of Ecology 34: 207-217. 
Kingsford RT, Watson JEM, Lundquist CJ, Venter O, Hughes L, Johnston EL, Atherton J, Gawel M, Keith DA, Mackey BG, Morley C, Possingham HP, Raynor B, Recher HF, Wilson KA. 2009. Major conservation policy issues for biodiversity in Oceania. Conservation Biology 23: 834-840.

Krebs CJ. 2008. Ecology: The Experimental Analysis of Distribution and Abundance, 6 ed. Benjamin Cummings, San Francisco, California.

Krimowa S. 2011. Pigeons and people: resource ecology and human dimensions of urban wildlife. Unpublished master's thesis, Victoria University, Wellington, New Zealand.

Lawson HM. 1979. Feral pigeon damage to field beans. Annals of Applied Biology 92: $153-157$.

Lefebvre L. 1985. Stability of flock composition in urban pigeons. Auk 102: 886-888.

Little RM. 1994. Marked dietary differences between sympatric feral rock doves and rock pigeons. South African Journal of Zoology 29: 33-35.

Loker CA, Decker DJ, Schwager SJ.1999. Social acceptability of wildlife management actions in suburban areas: 3 cases from New York. Wildlife Society Bulletin 27: 152159.

Long C. 2007, 14 December. No need to kill pigeons. The Dominion Post. Retrieved from http://www.stuff.co.nz/dominion-post/comment/letters-to-the-editor/letters-to-theeditor-archive/1877271/Pigeons-freedom-of-speech-Wellington-roading-and-rugby

Long JL. 1981. Introduced birds of the world. Universe Books, New York.

Luniak M. 2004. Synurbanization - adaptation of animal wildlife to urban development. In: Proceedings of the 4th International Symposium on Urban Wildlife Conservation (eds Shaw WW, Harris LK, Vandruff L): 50-55. Tucson, Arizona. 
Madden F. 2004. Creating coexistence between humans and wildlife: global perspectives on local efforts to address human-wildlife conflict. Human Dimensions of Wildlife 9: 247-257.

Magnino S, Haag-Wackernagel D, Geigenfeind I, Helmecke S, Dovc A, PruknerRadovcic E, Residbegovic E, Ilieski V, Laroucau K, Donati M, Martinov S, Kaleta EF. 2009. Chlamydial infections in feral pigeons in Europe: review of data and focus on public health implications. Vetinary Microbiology 135: 54-67.

Marzluff JM, Bowman R, Donelly R. 2001. A historical perspective on urban bird research: trends, terms, and approaches. In: Marzluff JM, Bowman R, Donelly R. Avian ecology and conservation in an urbanizing world. Kluwer Academic Publishers, Boston.

McDonald RI, Kareiva P, Forman RTT. 2008. The implications of current and future urbanization for global protected areas and biodiversity conservation. Biological Conservation 141: 1695-1703.

McDonnell MJ. 1997. A paradigm shift. Urban Ecosystems 1: 85-86.

McDonnell MJ, Pickett STA. 1993. Humans as components of ecosystems: the ecology of subtle human effects and populated areas. Springer-Verlag, New York.

McIntyre NE, Knowles-Yanez K, Hope D. 2000. Urban ecology as an interdisciplinary field: differences in the use of "urban" between the social and natural sciences. Urban Ecosystems 4: 5-24.

McKinney ML. 2006. Urbanization as a major cause of biotic homogenization. Biological Conservation 127: 247-260.

McLoughlin PD, Ferguson SH. 2000. A hierarchical pattern of limiting factors helps explain variation in home range size. Ecoscience 7: 123-130. 
Melles S, Glenn S, Martin K. 2003. Urban bird diversity and landscape complexity: Species-environment associations along a multiscale habitat gradient. Conservation Ecology 7: 5 .

Messmer TA. 2009. Human-wildlife conflicts: emerging challenges and opportunities. Human-Wildlife Conflicts 3: 10-17.

Miller JR. 2005. Biodiversity conservation and the extinction of experience. Trends in Ecology and Evolution 20: 430-434.

Miller JR, Hobbs RJ. 2002. Conservation where people live and work. Conservation Biology 16: 330-337.

Ministry of Social Development. 2010. The Social Report 2010. Ministry of Social Development, Wellington, New Zealand.

New Zealand Transport Agency. 2010. Network Statistics for the year ended June 2009. New Zealand Transport Agency, Wellington. Retrieved from http://www.nzta.govt.nz/resources/land-transport-statistics/docs/2008-2009.pdf

Moeed A. 1975. Food of skylarks and pipits, finches, and feral pigeons near Christchurch. Notornis 22: 135-142.

Moller AP. 2009. Successful city dwellers: a comparative study of the ecological characteristics of urban birds in the Western Palearctic. Oecologia 159: 849-858.

Murton RK, Coombs CFB, Thearle RJP. 1972a. Ecological studies of the feral pigeon Columba livia var. II. Flock behaviour and social organization. Journal of Applied Ecology 9: 875-89.

Murton RK, Thearle RJP, Thompson J. 1972b. Ecological studies of the feral pigeon Columba livia var. I. Population, breeding biology and methods of control. Journal of Applied Ecology 9: 835-874. 
NIWA. 2008. Climate Summaries. Retrieved from http://www.niwa.co.nz/educationand-training/schools/resources/climate/summary

Newton I. 1980. The role of food in limiting bird numbers. Ardea 68: 11-30.

Palmer JA, Suggate J, Robottom I, Hart P 1999. Significant life experiences and formative influences on the development of adults' environmental awareness in the UK, Australia and Canada. Environmental Education Research 5: 81-200.

Parsons H, Major RE, French K. 2006. Species interactions and habitat associations of birds inhabiting urban areas of Sydney, Australia. Austral Ecology 31: 217-227.

Pickett STA, Cadenasso ML, Grove JM, Boone CG, Irwin E, Groffman PM, Kaushal SS, Marshall V, McGrath BP, Nilon CH, Pouyat RV, Szlavecz K, Troy A, Warren P. 2011. Urban ecological systems: A decade of progress. Journal of Environmental Management 92: 331-362.

Pimentel D, Lach L, Zuniga R, Morrison D. 2000. Environmental and economic costs of nonindigenous species in the United States. BioScience 50: 53-65

Population Reference Bureau. 2010. World Population Highlights: Key Findings From PRB's 2010 World Population Data Sheet. Population Bulletin 65.

Retrieved from http://www.prb.org/pdf10/10wpds_eng.pdf

Pouyat RV, Groffman PM, Yesilonis I, Hernandez L. 2002. Soil carbon pools and fluxes in urban ecosystems. Environmental Pollution 116: 107-118.

R Development Core Team. 2010. R: a language and environment for statistical computing. R Foundation for Statistical Computing, Vienna, Austria. Available at http://www.R-project.org

Robb GN, McDonald RA, Chamberlain DE, Bearhop S. 2008. Food for thought: supplementary feeding as a driver of ecological change in avian population. Frontiers in Ecology and the Environment 6: 476-484. 
Robertson CJR, Hyvonen P, Fraser MJ, Pickard CR. 2007. Atlas of bird distribution in New Zealand 1999-2004. Wellington, Ornithological Society of New Zealand.

Rollinson D, O'Leary R, Jones DN. 2003. The practice of wildlife feeding in suburban Brisbane. Corella 27: 52-58.

Rose E, Haag-Wackernagel D, Nagel P. 2006a. Practical use of GPS-localization of feral pigeons Columba livia in the urban environment. Ibis 148: 231-239.

Rose E, Nagel P, Haag-Wackernagel D. 2006b. Spatio-temporal use of the urban habitat by feral pigeons (Columba livia). Behavioral Ecology and Sociobiology 60: 242-254.

Rottenborn SC. 1999. Predicting the impacts of urbanization on riparian bird communities. Biological Conservation 88: 289-299.

Sacchi R, Gentilli A, Razzetti E, Barbieri F. 2002. Effects of building features on density and flock distribution of feral pigeons (Columba livia var. domestica) in an urban environment. Canadian Journal of Zoology 80: 48-54.

Said S, Servanty S. 2005. The influence of landscape structure on female roe deer home-range size. Landscape Ecology 20: 1003-1012.

Sandstrom UG, Angelstam P, Mikusinski G. 2006. Ecological diversity of birds in relation to the structure of urban green space. Landscape and Urban Planning 77: 3953.

Saunders A, Norton DA. 2001. Ecological restoration at mainland islands in New Zealand. Biological Conservation 99: 109-119.

Shochat E, Warren PS, Faeth SH, McIntyre NE, Hope D. 2006. From patterns to emerging processes in mechanistic urban ecology. Trends in Ecology \& Evolution 21: $186-191$. 
Sol D, Senar JC. 1992. Comparison between two censuses of feral pigeon Columba livia var. from Barcelona: an evaluation of seven years of control by killing. Bulletin GCA 9: 29-32.

Sol D, Santos DM, Cuadrado M. 2000. Age-related feeding site selection in urban pigeons (Columba livia): experimental evidence of the competition hypothesis.

Canadian Journal of Zoology 7: 144-149.

Sol D, Santos D, Garcia J, Cuadrado M. 1998. Competition for food in urban pigeons: the cost of being juvenile. The Condor 100: 298-304.

Sol D, Senar JC. 1995. Urban pigeon populations: stability, home range, and the effect of removing individuals. Canadian Journal of Zoology 73: 1154-1160.

Soldatini C, Mainardi D, Baldaccini NE, Giunchi D. 2006. A temporal analysis of the foraging flights of feral pigeons (Columba livia f. domestica) from three Italian cities. Italian Journal of Zoology 73: 83-92.

Souch C, Grimmond S. 2006. Applied climatology: urban climatology, Progress in Physical Geography 30: 270-279.

Statistics New Zealand. 2006. QuickStats About Wellington City. Retrieved from http://www.stats.govt.nz.

Stout RJ, Stedman RC, Decker DJ, Knuth BA. 1993. Perceptions of risk from deerrelated vehicle accidents: implications for public preferences for deer herd size. Wildlife Society Bulletin 21: 237-249.

Tait MJ, Krebs CJ. 1981. The effect of extra food on small rodent populations: II. Voles (Microtus townsendii). Journal of Animal Ecology 50: 125-137.

Tangley L. 1986. The urban ecologist. BioScience 36: 68-71. 
Tansley AG. 1935. The use and abuse of vegetational concepts and terms. Ecology 16: 284-307.

Thomas L, Buckland ST, Rexstad EA, Laake JL, Strindberg S, Hedley SL, Bishop JRB, Marques TA, Burnham KP. 2010. Distance software: design and analysis of distance sampling surveys for estimating population size. Journal of Applied Ecology 47: 5-14.

Thompson WL. 2002. Towards reliable bird surveys: accounting for individuals present but not detected. The Auk 119: 18-25.

Tikka PM, Kuitunen MT, Tynys SM 2000. Effects of educational background on students' attitudes, activity levels, and knowledge concerning the environment. The Journal of Environmental Education 31: 12-19.

Timm RM, Baker RO, Bennett JR, Coolahan CC. 2004. Coyote attacks: an increasing suburban problem. Proceedings Vertebrate Pest Conference 21:47-57.

Treves A, Noughton-Treves L 2005. Evaluating lethal control in the management of human-wildlife conflict. In: Woodroffe R, Thirgood S, Rabinowitz A. People and Wildlife, Conflict or Co-existence? Cambridge University Press, New York.

Treves A, Wallace RB, Naughton-Treves L, Morales A. 2006. Co-managing humanwildlife conflicts: a review. Human Dimensions of Wildlife 11: 383-396.

Tufto J, Andersen R, Linnell J. 1996. Habitat use and ecological correlates of home range size in a small cervid: the roe deer. Journal of Animal Ecology 65: 715-724.

United Nations. 2006. World urbanization prospects: the 2005 revision. Population Division, Department of Economic and Social Affairs, United Nations, New York. Retrieved from http://www.un.org/esa/population/publications/WUP2005/2005wup.htm 
United Nations. 2010. World urbanization prospects: the 2009 revision. Population Division, Department of Economic and Social Affairs, United Nations, New York. Retrieved from http://esa.un.org/unpd/wup/Documents/WUP2009_Highlights_Final.pdf

Vatnick J, Foertsch S. 1998: Incubation temperature of the pigeon embryo (Columba livia). Journal of Thermal Biology 23:53-57.

Villegas M, Garitano-Zavala A. 2010. Bird community responses to different urban conditions in La Paz, Bolivia. Urban Ecosystems 13: 375-391.

Vitousek PM, Mooney HA, Lubchenco J, Melillo JM. 1997. Human domination of Earth's ecosystems. Science 277: 494-499.

Walker, S, Price R, Rutledge D, Theo Stephens RT, Lee WG. 2006. Recent loss of indigenous cover in New Zealand. New Zealand Journal of Ecology 30: 169-177.

Walsh CJ, Roy AH, Feminella JW, Cottingham PD, Groffman PM, Morgan RP. 2005. The urban stream syndrome: current knowledge and the search for a cure. Journal of the North American Benthological Society 24: 706-723.

Weber J, Haag D, Durrer H. 1994. Interaction between humans and pigeons. Anthrozoos 7: 55-59.

Wellington City Council. 2007, 10 December. Midland Park pigeons face unhappy New Year. Retrieved from http://www.scoop.co.nz/stories/AK0712/S00099.htm

Wellington City Council. 2008, 6 November. Proposed pigeon cull called off. Retrieved from http://www.scoop.co.nz/stories/AK0811/S00045.htm

Wellington City Council. 2011a. Wellington City Introduction and key statistics. Retrieved from http://profile.idnz.co.nz/Default.aspx?id=366\&pg=8112\&gid=10

Wellington City Council. 2011b. Current population estimates. Retrieved from http://profile.idnz.co.nz/Default.aspx?id=366\&pg=8510\&gid=10 
Wellington City Council. 2011c. Wellington City Council Community profile.

Retrieved from http://profile.idnz.co.nz

Wellington City Council. 2011d. Where do the workers come from? Retrieved from http://profile.idnz.co.nz/Default.aspx?id=366\&pg=8551\&gid=10

West BC, Parkhurst JA. 2002. Interactions between deer damage, deer density, and stakeholder attitudes in Virginia. Wildlife Society Bulletin 30: 139-147.

White PCL, Jennings NV, Renwick AR, Barker NHL. 2005. Questionnaires in ecology: a review of past use and recommendations for best practice. Journal of Applied Ecology 42: 421-430.

Whitehead J. 2008, 7 October. Pigeons no great health risk. The Dominion Post. Retrieved from http://www.stuff.co.nz/dominion-post/comment/letters-to-theeditor/letters-to-the-editor-archive/1881182/Culling-pigeons-young-people-and-theelection-and-rubbish-collection

World Parks Congress Recommendation. 2003. V.20: Preventing and mitigating human-wildlife conflicts. International Union for Conservation of Nature. Retrieved from http://cmsdata.iucn.org/downloads/recommendationen.pdf.

Young RF. 2009. Interdisciplinary foundations of urban ecology. Urban Ecosystems 12: $311-331$. 


\section{Appendix One: DISTANCE analysis Introduction}

Distance sampling is a method which uses the distances of objects from a line or point to estimate density. It is most often used to estimate animal densities, usually in the form of line transect sampling (Thomas et al. 2010). It allows for the fact that some objects may go undetected. It is based upon the concept of a detection function, which is the probability of detecting an object depending on its distance from the transect line. This probability of detectability can be modelled using the programme DISTANCE (Thomas et al. 2010). Suitable models are chosen to be fitted to the data and density estimates are given from the best fitting model (Buckland et al. 2001).

\section{Method}

Models recommended by Buckland et al. (2001) (half normal + cosine, half normal + hermite polynomial and uniform + cosine) were used to model the pigeon observation data in DISTANCE 6.0 release 2 (Thomas et al. 2010). These models were chosen also because they are robust to rounding at zero distance. Distance analysis was performed separately on the summer, summer commercial, winter and winter commercial data. The wharf, green and residential landscape types did not have enough observations for an analysis in DISTANCE. Out of 138 summer observations, five were excluded due to incomplete data, leaving 133 observations for analysis. The summer data had a prominent spike at zero distance and a long tail, which resulted in truncation of $10 \%$ of the data. (133 observations, $10 \%=14$ observations, truncation at $58 \mathrm{~m})$. A total of 131 observations were obtained in winter, of which three were eliminated due to incomplete information, resulting in 128 observations for analysis. There were some outliers so 5\% 
of the observations were truncated (128 observations, $5 \%=6$ observations, truncation at $65 \mathrm{~m})$.

\section{Results}

\section{Summer}

A total of 133 observations were included in the summer data analysis. The best performing model was half normal + cosine, which estimated overall pigeon density in summer to be 4.5 pigeons/ha. (Table A1, Figure A1). Of the summer commercial observations, 81 were classified as part of the commercial landscape type. The best fitting model was the uniform + cosine model, which estimated commercial pigeon density at 5.9 pigeons/ha. (Table A2, Figure A2).

Table A1. Distance results for all summer data, ranked in descending order based on Akaike's Information Criterion (AIC).

\begin{tabular}{lccccc}
\hline Model & \# parameters & AIC & $\Delta$ AIC & Density $(95 \%$ CI $)$ & DCV \\
\hline Half normal + cosine & 4 & 907.49 & 0.00 & $4.499(2.1,9.7)$ & 0.357 \\
Uniform + cosine & 4 & 907.56 & 0.06 & $4.355(2.0,9.4)$ & 0.354 \\
Half normal + hermite & 1 & 921.49 & 14.00 & $3.161(1.5,6.7)$ & 0.341 \\
polynomial & & & & & \\
\hline
\end{tabular}




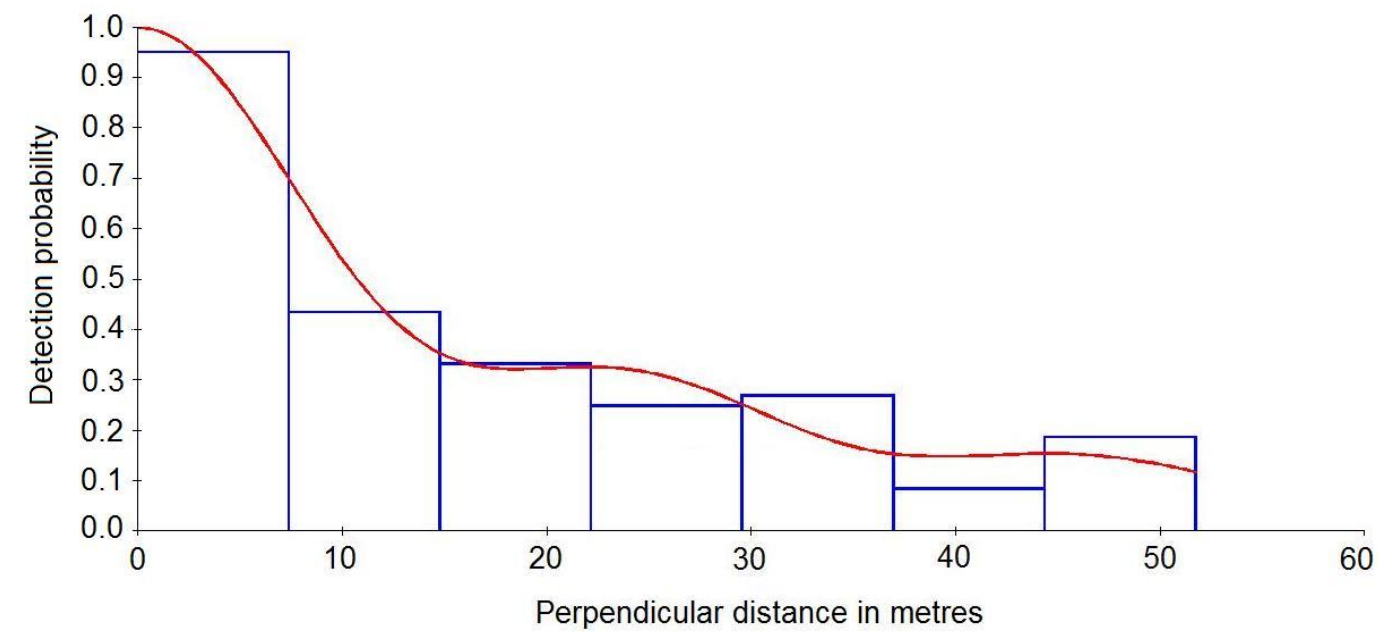

Figure A1. Best fitting model for all summer data, half normal + cosine, $10 \%$ truncation .

Table A2. Distance results for summer commercial data, ranked in descending order based on Akaike's Information Criterion (AIC).

\begin{tabular}{lccccc}
\hline Model & \# parameters & AIC & $\Delta$ AIC & Density $(95 \%$ CI $)$ & DCV \\
\hline Uniform + cosine & 4 & 625.39 & 0 & $5.909(4.2,8.4)$ & 0.180 \\
Half normal + cosine & 3 & 625.06 & 0.67 & $5.967(4.2,8.4)$ & 0.176 \\
$\begin{array}{l}\text { Half normal + hermite } \\
\text { polynomial }\end{array}$ & 1 & 635.97 & 10.58 & $4.455(3.3,6.0)$ & 0.151 \\
\hline
\end{tabular}

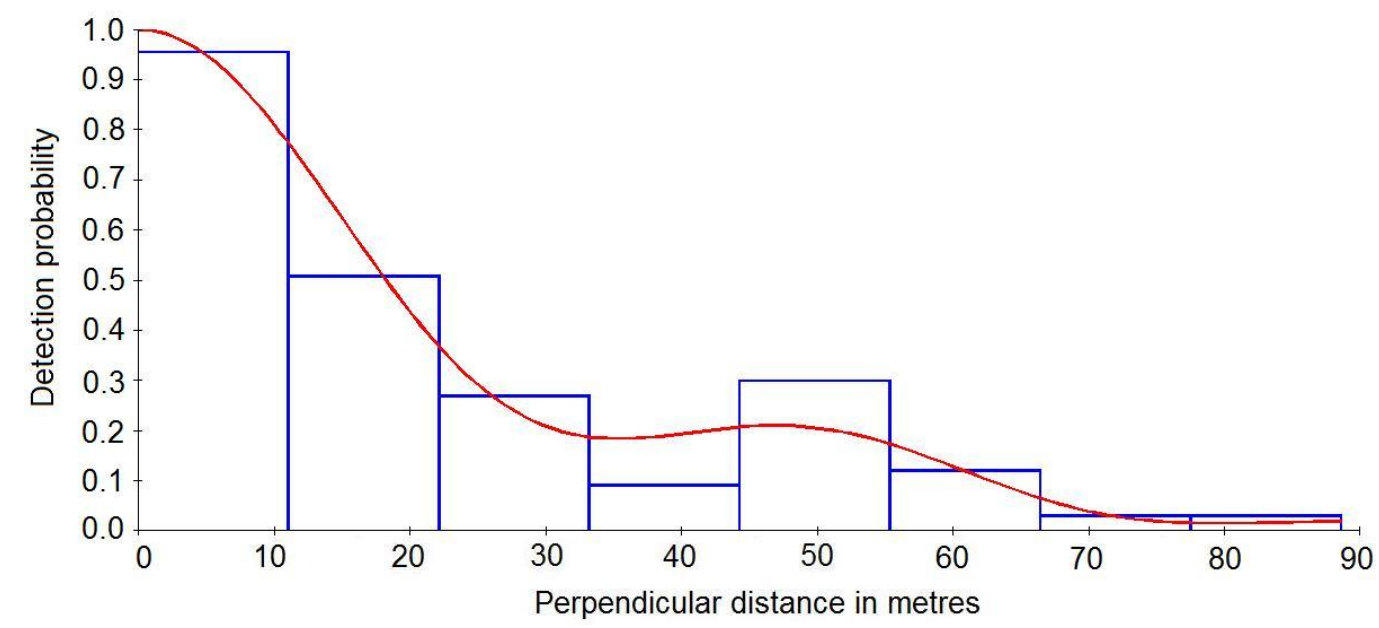

Figure A2. Best fitting model for summer commercial data, uniform + cosine, $5 \%$ truncation. 


\section{Winter}

A total of 128 observations were included in the winter data analysis. The uniform + cosine model had the lowest AIC, and estimated pigeon density at 6.8 pigeons/ha (Table A3, Figure A3). Of the winter observations, 104 were classified in the commercial landscape type. The best fitting model for the winter commercial data was half normal + cosine, which estimated pigeon density at 17.8 pigeons/ha (Table A4, Figure 4).

Table A3. Distance results for all winter data, ranked in descending order based on Akaike's Information Criterion (AIC).

\begin{tabular}{lccccc}
\hline Model & \# parameters & AIC & $\Delta$ AIC & Density $(95 \%$ CI $)$ & DCV \\
\hline Uniform + cosine & 3 & 940.59 & 0.82 & $6.757(3.3,13.8)$ & 0.340 \\
Half normal + cosine & 3 & 940.85 & 1.08 & $7.347(3.6,15.1)$ & 0.346 \\
Half normal + hermite & 1 & 948.49 & 8.72 & $4.555(2.2,9.2)$ & 0.334 \\
polynomial & & & & & \\
\hline
\end{tabular}

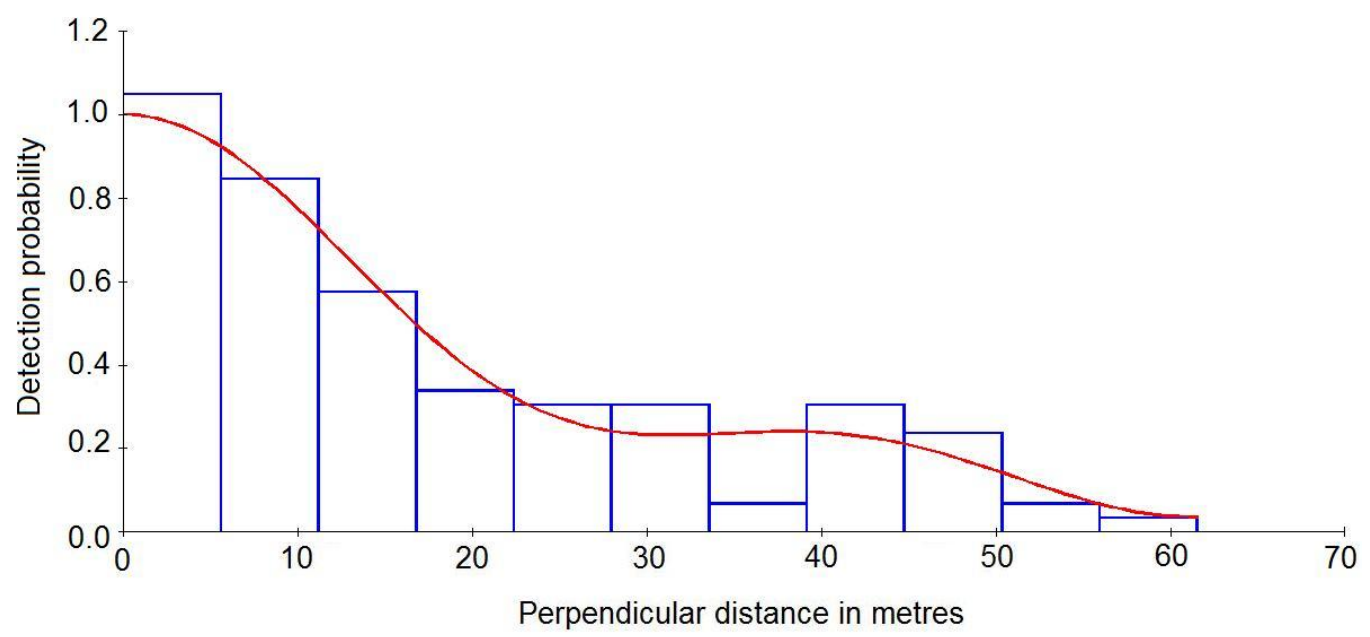

Figure A3. Best fitting model for all winter data, uniform + cosine, $5 \%$ truncation 
Table A4. Distance results for winter commercial data, ranked in descending order based on Akaike's Information Criterion (AIC).

\begin{tabular}{lccccc}
\hline Model & \# parameters & AIC & $\Delta$ AIC & Density $(95 \%$ CI $)$ & DCV \\
\hline Half normal + cosine & 3 & 737.01 & 1.64 & $17.719(12.3,25.6)$ & 0.187 \\
Uniform + cosine & 4 & 738.21 & 2.84 & $17.669(12.3,25.4)$ & 0.186 \\
Half normal + hermite & 1 & 742.44 & 7.07 & $11.393(8.2,15.8)$ & 0.166 \\
polynomial & & & & &
\end{tabular}

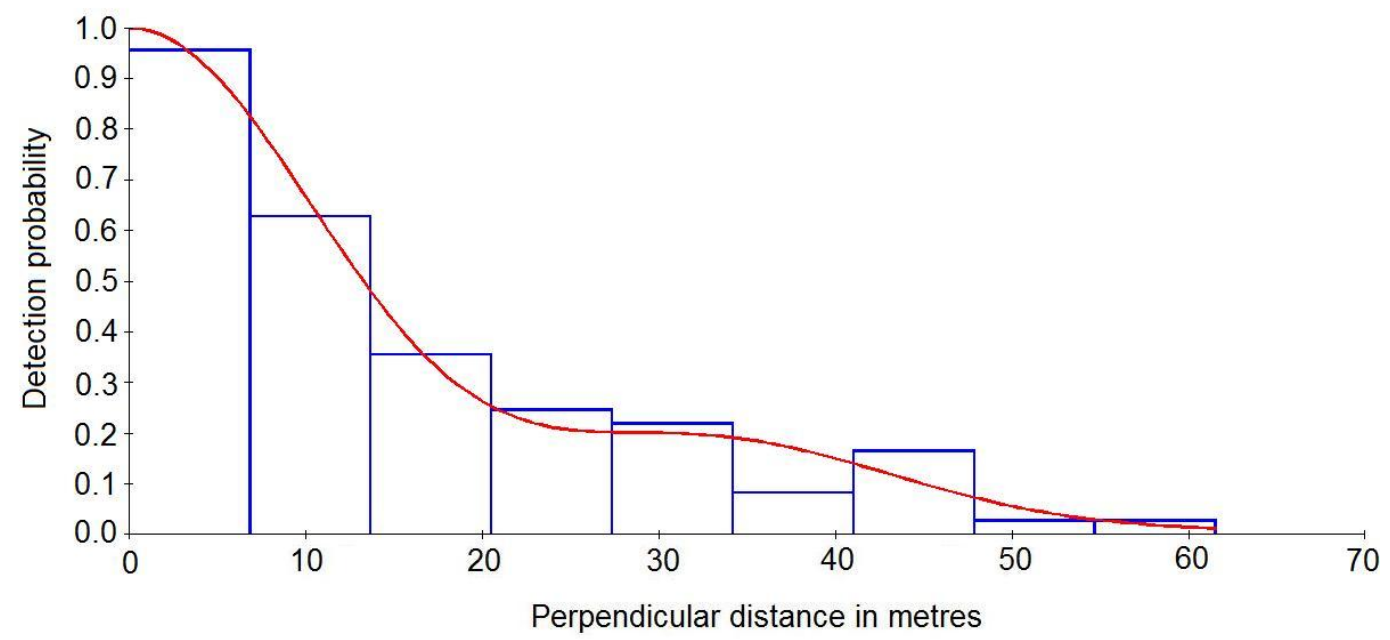

Figure A4. Best fitting model for winter commercial data, half normal + cosine, 5\% truncation. 
Appendix Two: Questionnaire 


\section{Residents' Relationship with Feral Pigeons in Wellington Survey}

1. How large is the group of feral pigeons that you routinely see on your property? Tick $\square$ the appropriate box

$\square$ No pigeons visit my property

$\square 1$ or 2 pigeons

3 to 5

6 to 10

11 to 20

More than 20

2. In your opinion, in Wellington City there are: Tick $\square$ the appropriate box
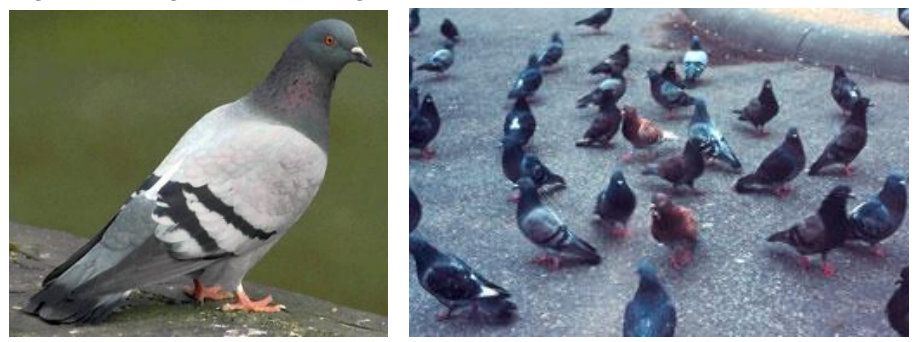

$\square$ Too many feral pigeons

About the right number of feral pigeons

Not enough feral pigeons

I have no opinion about the number of pigeons $\longrightarrow$ If you ticked $\square$ this option, go to question 4

3. Please give the main reason or reasons for your answer to Question 2.

4. What actions would you support to manage pigeon numbers in Wellington City? Tick ( $\square)$ those that apply.

Poisoning pigeons

Shooting pigeons

Destruction of pigeon nests on private and public property

Regulation for barriers to prevent pigeons from using private and public buildings to nest and roost

Regulation to prevent pigeons from feeding on food waste from rubbish bins and skips

Regulation to prevent the public feeding pigeons

Other (please specify):

5. How often did you visit a green space (park, reserve, or public garden) in the last year? Tick $\square$ the appropriate box

Not at all $\longrightarrow$ Go to Question 7

Once or twice a year

About once a month

$\square$ Two to three times a month

Two to three times a week

6. Name the three green spaces (parks, reserves or public gardens) that you most recently visited?

i. iii.

7. Do you provide food or water for birds?

Yes $\longrightarrow$ If Yes: which three bird species do you feed or water most: $\longrightarrow 1$

No

2.

3

8. As a child, how much time did you spend outdoors in the following places? Circle a number for each

$\begin{array}{lccccc} & \text { None } & \text { Seldom } & \text { Occasionally } & \text { Often } & \text { Frequently } \\ \text { Private backyards } & 1 & 2 & 3 & 4 & 5 \\ \text { Neighbourhood parks } & 1 & 2 & 3 & 4 & 5 \\ \text { National and regional parks } & 1 & 2 & 3 & 4 & 5\end{array}$

9. As a child, how much time did you spend in the following activities as a child? Circle appropriate number

$\begin{array}{lccccc} & \text { None } & \text { Seldom } & \text { Occasionally } & \text { Often } & \text { Frequently } \\ \text { Hunting } & 1 & 2 & 3 & 4 & 5 \\ \text { Watching wildlife } & 1 & 2 & 3 & 4 & 5 \\ \text { Feeding wild animals } & 1 & 2 & 3 & 4 & 5 \\ \text { Rescuing injured wild animals } & 1 & 2 & 3 & 4 & 5\end{array}$


10. Write the name of the bird species pictured* in the blank spaces provided, or tick the 'don't know' box if unsure.

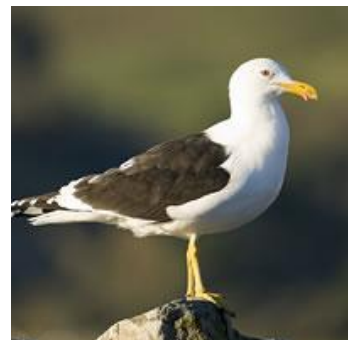

Bird 1

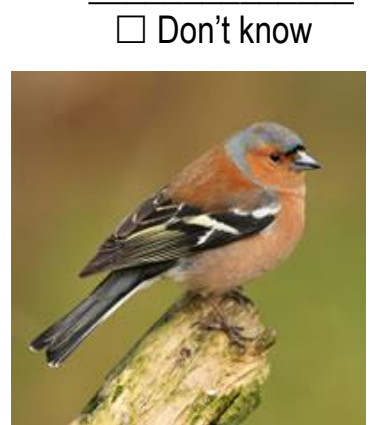

Bird 5

$\square$ Don't know

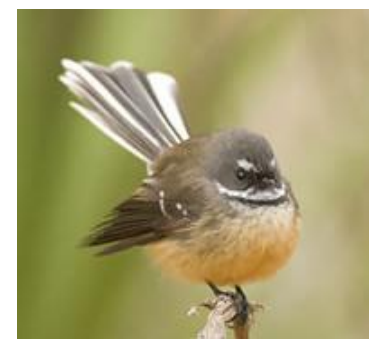

Bird 2

$\square$ Don't know

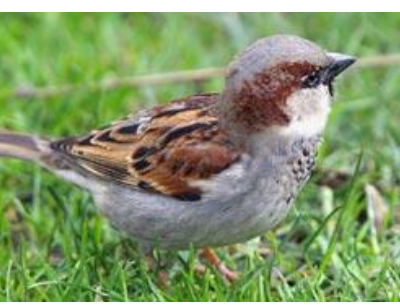

Bird 6

$\square$ Don't know

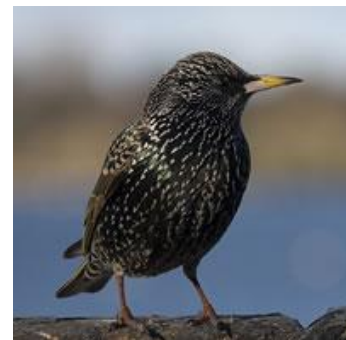

Bird 3

$\square$ Don't know

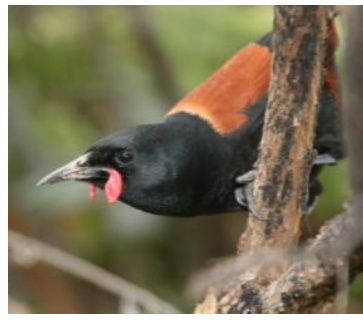

Bird 7

$\square$ Don't know

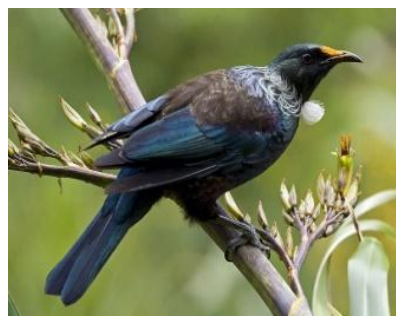

Bird 4

$\square$ Don't know

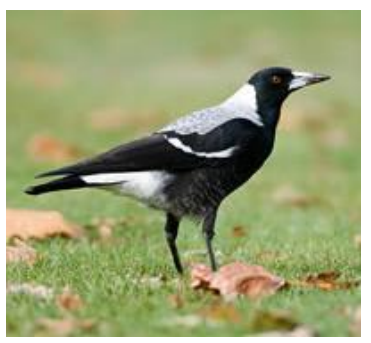

Bird 8

$\square$ Don't know

11. What do you think are the three greatest threats to native plants and animals in New Zealand i. ii. iii.

12. At your home:

\begin{tabular}{|l|c|c|}
\hline which of these activities have you done in the last month? & Yes & No \\
\hline Composting organic waste & $\square$ & $\square$ \\
\hline Kerbside recycling & $\square$ & $\square$ \\
\hline Used your own bags to carry groceries from the supermarket & $\square$ & $\square$ \\
\hline which of these activities have you done in the last year? & Yes & No \\
\hline Donated to an environmental charity & $\square$ & $\square$ \\
\hline Volunteered for an environmental organisation & $\square$ & $\square$ \\
\hline Attended a public meeting in support of the environment & $\square$ & $\square$ \\
\hline Signed a petition in support of the environment & $\square$ & $\square$ \\
\hline
\end{tabular}

13. Are you:
$\square \quad$ Female
$\square \quad$ Male

14. Please tick $\square$ the age group you belong to.
$\square \quad 18-25$
$26-35$
$36-50$
$51-70$
$\square \quad$ Over 70

16. What is your highest educational level?

$\square \quad$ No formal qualifications

$\square$ High school qualification

$\square$ Vocational or Trade qualification

$\square$ Bachelor degree

$\square$ Postgraduate degree

Thank you for your help. Return of the survey implies you have consented to participating in this study. You will receive a letter reminding you to return the survey. If you have already returned the survey, please ignore this letter. Surveys can be returned in the envelope provided, or send to: Freepost BIRD STUDY, School of Biological Sciences, Victoria University of Wellington, PO Box 600 , Wellington 6140
15. Which ethnic group do you belong to?

$\square$ New Zealand European

$\square$ Maori

$\square$ Pacific Islander

$\square$ Asian

$\square$ Other. Please specify

17. Which describes your annual personal income before tax?
$\square$ Less than $\$ 10,000$
$\square \$ 10,001-30,000$
$\square \$ 30,001-50,000$
$\square \$ 50,001-70,000$
$\square \$ 70,001-100,000$
$\square \$ 100,000$ or more
$\square$ Don't know 
